\title{
DANILO BELPIEDE
}

APLICAÇÃO DE ALGORITMOS EVOLUTIVOS PARA A

OTIMIZAÇÃO DO FLUXO DE POTÊNCIA EM SISTEMAS DE SUBTRANSMISSÃO DE ENERGIA ELÉTRICA 


\section{DANILO BELPIEDE}

\section{APLICAÇÃO DE ALGORITMOS EVOLUTIVOS PARA A OTIMIZAÇÃO DO FLUXO DE POTÊNCIA EM SISTEMAS DE SUBTRANSMISSÃO DE ENERGIA ELÉTRICA}

Dissertação apresentada à Escola Politécnica da Universidade de São Paulo para a obtenção do título de Mestre.

Área de concentração: Engenharia Elétrica Orientador: Prof. Dr. Nelson Kagan 
Este exemplar foi revisado e alterado em relação à versão original, sob responsabilidade única do autor e com a anuência de seu orientador.

São Paulo, de dezembro de 2006.

Assinatura do autor

Assinatura do orientador

\section{FICHA CATALOGRÁFICA}

Belpiede, Danilo

Aplicação de algoritmos evolutivos para a otimização do fluxo de potência em sistemas de subtransmissão de energia elétrica / D. Belpiede. -- ed.rev. -- São Paulo, 2006. $116 \mathrm{p}$.

Dissertação (Mestrado) - Escola Politécnica da Universidade de São Paulo. Departamento de Engenharia de Energia e Automação Elétricas.

1.Redes de distribuição de energia elétrica (Otimização) 2.Algoritmos evolutivos I.Universidade de São Paulo. Escola Politécnica. Departamento de Engenharia de Energia e Automação Elétricas II.t. 
À minha família,

Que este trabalho seja um incentivo a eles para a busca pelo melhor de si. 


\section{AGRADECIMENTOS}

Agradeço ao orientador, professor Dr. Nelson Kagan, pela sua atenção e dedicação depositadas neste trabalho. Seu conhecimento e sua enorme experiência foram fundamentais para que esta dissertação atingisse plenamente todos os objetivos desejados.

Agradeço aos professores Dr. Carlos César Barioni de Oliveira e Dr. Hernán Prieto Schmidt, pela colaboração direta na realização desta dissertação. Agradeço também, colaborando diretamente, ao amigo Henrique Kagan, pelo tempo dedicado no desenvolvimento dos módulos computacionais de otimização do fluxo de potência ativa e reativa.

Agradeço igualmente a todos os outros que colaboraram de qualquer outra forma em algum momento deste trabalho. Esta dissertação possui um pouco de cada uma dessas pessoas, por menor que seja.

Por fim, agradeço o apoio e incentivo de meu pai, Walter Belpiede, minha mãe, Regina Célia Nogueira Belpiede e minha irmã, Débora Belpiede. Esse apoio foi muito importante para que este trabalho seguisse até o seu fim. E agradeço a Deus, a energia transformadora que deposito em tudo o que faço e que me impulsiona ao longo da minha trajetória nesse mundo. 


\section{RESUMO}

Esta dissertação apresenta uma metodologia de otimização do fluxo de potência em sistemas elétricos de subtransmissão utilizando duas técnicas da Computação Evolutiva, os Algoritmos Genéticos e as Estratégias Evolutivas.

A metodologia decompõe o problema em duas partes e o trata seqüencialmente. A primeira parte procede com a otimização do fluxo de potência ativa e a segunda com a otimização do fluxo de potência reativa.

São apresentadas as características e estruturas básicas dos Algoritmos Genéticos e das Estratégias Evolutivas. A técnica dos Algoritmos Genéticos é implementada no modelo de otimização do fluxo de potência ativa e a técnica das Estratégias Evolutivas no modelo de otimização do fluxo de potência reativa. As variáveis de controle dos modelos desenvolvidos são, respectivamente, os estados dos dispositivos de seccionamento e os níveis de tensão dos barramentos dos pontos de fronteira, associadas ao sistema analisado.

Analisam-se os sistemas elétricos de subtransmissão que contêm múltiplos pontos de fronteira (conexão) com a Rede Básica e diversas possibilidades de configuração operativa. A metodologia proposta é aplicada a um sistema elétrico de subtransmissão real a fim de

minimizar o custo dos encargos de uso dos sistemas de transmissão. Os resultados obtidos mostram a eficácia dos algoritmos desenvolvidos na busca das soluções desejadas. 


\begin{abstract}
This dissertation presents a power flow optimization methodology on subtransmission electric systems using two techniques of Evolutionary Computation, namely the Genetic Algorithms and the Evolution Strategies.

The methodology splits the problem into two parts and treats it separately. On the first step it proceeds to optimize the active power flow and on the second step to optimize the reactive power flow.

Characteristics and basic structures of the Genetic Algorithms and the Evolution Strategies are shown. The Genetic Algorithms technique is implemented on the active power flow optimization model and the Evolution Strategies technique on the reactive power flow optimization model. The control variables of developed models are, respectively, the switch states and the border point bar voltage levels, associated to the analyzed system.

The subtransmission electric systems that have multiple border (connection) points to the Basic Network and many operative configuration possibilities are analyzed. The proposed methodology is applied to a real subtransmission electric system in order to minimizes the transmission system use duty costs. The obtained results show the efficacy of the developed algorithms in the search of desired solutions.
\end{abstract}




\section{SUMÁRIO}

1 INTRODUÇÃO ..........................................................................................................9

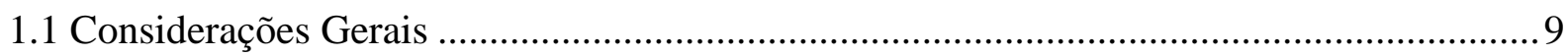

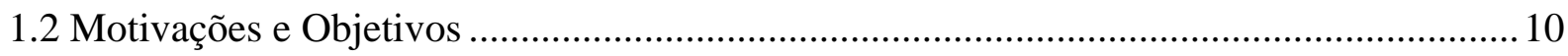

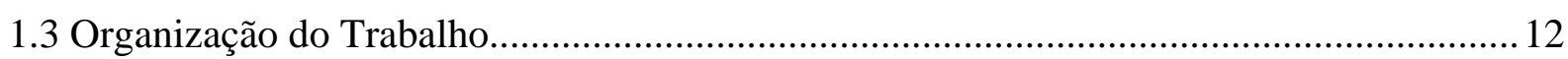

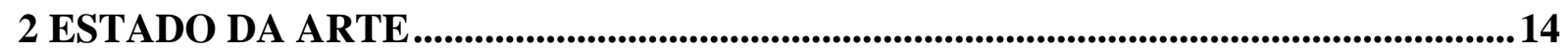

2.1 Otimização e Técnicas de Busca de Solução..................................................................... 14

2.2 A Computação Evolutiva e os Algoritmos Evolutivos.................................................. 20

2.3 O Planejamento Operacional de Sistemas Elétricos de Subtransmissão e a Computação

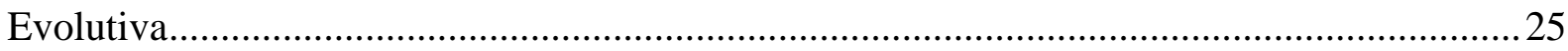

2.4 A Estrutura Física e Operativa do Sistema Elétrico Brasileiro ........................................ 31

3 MODELO DE OTIMIZAÇÃO DO FLUXO DE POTÊNCIA ATIVA UTILIZANDO

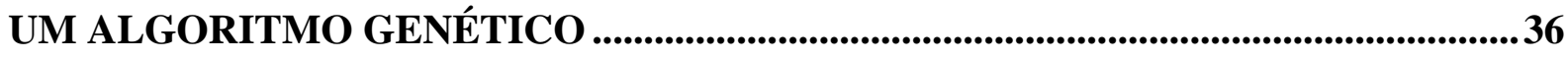

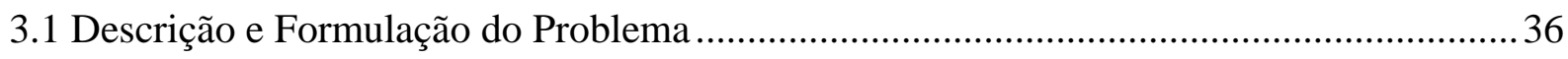

3.2 Aplicação de um Algoritmo Genético ao Problema ........................................................ 42

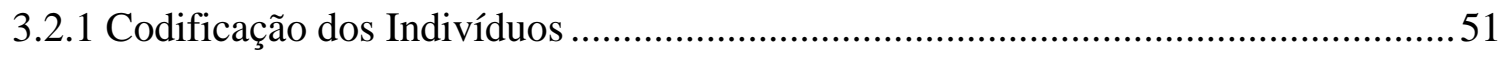

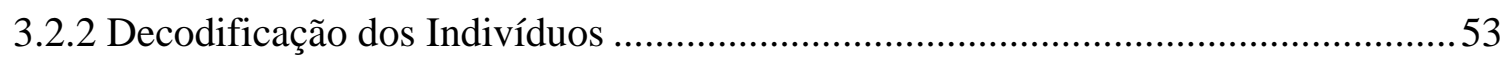

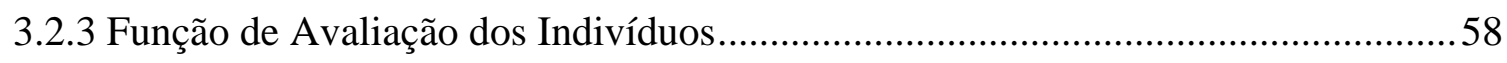

3.2.3.1 Fator de penalização por transgressão de carregamento dos transformadores de fronteira 64

3.2.3.2 Fator de penalização por transgressão de carregamento dos trechos das linhas de subtransmissão 68

3.2.3.3 Fator de penalização por transgressão do nível de tensão nos barramentos das subestações 
4 MODELO DE OTIMIZAÇÃO DO FLUXO DE POTÊNCIA REATIVA UTILIZANDO UMA ESTRATÉGIA EVOLUTIVA ......................................................74

4.1 Descrição e Formulação do Problema .......................................................................... 74

4.2 Aplicação de uma Estratégia Evolutiva ao Problema.................................................... 76

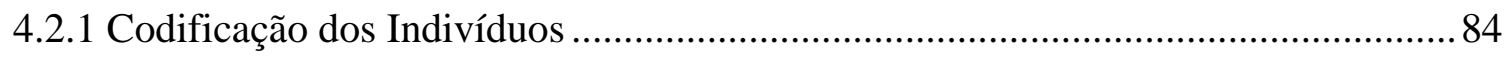

4.2.2 Função de Avaliação dos Indivíduos..................................................................... 85

5 APLICAÇÃo DOS MODELOS DE OTIMIZAÇÃO DO FLUXO DE POTÊNCIA ATIVA E REATIVA DE SISTEMAS ELÉTRICOS DE SUBTRANSMISSÃO .............87

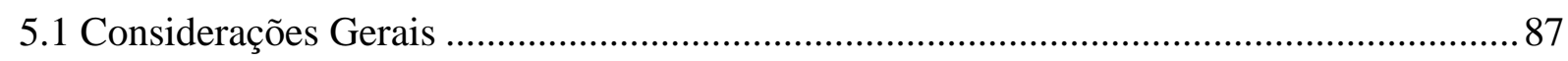

5.2 Otimização do Fluxo de Potência Ativa de um Sistema Elétrico de Subtransmissão.........89

5.3 Otimização do Fluxo de Potência Reativa de um Sistema Elétrico de Subtransmissão..... 99

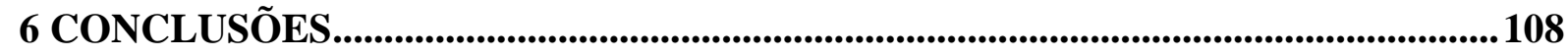




\section{INTRODUÇÃO}

\subsection{Considerações Gerais}

A otimização do fluxo de potência em sistemas elétricos de subtransmissão é o processo de busca da melhor configuração operativa de um sistema analisado visando alcançar um determinado objetivo. Essa configuração envolve a otimização tanto do fluxo de potência ativa quanto do fluxo de potência reativa.

Atualmente, a definição do estado ótimo de um sistema de subtransmissão de energia elétrica é de grande importância para o planejamento da operação elétrica do mesmo. Dado um sistema elétrico de subtransmissão qualquer, pretende-se encontrar a configuração da rede e os níveis de tensão nos pontos de fronteira com a Rede Básica adequados para solucionar um determinado problema referente ao sistema em análise. Para isso, neste trabalho estuda-se os Algoritmos Evolutivos (AE), técnicas de otimização que atualmente estão bastante consolidadas nacional e internacionalmente através de diversos trabalhos e pesquisas científicas.

O presente trabalho propõe o desenvolvimento de uma metodologia de otimização do fluxo de potência em sistemas elétricos de subtransmissão para o auxílio ao planejamento operacional de empresas concessionárias de distribuição de energia elétrica.

Inicialmente, apresenta-se a problemática das empresas de distribuição de energia elétrica relativa ao atual contexto do Setor Elétrico Brasileiro e a importância da otimização dos sistemas de subtransmissão de energia elétrica no planejamento operacional. Será visto um panorama geral das técnicas de otimização mais conhecidas e utilizadas, dentre elas, as 
pertencentes à área da Computação Evolutiva (CE), que engloba os Algoritmos Genéticos (AG) e as Estratégias Evolutivas (EE).

Ao longo do trabalho, aborda-se separadamente os problemas da otimização dos fluxos de potência ativa e reativa de sistemas de subtransmissão de energia elétrica. Para cada abordagem diferente, propõe-se o desenvolvimento de um AE, baseados nos conceitos de AG ou EE, com enfoque nos seus princípios de funcionamento e características de aplicação. Dependendo do tipo de otimização a ser realizada, uma das duas técnicas torna-se mais adequada para ser utilizada na busca da solução do problema.

Vale acrescentar que o objetivo desta dissertação não é apenas demonstrar a aplicabilidade das técnicas da CE em sistemas de subtransmissão de energia elétrica, mas que as metodologias propostas podem ser estendidas para a otimização de múltiplos objetivos do planejamento operacional e seus diversos graus de importância em determinados contextos da operação desses sistemas, bastando para isso algumas alterações e ajustes na configuração do problema.

\subsection{Motivações e Objetivos}

Para atender às imposições do órgão regulador do setor elétrico e a um mercado cada vez mais exigente, as empresas concessionárias de energia elétrica têm constantemente desenvolvido esforços no sentido de melhorar a qualidade e a continuidade do fornecimento de energia elétrica aos seus consumidores. Nesse contexto, a necessidade de operação dos sistemas elétricos de potência de forma o mais eficiente possível está tornando o planejamento operacional cada vez mais complexo. Em um sistema elétrico contendo uma grande 
quantidade de linhas de subtransmissão, além de diversos pontos de fronteira com a Rede Básica através de diferentes sistemas das concessionárias transmissoras de energia elétrica, pode existir um número elevado de alternativas viáveis de operação do mesmo, dificultando a obtenção de soluções eficientes ou otimizadas. Além disso, dependendo dos anseios da empresa ou do planejador, pode ser necessário contemplar múltiplos objetivos na busca destas soluções, mesmo que esses objetivos possuam diferentes graus de importância.

Sendo assim, torna-se essencial aos planejadores e operadores do sistema buscarem novas ações necessárias para a redução dos custos operacionais, como forma de proporcionarem ganhos em competitividade dentro do setor. Considerando os sistemas de subtransmissão de energia elétrica, uma alternativa de curto ou médio prazo para o planejamento operacional é a obtenção do melhor estado operativo de um sistema em análise, visando alcançar determinado objetivo, mantendo as demais condições externas à rede.

Aliando a proposta de solução deste problema às novas técnicas de sistemas inteligentes em crescente desenvolvimento, como é o caso da CE, surge a motivação para o desenvolvimento de uma metodologia de resolução de problemas de otimização do fluxo de potência em sistemas de subtransmissão de energia elétrica empregando-se duas técnicas da CE: os AG e as EE.

Em particular, pretende-se lançar mão de uma metodologia capaz de auxiliar o planejamento operacional dos sistemas elétricos de subtransmissão compostos de múltiplos pontos de fronteira com a Rede Básica e diversas opções de configuração de rede. O problema a ser solucionado, portanto, consiste em buscar um estado operativo da rede de um sistema elétrico de subtransmissão que contemple a otimização de determinados objetivos do planejamento da operação elétrica de curto ou médio prazo.

Destacam-se abaixo as principais metas a serem atingidas por esta dissertação: 
- Sensibilização ao problema do planejamento operacional dos sistemas de subtransmissão de energia elétrica e seus múltiplos objetivos.

- Formulação do problema de otimização da condição operativa de sistemas de subtransmissão de energia elétrica.

- Descrição de um AG canônico e de uma EE canônica, destacando-se as principais características de seus funcionamentos.

- Desenvolvimento de um AG e de uma EE aplicados ao problema de otimização do fluxo de potência ativa e reativa, respectivamente, em sistemas elétricos de subtransmissão de energia, com descrição de suas características.

- Análise do problema de minimização do custo dos encargos de uso dos sistemas de transmissão, isto é, dos custos por demanda de energia de cada ponto de fronteira dos sistemas elétricos de subtransmissão, modelado através dos algoritmos propostos.

- Proposição de casos de estudo, com aplicação dos algoritmos desenvolvidos em uma rede de subtransmissão real e análise dos resultados obtidos.

\subsection{Organização do Trabalho}

O Capítulo 2 define a otimização e descreve as técnicas de busca de solução, com destaque para a categoria de algoritmos "naturais", que têm seu funcionamento baseado em determinados processos da natureza na busca pela solução otimizada de um problema. Nele, o planejamento operacional de sistemas elétricos de potência é apresentado, mostrando os problemas e as necessidades envolvidas nessa área. 
O Capítulo 3 desenvolve o problema de otimização do fluxo de potência ativa em sistemas elétricos de subtransmissão. Nesse capítulo, descreve-se o funcionamento e características de um AG canônico e elabora-se um procedimento de codificação e decodificação de estruturas de informações utilizadas pelo AG para validação das configurações de redes elétricas, mecanismo essencial para o funcionamento adequado do algoritmo nesta categoria de problema.

No Capítulo 4, desenvolve-se o problema de otimização do fluxo de potência reativa em sistemas elétricos de subtransmissão. São apresentados a formulação de uma EE canônica, com enfoque em seu princípio elementar de funcionamento, e os detalhes de sua modelagem para a resolução deste problema.

O $\underline{\text { Capítulo } 5}$ contém a aplicação da metodologia proposta em uma rede com características reais de parâmetros e carregamentos e demonstra-se a eficácia do algoritmo na busca da solução para atendimento ao objetivo de minimização dos encargos de uso dos sistemas de transmissão.

Finalmente, o Capítulo 6 apresenta as conclusões do trabalho, contendo uma síntese dos principais resultados obtidos com o emprego da metodologia desenvolvida e as possíveis pesquisas posteriores para o avanço nos estudos da otimização do fluxo de potência em sistemas de subtransmissão de energia elétrica. 


\section{ESTADO DAARTE}

\subsection{Otimização e Técnicas de Busca de Solução}

A palavra otimização é definida por Ferreira [1] como sendo o "processo pelo qual se determina o valor ótimo de uma grandeza”. Ele ainda define o ótimo como sendo "aquilo que há ou pode haver de melhor ou muito bom”.

Tecnicamente, a otimização é o processo de encontrar a melhor solução de um conjunto de soluções para um problema. O problema geral de otimização consiste na composição de uma função objetivo que relacione diferentes variáveis do problema considerado sujeita, ou não, a restrições impostas. Matematicamente, resolver um problema de otimização requer encontrar um vetor solução $\vec{x}$, composto por variáveis relacionadas ao problema em questão, tal que nenhum outro vetor do espaço de possíveis soluções propicie um valor real maior à função objetivo descritora do problema, caso seja requerida sua maximização. Formalmente, pode-se escrever que maximizar a função objetivo $f(\vec{x}): M \rightarrow \Re$ é encontrar $\vec{x} \in M: \forall \vec{x}^{\prime} \in M$, $f(\vec{x}) \geq f\left(\vec{x}^{\prime}\right)$, sendo $M$ o espaço delimitado pelas possíveis soluções do problema.

A resolução é análoga para o caso em que é necessária a minimização da função objetivo, pois $\operatorname{Max}(f(\vec{x}))=-\operatorname{Min}(-f(\vec{x}))$.

Uma formulação matemática para o tratamento de problemas de otimização com múltiplos objetivos pode ser descrita na forma: 


$$
\min \mu_{o b j}=\min \frac{\sum_{i=1}^{m} \alpha_{i} z_{i}(\vec{x})}{\sum_{i=1}^{m} \alpha_{i}}
$$

Sujeito a,

$$
h_{j}(\vec{x}) \leq 0, j=1,2, \ldots, n_{\text {restr }}
$$

Onde,

$\mu_{o b j}=$ função utilidade.

$Z_{i}(\vec{x})=$ função objetivo $i$.

$\alpha_{i}=$ ponderação da função objetivo $i$.

$m$ = número de objetivos do problema.

$h_{j}(\vec{x})=$ função de restrição $j$.

$n_{\text {restr }}=$ número de restrições do problema.

$\vec{X}=$ vetor de variáveis do problema

Uma possibilidade para simplificar o problema de otimização enunciado acima consiste em incluir suas restrições diretamente na função objetivo inicial, de maneira a degradar seu valor quando tais restrições não forem respeitadas em alguma configuração. Através do Método das Penalizações [2], pode-se obter um problema equivalente, sem restrições, na forma:

$$
\min \left(\mu_{o b j}+\sum_{k=1}^{n_{\text {restr }}} r_{k} P_{k}(\vec{x})\right)
$$


Onde,

$P_{k}(\vec{x})=$ função de penalidade para a restrição $k$.

$r_{k}=$ coeficiente de penalidade para a restrição $k$.

Na equação (2.3), cada fator de penalização $P_{k}(\vec{x})$ corresponde a uma das restrições $n_{\text {restr }}$ do problema original ponderadas por fatores $r_{k}$. Nos problemas de minimização, em geral, são utilizados fatores $r_{k}$ elevados, o que afasta os algoritmos de otimização das soluções inviáveis.

Existem inúmeras técnicas e métodos atualmente desenvolvidos que se propõem a solucionar problemas de otimização de variáveis objetivas representativas de problemas reais. A aplicação de cada uma delas depende essencialmente do tipo de problema abordado. É praticamente impossível, no entanto, comparar técnicas aplicadas a problemas específicos, já que, para cada característica, técnicas diferentes apresentam desempenhos diferentes.

O chamado "No-free-lunch theorem" [3] afirma que não pode existir um algoritmo que consiga resolver todos os problemas de otimização de variáveis de forma a apresentar desempenho superior a qualquer técnica ou algoritmo competidor. Isto quer dizer que características como robustez, velocidade, eficácia e eficiência podem compor combinações antagônicas e divergentes se analisadas classes de problemas diferentes solucionadas por técnicas diferentes.

As técnicas de otimização devem ser utilizadas quando não existe uma solução simples e diretamente calculável para o problema. Isso geralmente ocorre quando a estrutura do problema é complexa, ou existem milhões de possíveis soluções. Nesses casos, é possível que 
não exista nenhum procedimento direto de solução, de forma que as técnicas de otimização podem ser utilizadas na busca pela melhor solução para o problema em questão.

As soluções em um problema de otimização podem ser divididas em ótimo local e ótimo global. Uma solução é um ótimo local se ela é viável e se sua vizinhança não contém pontos que sejam ao mesmo tempo viáveis e possuam melhores valores da função objetivo. Já uma solução é um ótimo global se ela é viável e se não há nenhuma outra solução viável que possua melhor valor da função objetivo. Assim, todo ótimo global é um ótimo local, mas um ótimo local pode não ser um ótimo global.

Pode ser praticamente impossível de se encontrar uma solução ótima global em algumas aplicações, entretanto, uma solução ótima local pode ser bastante eficiente. Em muitos casos, encontrar o ótimo global não é necessário, porém, encontrar rapidamente uma boa solução, isto é, um ótimo local pode ser mais desejável do que encontrar demoradamente a melhor solução possível.

A técnica de otimização empregada depende da estrutura do problema e do grau de confiabilidade das variáveis utilizadas. O trabalho de Oliveira [4] faz uma classificação detalhada de alguns dos métodos para busca de solução de problemas de otimização mais conhecidos. De maneira genérica e simplificada, pode-se orientar a classificação destas técnicas em:

- Técnicas baseadas em cálculo matemático

- Técnicas baseadas em programação matemática

- Técnicas baseadas em busca aleatória direcionada

As técnicas baseadas em cálculo matemático, subdivididas em diretas e indiretas, têm sido intensamente empregadas para a classe de problemas que apresenta funções matemáticas bem 
definidas, contínuas e diferenciáveis. No entanto, e apesar das grandes contribuições do cálculo matemático e numérico, os problemas reais são complexos, suas funções descontínuas e, na maioria dos casos não se conhece uma função objetivo que os descreva com eficiente representatividade, tornando estas técnicas pouco robustas e pouco adaptáveis aos problemas reais considerados.

Com relação às principais técnicas baseadas em programação matemática, pode-se citar a Programação Linear, Programação Linear Inteira, Programação Linear Inteira-Mista, Programação Não Linear, os Algoritmos de Transporte e a Programação Dinâmica.

As técnicas de programação linear, programação linear inteira, linear inteira-mista e os algoritmos de transporte são basicamente algoritmos matemáticos de solução de maximizações e minimizações de funções objetivo de primeira ordem [2]. Para tal, a função objetivo do problema obrigatoriamente é dada ou aproximada por funções descritoras lineares e todas as restrições, também lineares, são formatadas de acordo com a técnica empregada. As vantagens da utilização destas técnicas estão na velocidade de processamento dos algoritmos, relativa facilidade de implementação e resultados precisos para certa classe de problemas. As desvantagens estão basicamente concentradas na adaptação do problema real aos padrões e formatações requeridas pelos algoritmos de solução, pois se torna necessário linearizar parâmetros e funções representativas, o que pode tornar o modelo de solução distante do problema original.

As técnicas de programação dinâmica consistem em algoritmos matemáticos que podem ser aplicados a problemas de otimização com múltiplos estágios, onde é possível identificar claramente, a cada estágio, os estados do sistema. A desvantagem desta técnica consiste no fato de não haver uma formulação robusta para diferentes classes de problemas, tornando-se necessário uma nova implementação a cada problema proposto. 
As técnicas de otimização baseadas em cálculo matemático e programação matemática são conhecidas há mais de um século e, por serem bastante confiáveis, possuem aplicações nos mais diversos campos da física, engenharia e outras ciências. Porém, conforme mencionado, estas técnicas podem apresentar algumas dificuldades numéricas e problemas de robustez relacionados com a falta de continuidade das funções a serem otimizadas ou de suas restrições, funções não convexas, multimodalidade, existência de ruídos nas funções, necessidade de se trabalhar com valores discretos para as variáveis, existência de mínimos ou máximos locais, etc.

As técnicas baseadas em busca aleatória direcionada alcançaram surpreendente popularidade e proporcionaram avanços notáveis na área de sistemas inteligentes voltada principalmente à CE. Os métodos de otimização por busca aleatória direcionada são baseados nos princípios da evolução biológica natural. Todas elas têm como fundamento principal simular a evolução natural através de conceitos e operadores a fim de encontrar aleatoriamente, porém em um processo dirigido, os melhores indivíduos representantes de configurações ou codificações de resultados ótimos. Esses métodos têm recebido interesse crescente nas últimas décadas, devido principalmente à sua versatilidade na resolução de problemas complexos, nas áreas de otimização e aprendizado de máquinas.

Um fator limitante destes métodos é a necessidade de um número elevado de avaliações da função objetivo. A sofisticação dos recursos computacionais desenvolvidos nos últimos anos, porém, tem motivado um grande avanço no desenvolvimento e aplicação dessas técnicas, que apresentam como característica marcante a adaptação robusta na busca de solução para problemas de otimização. As técnicas de busca aleatória direcionada são especialmente úteis às tarefas de otimização global, onde os métodos determinísticos podem levar às soluções locais. Por conseguinte, elas são aptas à resolução de um amplo espectro de problemas não lineares, descontínuos, discretos, multivariáveis, entre outros. 


\subsection{A Computação Evolutiva e os Algoritmos Evolutivos}

O termo Computação Evolutiva representa uma generalização das técnicas de otimização que empregam os princípios funcionais dos processos evolutivos biológicos. Estes princípios oriundos do “mundo biológico" são baseados na teoria da evolução Darwiniana. O trabalho de Darwin [5] descreve o processo de evolução biológica, destacando os mecanismos naturais de competição, seleção natural e sobrevivência dos mais adaptados ao ambiente. Estas técnicas têm semelhanças fundamentais, como a codificação de soluções representadas por diferentes indivíduos, contidos em uma população ou um conjunto de soluções. Além disto, empregam métodos de recombinação, variações aleatórias, competição e seleção de soluções, na busca pela solução ótima de um problema.

A Computação Evolutiva (CE) é uma ramificação da ciência da computação que, juntamente com o estudo de Fuzzy Systems e Redes Neurais, forma a área denominada Inteligência Computacional (IC) [6]. Esta, por sua vez, em conjunto com outras áreas tais como Vida Artificial, Geometria Fractal, Teoria do Caos, Sistemas Complexos, etc., delimita um campo conhecido como Computação Natural (CN). No sentido oposto, a CE é constituída em princípio por cinco diferentes linhas: Algoritmos Genéticos (AG), Programação Evolutiva (PE), Estratégias de Evolução ou Evolutivas (EE), Sistemas de Classificação ou Classificadores (SC) e Programação Genética (PG). A Figura 2.1 abaixo esquematiza essa classificação. 


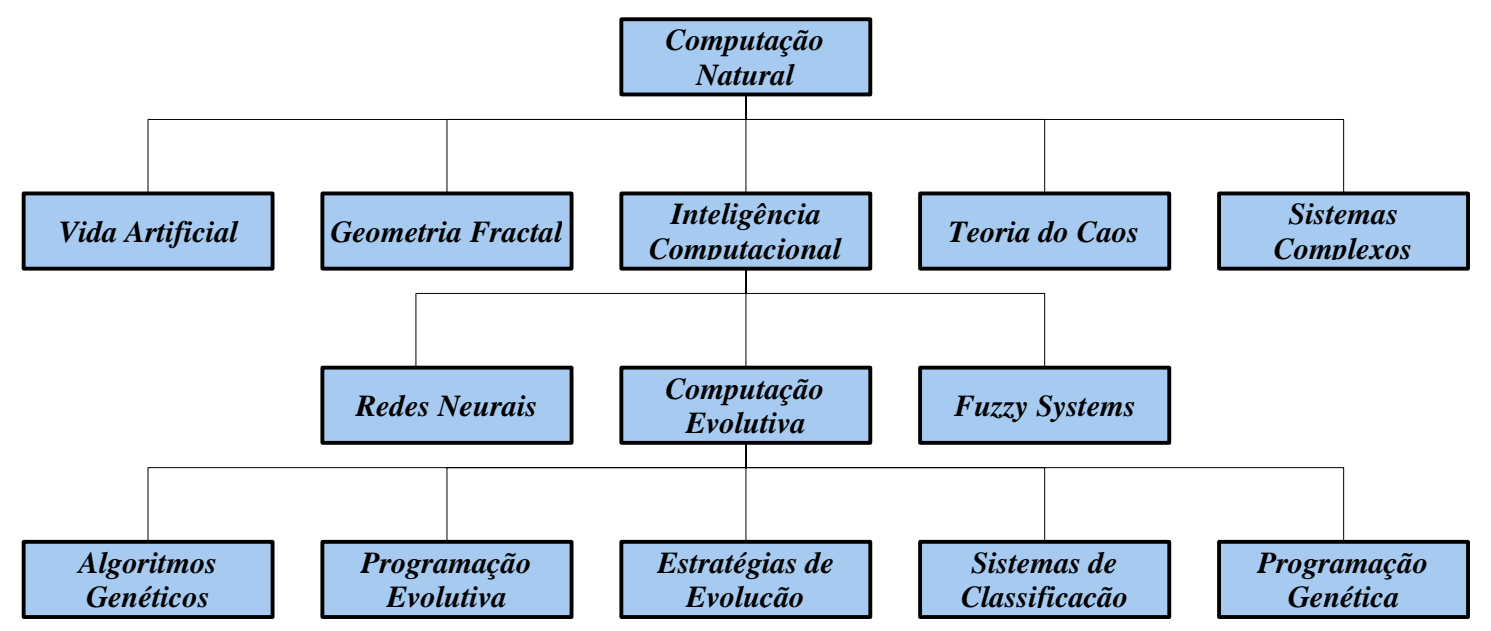

Figura 2.1 - Taxonomia da Computação Natural

Os algoritmos desenvolvidos na área da CE denominam-se Algoritmos Evolutivos (AE), um termo que define os sistemas para a solução de problemas que empregam modelos computacionais de processos evolutivos como elementos básicos de projeto e implementação. As origens da CE podem ser traçadas por trabalhos pioneiros de R. M. Friedberg, H. J. Bremermann, W. Spendley, F. E. Satterthwaite, entre outros, nos anos 50. Após esta fase, este campo do conhecimento permaneceu relativamente desconhecido ou inexplorado pela maioria da comunidade científica, por mais de três décadas. Este fato deve-se, principalmente, à falta de plataformas computacionais poderosas naquela época, da formalização e caracterização deficiente de cada metodologia evolutiva nos primeiros estudos nesta área. Os trabalhos fundamentais de Holland, Rechenberg, Schwefel e Fogel, serviram à realização de mudanças neste cenário, durante a década de 70. Atualmente, observa-se um relevante e permanente crescimento do número de publicações, aplicações e conferências no campo da CE. A maioria das abordagens correntes dos AE descende dos princípios das diferentes metodologias já citadas, principalmente: 
- Algoritmos Genéticos, desenvolvidos principalmente por A. S. Fraser, H. J. Bremermann, J. Reed e J. H. Holland, entre a década de 50 e 70, com refinamentos posteriores por D. Whitley, D. E. Goldberg, K. De Jong e J. Grefenstette;

- Programação Evolutiva, desenvolvidas por L. J. Fogel, A. J. Owens e M. J. Walsh, nos Estados Unidos, na década de 60, refinada recentemente por D. B. Fogel, G. H. Burgin, P. J. Angeline, V. W. Porto e W. Atmar;

- Estratégias Evolutivas, desenvolvidas na Alemanha, por I. Rechenberg e H. P. Schwefel, na década de 60, com aprimoramentos posteriores de G. Rudolph, H. G. Beyer, F. Kursawe e T. Bäck;

- Sistemas de Classificação, originalmente proposto por J. H. Holland em 1975 e posteriormente abordado por L. B. Booker e D. E. Goldberg;

- Programação Genética, abordadas pelos pesquisadores J. R. Koza, J. P. Rice, K. E. Kinnear e P. J. Angeline.

Um fato relevante é que, ao longo do tempo, as metodologias que constituem os procedimentos do tipo evolutivo foram desenvolvidas independentemente uma das outras. O termo Algoritmos Evolutivos foi proposto em 1990, buscando reunir todas essas variantes e também todas as outras técnicas que fossem baseadas em princípios evolutivos para a solução de problemas. Os AE não são algoritmos computacionais em seu significado usual, mas formam uma classe de métodos regidos por princípios similares e, embora cada uma dessas variantes tenha características particulares, cada vez mais as fronteiras entre elas estão se tornando menos claras.

Desta forma, os AE referem-se aos procedimentos baseados em princípios que são encontrados na evolução dos sistemas biológicos. Os AE tentam abstrair e imitar alguns dos mecanismos evolutivos à resolução de problemas que requerem adaptação, busca e 
otimização. Usando esses princípios, a tarefa de encontrar a solução de um problema pode ser vista com uma tarefa de sobrevivência, isto é, possíveis soluções competem entre si pela sobrevivência e também pelo direito de reproduzirem-se.

Os AE compartilham uma base conceitual comum para a evolução de estruturas individuais por meio de processos de seleção, recombinação e mutação. Os processos dependem da percepção do desempenho das estruturas individuais, no sentido definido pelo seu ambiente. Mais precisamente, os AE operam sobre uma população de estruturas que evoluem de acordo com leis de seleção e outros operadores denominados operadores genéticos, tais como avaliação, recombinação e mutação. Cada indivíduo na população recebe uma medida correspondente à sua adequação ao ambiente. Os descendentes destes indivíduos são gerados através de processos aleatórios de mutação e recombinação. O operador mutação representa as variações aleatórias, que podem ocorrer em um indivíduo e são, tipicamente, de pequena ordem. Já o operador recombinação, ou cruzamento, obtém novos indivíduos a partir da troca de informações entre dois ou mais indivíduos presentes na população. A partir dos respectivos valores de avaliação, obtidos através da decodificação de cada indivíduo na função objetivo do problema, o operador seleção favorece aqueles relativamente melhor avaliados a participarem em maior número de cruzamentos e contribuírem de maneira mais significativa na geração seguinte.

Assim, nos $\mathrm{AE}$ os pontos no espaço de busca são modelados através de indivíduos que interagem em um ambiente artificial até que um critério de convergência ou de parada seja satisfeito. Um conjunto de soluções, denominado população, é manipulado a cada iteração, em contraste com outros métodos de otimização onde apenas uma solução para o problema é utilizada. A chance que um indivíduo da população seja selecionado na próxima geração depende da função de avaliação do indivíduo (existem outros sinônimos, utilizados na literatura, tais como: função de aptidão, adequação, adequabilidade ou fitness), que consiste, 
geralmente, de uma função objetivo ou mesmo uma transformação simples desta para geralmente a resolução de um problema de maximização ou minimização de algum índice de desempenho.

O ciclo básico dos dados num AE pode ser sintetizado nos seguintes passos:

1. Inicialização aleatória da população de soluções;

2. Avaliação da função de aptidão;

3. Seleção dos indivíduos mais aptos de acordo com uma estratégia de seleção;

4. Aplicação dos operadores de recombinação e mutação;

5. Geração de uma nova população de soluções candidatas;

6. Repetição dos passos 2 a 5 até que uma condição de parada seja satisfeita.

Ainda que muito simplificados do ponto de vista biológico, os AE são suficientemente complexos para permitir a construção de poderosos mecanismos evolutivos.

Entre os anos de 80 e 90, os avanços no desempenho das plataformas computacionais habilitaram a aplicação de AE à resolução de problemas de otimização do mundo real e em projetos relevantes. A principal vantagem dos AE sobre os outros métodos de otimização reside na grande flexibilidade e adaptabilidade aos problemas reais, combinando robustez e pesquisa abrangente das soluções. Mais do que um conjunto de procedimentos prontos para uso, em aplicações pré-definidas, os $\mathrm{AE}$ apresentam um conceito genérico, que pode ser aplicado para a resolução de problemas complexos de otimização.

Outros aspectos positivos dos AE devem ser mencionados. Estas técnicas trabalham com a modelagem real do problema, sem necessidade de informações auxiliares, como derivadas, ou aproximações quaisquer, como linearizações, o que poderia inviabilizar seu emprego em classes de problemas não diferenciáveis ou tenderia a distanciar a resposta obtida da 
realidade. Desta forma, estes métodos conciliam robustez e simplicidade na implementação para a resolução de problemas com múltiplos objetivos e com grande número de restrições.

Por fim, os AE não requerem o conhecimento das características do problema de otimização e não dependem de certas propriedades da função objetivo, tais como convexidade ou diferenciabilidade. Os AE são guiados pela avaliação da função de aptidão dos indivíduos e possuem pouca dependência do tipo de problema que está sendo resolvido.

\subsection{O Planejamento Operacional de Sistemas Elétricos de Subtransmissão e a Computação Evolutiva}

O processo de planejamento pode ser definido como uma análise sistemática e ordenada de informações face a objetivos desejados, para fornecer subsídios à tomada de decisão.

O planejamento operacional de sistemas elétricos de subtransmissão diz respeito à operação elétrica da rede no qual se analisa o sistema existente e as intervenções a serem nele realizadas. Esta modalidade trabalha com o mínimo de incertezas e o máximo de informações para as tomadas de decisão, na maioria dos casos, exclusivamente técnicas.

Existem diversos estudos elétricos realizados pelo planejamento operacional. Um deles é o de fluxo de potência, em que são realizadas simulações e análises com o objetivo de avaliar o desempenho de um sistema em um determinado instante do tempo, denominado ponto de operação. Essas análises contemplam a operação do sistema tanto em condição normal de operação quanto sob contingências. Os estudos de fluxo de potência são efetuados para verificar o comportamento do sistema em regime permanente e têm como objetivo avaliar se os níveis de tensão nos barramentos e os carregamentos nas linhas, transformadores e demais 
componentes da rede de subtransmissão, para cada uma das configurações do sistema previstas no horizonte em análise atendem aos critérios estabelecidos nos Procedimentos de Rede.

Os Procedimentos de Rede são documentos elaborados pelo Operador Nacional do Sistema (ONS), com a participação dos Agentes e homologados pela Agência Nacional de Energia Elétrica (ANEEL), que estabelecem os procedimentos e os requisitos técnicos para o planejamento, a implantação, o uso e a operação do Sistema Interligado Nacional (SIN) e as responsabilidades do ONS e de todos os demais Agentes de Operação [7].

De acordo com os Procedimentos de Rede, a operação de um sistema elétrico de potência integrante do SIN deve respeitar as restrições técnicas de nível de tensão e capacidade de carregamento das linhas, transformadores e trechos de rede, já que esses parâmetros afetam diretamente a qualidade de fornecimento. De forma complementar e não menos essencial, deve-se operar um sistema elétrico de modo que as perdas técnicas sejam as menores possíveis, além da confiabilidade que o sistema deve possuir para garantir a segurança no fornecimento de energia elétrica.

Define-se que o sistema elétrico opera em condições de normalidade sempre que os parâmetros de avaliação relacionados atendem aos critérios e estão situados dentro das faixas admissíveis estabelecidas nos Procedimentos de Rede e resoluções da ANEEL. Quando não for possível manter os parâmetros de avaliação dentro das faixas admissíveis, tem-se uma condição de anormalidade. Nesta situação, busca-se operar o sistema com segurança, ou seja, priorizando o atendimento à carga ao mesmo tempo em que se resguardam as instalações de danos físicos.

É essencial que os planejadores e operadores do sistema busquem sempre novas ações para a redução dos custos operacionais, como forma de proporcionarem ganhos em competitividade dentro do setor. A crescente automatização dos sistemas elétricos de potência traz a 
possibilidade de se alterar mais facilmente o estado operativo de uma rede, viabilizando ações que permitam operar o sistema sempre da maneira mais adequada, com redução de custos operacionais e melhoria nos níveis de tensão e de carregamento dos equipamentos.

O planejamento da operação de sistemas elétricos de potência constitui-se num conjunto de intervenções na rede, com o fim de buscar a otimização global do sistema, tanto quanto possível. Considerando as redes de subtransmissão de energia elétrica, uma alternativa a curto ou médio prazo para o planejamento operacional é a obtenção do melhor estado operativo de um sistema em análise visando alcançar determinado objetivo, mantido as demais condições externas à rede.

Uma formulação para o problema de otimização do fluxo de potência no âmbito do planejamento operacional de sistemas elétricos de subtransmissão pode ser descrita na forma:

\begin{tabular}{|l|}
\hline min (objetivos do planejamento operacional) \\
s.a - restrição de carregamento dos TR's de fronteira. \\
- restrição de carregamento dos trechos das LT's \\
- restrição de nível de tensão nos barramentos das SE's \\
\hline
\end{tabular}

As variáveis do problema de otimização do fluxo de potência em sistemas elétricos de subtransmissão estão relacionadas às mudanças no estado operativo do sistema. Para se alterar o estado operativo de um sistema elétrico de subtransmissão é necessário modificar a configuração interna da rede ou dos taps dos transformadores de fronteira do sistema. Assim, pode-se afirmar que as variáveis de controle do problema de otimização do fluxo de potência em sistemas elétricos de subtransmissão, que verificam as mudanças no estado operativo do sistema, são os estados dos dispositivos de seccionamento do sistema (chaves seccionadoras 
ou disjuntores) e os níveis de tensão dos barramentos dos pontos de fronteira do sistema. Aplicando-se essas variáveis de controle na formulação matemática definida em (2.1) e (2.2), têm-se:

$$
\min \mu_{o b j}=\min \frac{\sum_{i=1}^{m} \alpha_{i} z_{i}(\vec{\delta}, \vec{y})}{\sum_{i=1}^{m} \alpha_{i}}
$$

Sujeito a,

$$
h_{j}(\vec{\delta}, \vec{y}) \leq 0, j=1,2, \ldots, n_{\text {restr }}
$$

Onde,

$\mu_{o b j}=$ função utilidade.

$z_{i}(\vec{\delta}, \vec{y})=$ função objetivo $i$ (por exemplo, minimização do custo dos encargos de uso dos sistemas de transmissão, minimização das perdas do sistema, etc).

$\alpha_{i}=$ ponderação da função objetivo $i$.

$m$ = número de objetivos do problema.

$h_{j}(\vec{\delta}, \vec{y})=$ função de restrição $j$.

$n_{\text {restr }}=$ número de restrições do problema.

$\vec{\delta}$ = vetor de variáveis binárias (estado dos dispositivos de seccionamento do sistema).

$\vec{y}$ = vetor de variáveis contínuas (nível de tensão dos barramentos de fronteira do sistema). 
O problema do planejamento operacional apresenta características que dificultam sua solução, como o não conhecimento literal da função objetivo, sendo impossível determinar formalmente como as variáveis influenciam na solução do problema. Ele é caracterizado também pela sua natureza combinatória, ou seja, para sistemas reais o número de possíveis alternativas pode tornar-se sobremodo elevado, dificultando a obtenção de soluções eficientes ou otimizadas. Outra consideração a ser feita é que, geralmente, o problema apresenta aspectos de incerteza e subjetividade presentes na maioria dos casos.

Estes problemas podem ser classificados como pertencentes à classe de Problemas de Decisão com Restrições (PDR), que são problemas de decisão de planejamento que se caracterizam por conter múltiplos objetivos e podem ser decompostos em sub-problemas mais específicos, através de uma estrutura hierárquica, atendendo a uma série de restrições, globais ou específicas.

Atendidas as restrições impostas, deve-se otimizar o sistema em análise de acordo com os objetivos vislumbrados pelo planejador como, por exemplo, operar o sistema de modo que as perdas técnicas sejam as menores possíveis, ou adequar o fluxo de potência para minimizar os encargos de uso dos sistemas de transmissão, ou mesmo uma combinação destes e de outros objetivos propostos.

Os sistemas elétricos de subtransmissão caracterizados por conter múltiplos pontos de fronteira com a Rede Básica e diversas opções de configuração de rede tornam a operação destes sistemas mais complexa. Conseqüentemente, o planejamento operacional dessas redes necessita de metodologias e modelos científicos de análise operacional mais robustos e precisos. Da mesma forma, a crescente demanda por qualidade e continuidade no fornecimento, assim como por menores custos de operação dos sistemas elétricos, fazem com que novas implementações e aprimoramentos de técnicas consolidadas sejam necessários. 
Aliando a necessidade de solução de um problema atual e complexo como esse às novas técnicas em crescente desenvolvimento, como é o caso da CE, surge a motivação para o desenvolvimento de uma metodologia de resolução de problemas de otimização do fluxo de potência em sistemas de subtransmissão de energia elétrica empregando-se duas técnicas da CE: os AG e as EE.

O planejamento operacional de sistemas elétricos de potência em seus níveis de subtransmissão e distribuição tem recebido enormes contribuições metodológicas através de modelagens matemáticas utilizando AE que se propõem a otimizar funções representativas dos diversos problemas operacionais dessas redes. É o caso dos modelos definidos por Bento [8] e Hage [9], que incluem as técnicas de AG e EE, respectivamente, e têm respondido de forma bastante eficiente a essas questões.

As técnicas de AG e EE foram selecionadas por evitar a determinação de ótimos locais em uma varredura do espaço de soluções, através da análise de diferentes configurações completas durante o procedimento de busca pela melhor avaliação e solução do problema. Conforme Kagan [10] destaca, “a principal motivação na aplicação desses algoritmos vem de sua potencialidade como técnicas de otimização de características particulares, combinando intrinsecamente procedimentos de busca direcionada e aleatória”, de modo a ser obtido o ponto ótimo de dada função, mesmo quando esta apresenta características não lineares, múltiplos picos e descontinuidades.

No problema específico de configuração de estados operativos de redes de subtransmissão de energia elétrica, a principal motivação é quanto à dimensionalidade do problema, em função do número de variáveis envolvidas. Além de ser um problema de natureza combinatória, também apresenta algumas dificuldades de modelagem, principalmente quando são utilizados métodos convencionais de otimização. Nas técnicas de AE, o espaço de possíveis soluções é percorrido com certa aleatoriedade incorporada, porém sem ser um tipo de busca sem direção, 
levando à grande eficiência para a obtenção da solução almejada do problema real em questão.

\subsection{A Estrutura Física e Operativa do Sistema Elétrico Brasileiro}

A estrutura física de um sistema de energia elétrica, de um modo geral, é formada por geradores, transformadores elevadores/abaixadores, linhas de transmissão e alimentadores de distribuição. Os geradores transformam energia mecânica em energia elétrica e injetam a potência elétrica gerada na rede de transmissão. Por razões econômicas (minimização de perdas), a transmissão é normalmente efetuada em tensões elevadas (por exemplo, 345kV, $440 \mathrm{kV}, 500 \mathrm{kV}$ ou $750 \mathrm{kV}$ para transmissão e $69 \mathrm{kV}$ ou $138 \mathrm{kV}$ para subtransmissão). Devido a limitações físicas e de isolamento elétrico, os geradores não podem operar nesses níveis de tensão. Tipicamente, com as tecnologias convencionais, geradores operam com tensões na faixa de $10 \mathrm{kV}$ a $30 \mathrm{kV}$. Assim, geradores que estão afastados dos centros de carga injetam sua potência gerada na rede através de transformadores elevadores que têm por finalidade transformar a potência gerada dos níveis de tensão de geração para os níveis de tensão de transmissão, com conseqüente redução dos níveis de corrente e, portanto, das perdas de transmissão (perdas ôhmicas). Por razões práticas, a potência entregue aos centros de carga não pode, em geral, ser consumida nos níveis de tensão em que é feita a transmissão. Então, transformadores abaixadores são utilizados nas proximidades das cargas para reduzir os níveis de tensão para valores aceitáveis.

O sistema de produção e transmissão de energia elétrica do Brasil, definido por Sistema Interligado Nacional (SIN), pode ser classificado como hidrotérmico de grande porte, com 
forte predominância de usinas hidrelétricas e com múltiplos proprietários [7]. O SIN é formado pelos Agentes das regiões Sul, Sudeste, Centro-Oeste, Nordeste e parte da região Norte.

A maior parte da capacidade instalada é composta por usinas hidrelétricas, que se distribuem em 12 diferentes bacias hidrográficas nas diferentes regiões. A integração eletroenergética entre os sistemas de produção e transmissão para o suprimento do mercado consumidor que se dá através da Rede Básica de Transmissão é ilustrada abaixo pela Figura 2.2:

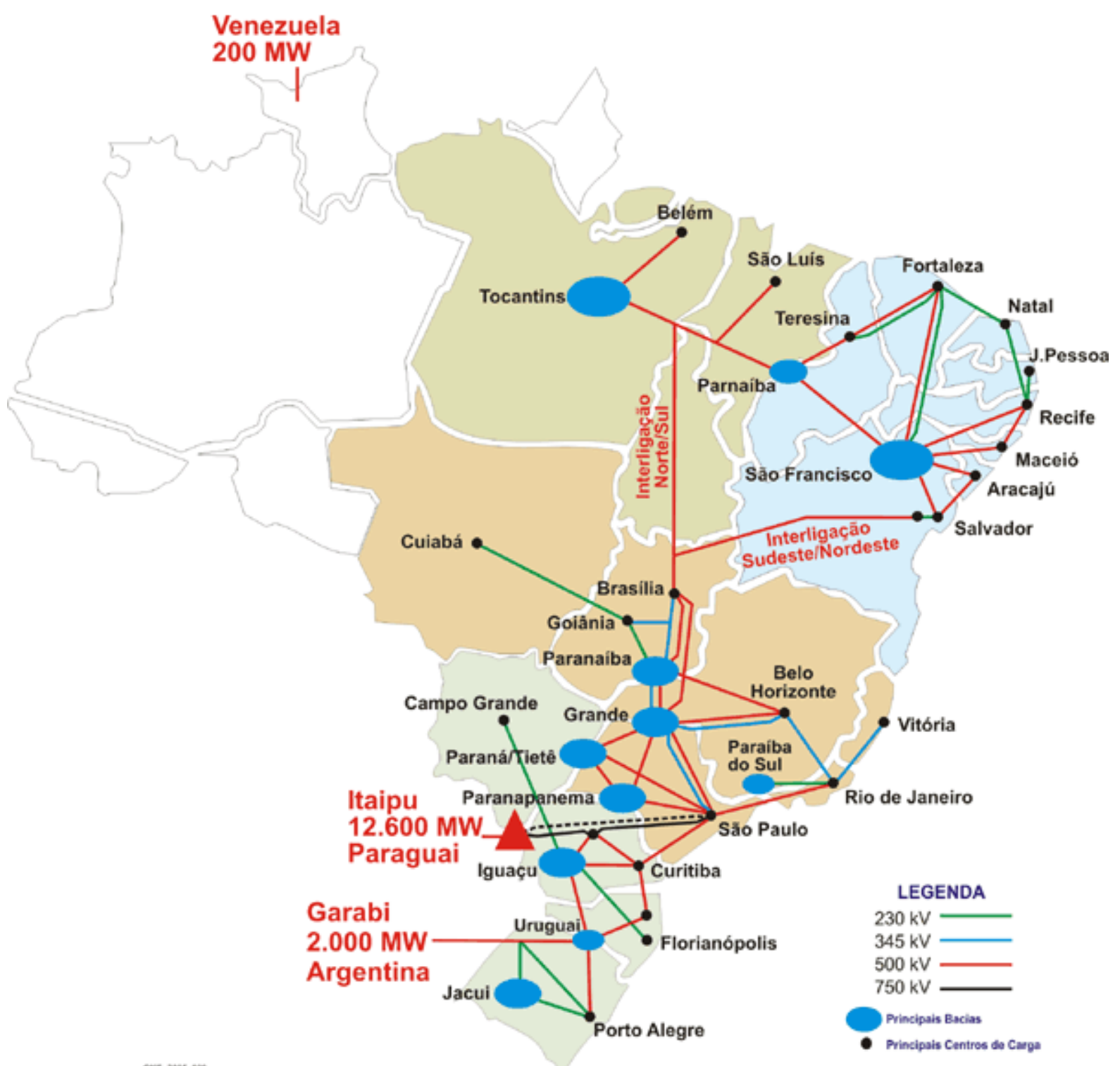

Figura 2.2 - A integração eletroenergética no Brasil 
Conceitualmente, a operação centralizada do SIN está embasada na interdependência operativa entre as usinas, na interconexão dos sistemas elétricos e na integração dos recursos de geração e transmissão no atendimento ao mercado.

O processo de reestruturação do setor elétrico brasileiro tem como pontos principais a desverticalização das empresas, a implantação de um modelo comercial competitivo, a garantia do livre acesso à rede e a redução do papel do Estado nas funções empresariais no setor, o que vem ocorrendo com a privatização das empresas existentes e a licitação da expansão. Também faz parte do novo modelo a instituição de entidades especializadas para executar as funções de regulação, planejamento da expansão, operação e financiamento do setor. O Operador Nacional do Sistema Elétrico (ONS) é fruto desse modelo, tendo sido criado para substituir a estrutura cooperativa de coordenação da operação existente e tendo como responsabilidade manter os ganhos sinérgicos resultantes da otimização da operação dos sistemas de transmissão e geração de energia elétrica e viabilizar a expansão do sistema de transmissão a mínimo custo [7].

Instituído pela Lei $n^{\circ}$ 9648, de 27 de maio de 1998, e pelo Decreto ${ }^{\circ}$ 2655, de 2 de julho de 1998, o ONS foi criado em 26 de agosto de 1998 e teve seu funcionamento autorizado pela Resolução Normativa ${ }^{\circ}$ 351, de 11 de novembro de 1998, da ANEEL. O ONS é uma entidade de direito privado responsável pela coordenação e controle da operação das instalações de geração e transmissão de energia elétrica nos sistemas interligados brasileiros com os objetivos básicos de:

(a) Promover a otimização da operação do sistema eletroenergético, visando o menor custo para o sistema, observados os padrões técnicos, os critérios de confiabilidade e as Regras do Mercado; 
(b) Garantir que todos os agentes do setor elétrico tenham acesso à rede de transmissão de forma não discriminatória;

(c) Contribuir, de acordo com a natureza de suas atividades, para que a expansão do sistema eletroenergético se faça ao menor custo e vise as melhores condições operacionais futuras.

A missão do ONS é otimizar a utilização dos recursos de geração e transmissão do SIN, administrar a Rede Básica de Transmissão, garantindo o livre acesso, e assegurar a continuidade, a qualidade e a economicidade do suprimento de energia elétrica aos usuários. A Rede Básica é a rede oficialmente definida e regulamentada pela ANEEL. De acordo com o artigo terceiro da Resolução Normativa $n^{\circ}$ 67, de 8 de Junho de 2004, da ANEEL [11], a qual estabelece os critérios para a composição da Rede Básica do Sistema Interligado Nacional e dá outras providências,

Art. $3^{\circ}$ Integram a Rede Básica do Sistema Interligado Nacional - SIN as Instalações de Transmissão, definidas conforme inciso II do artigo anterior, que atendam aos seguintes critérios:

I - linhas de transmissão, barramentos, transformadores de potência e equipamentos de subestação em tensão igual ou superior a $230 \mathrm{kV}$; e II - transformadores de potência com tensão primária igual ou superior a $230 \mathrm{kV}$ e tensões secundária e terciária inferiores a $230 \mathrm{kV}$, bem como as respectivas conexões e demais equipamentos ligados ao terciário, a partir de $1^{\circ}$ de julho de 2004.

Os sistemas elétricos de subtransmissão não constituem elementos da Rede Básica, pois operam com uma tensão abaixo de $230 \mathrm{kV}$. Esses sistemas fazem parte das redes de 
distribuição de energia elétrica. É importante, porém, a compreensão da operação elétrica do SIN e de como uma rede de subtransmissão analisada está nele conectada. Alguns sistemas elétricos de subtransmissão possuem diversos pontos de fronteira com a Rede Básica, podendo inclusive apresentar uma configuração operativa interna em anel. Esses sistemas, objeto de estudo deste trabalho, dependendo da sua configuração e localização geoelétrica no SIN, sofrem influência da operação elétrica da Rede Básica nos seus fluxos de potência injetados em cada um desses pontos. Assim, a metodologia de otimização do fluxo de potência ativa e reativa proposta neste trabalho deve levar em conta a rede externa conectada ao sistema analisado. 


\section{MODELO DE OTIMIZAÇÃO DO FLUXO DE POTÊNCIA ATIVA UTILIZANDO UM ALGORITMO GENÉTICO}

\subsection{Descrição e Formulação do Problema}

A potência ativa injetada em um sistema de subtransmissão de energia elétrica varia de um ponto de fronteira para outro e é influenciada fortemente pela configuração de rede interna do sistema, pela configuração operativa das linhas de transmissão da Rede Básica, bem como pelos níveis de geração despachados centralmente pelo ONS, além do intercâmbio de energia entre as regiões geoelétricas. Desta forma, o controle da potência ativa que ingressa no sistema é restrito à abertura ou fechamento estratégico de algumas linhas de subtransmissão. O problema de otimização do fluxo de potência ativa em sistemas de subtransmissão de energia elétrica contendo múltiplos pontos de fronteira com a Rede Básica consiste em determinar uma configuração para uma rede de subtransmissão analisada, visando atender a um ou mais objetivos e sujeito às restrições impostas e que não devem ser violadas.

As principais variáveis de controle do problema são as chaves seccionadoras e disjuntores das linhas de subtransmissão do sistema em análise. Assim, o modelo a ser elaborado considera os dispositivos de seccionamento das linhas estratégicos para o sistema, isto é, que possam influenciar na configuração operativa da rede, para buscar uma alternativa de solução do problema em que as necessidades do planejador sejam plenamente satisfeitas.

Algumas premissas devem estar incorporadas ao modelo: 
- Todos os transformadores de fronteira devem operar dentro dos limites técnicos de capacidade de transformação;

- Todos os trechos das linhas de subtransmissão devem operar dentro dos limites técnicos de carregamento admissíveis; e

- Todos os barramentos das subestações do sistema devem apresentar níveis de tensão apropriados.

A modelagem proposta considera ainda algumas outras limitações, todas compatíveis com o planejamento operacional, a saber:

- Todas as demandas dos consumidores devem ser plenamente atendidas;

- Todas as cargas existentes devem ser conectadas a, pelo menos, um ponto de fornecimento, uma condição com justificativa evidente;

- Os sistemas elétricos de subtransmissão podem operar tanto em configuração de rede radial quanto em anel;

- Admite-se que as chaves estrategicamente pré-estabelecidas do sistema possam ter seus estados alterados, indiferentemente;

- Não se consideram investimentos na rede, sendo que as únicas variáveis consideradas são os estados das chaves analisadas.

A principal ferramenta para a análise operacional de um sistema elétrico, capaz de responder às questões necessárias ao diagnóstico operacional, consiste no cálculo de fluxo de potência [12], [13].

Dado que a maioria dos sistemas elétricos de distribuição de energia, notadamente na subtransmissão, são trifásicos e aproximadamente equilibrados, foi conveniente modelá-los, 
para análise de fluxo de potência, através dos diagramas de seqüência positiva para suprimentos e geradores, transformadores, trechos e cargas em geral.

Este modelo é conveniente porque, como os sistemas são aproximadamente equilibrados e as linhas de transmissão são fisicamente transpostas, todas as transformações para componentes simétricas resultam em diagramas seqüenciais desacoplados, ou sem impedâncias mútuas entre seqüências, o que resulta em um cálculo de fluxo de potência monofásico, considerando apenas impedâncias de seqüência positiva.

A rede elétrica é modelada, de acordo com análise nodal de redes, pela sua matriz $Y$ de admitâncias nodais para seqüência positiva. O método numérico para o cálculo do fluxo de potência é o método de Newton-Raphson [13], capaz de calcular o fluxo de potência de um sistema em malha, contendo geradores do tipo $P V$, suprimentos do tipo $V \theta$ ou $P V$, e cargas do tipo $P Q$. O método numérico de Newton-Raphson fornece, como resultado, as tensões em todas as barras, os fluxos em todos os trecho da rede, as potências ativas e reativas das barras do tipo $V \theta$ e as potências reativas das barras do tipo $P V$.

Um sistema elétrico de subtransmissão conta basicamente com três tipos de barras, conforme mostra a Figura 3.1:

1. Barras de suprimento (em geral, para o caso da subtransmissão, swing de conexão do sistema com a Rede Básica).

2. Barras de geração (geração distribuída e pontos de conexão do sistema com a Rede Básica).

3. Barras de carga (subestações próprias e/ou particulares). 


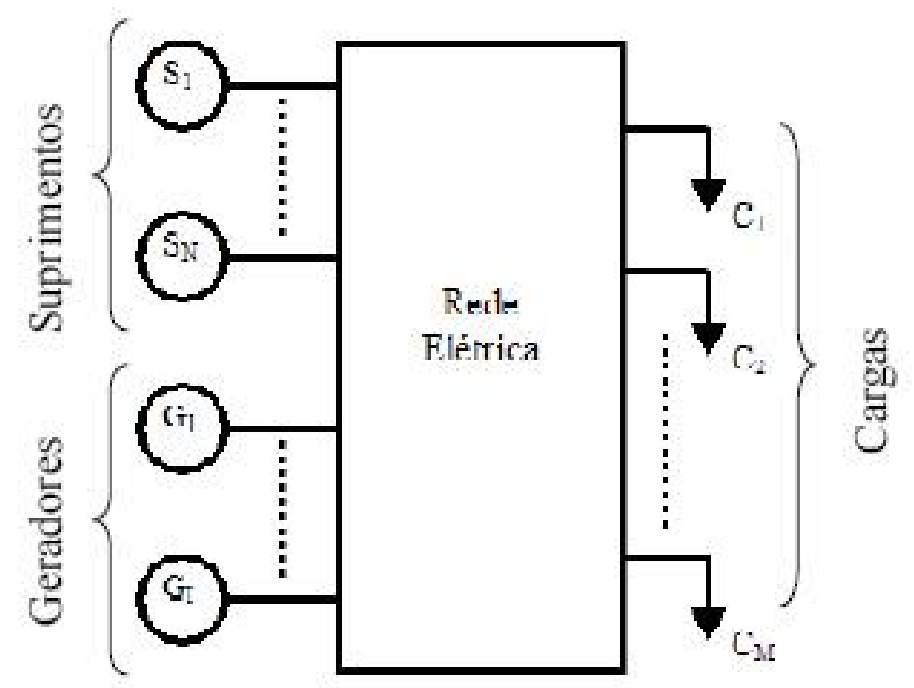

Figura 3.1 - Sistema elétrico de subtransmissão genérico

Outros tipos de barras podem ser considerados para modelagem de outros controles, como é o caso dos transformadores LTC (load tap changer), modelados com barras $P Q V$.

O fluxo de potência ativa em uma rede de subtransmissão pode ser alterado ao modificar-se a configuração da rede, isto é, considerando nova rotas de atendimento às subestações e suas cargas. Para aumentar a confiabilidade do sistema, freqüentemente são instaladas chaves entre diferentes circuitos, dispositivos normalmente abertos existentes especificamente para o atendimento de regiões da rede sob condições especiais de contingência ou manutenção. Além destas chaves de interconexão entre circuitos, são também instalados dispositivos de proteção e seccionamento em cada circuito, elementos normalmente fechados, como chaves seccionadoras de linha e disjuntores. Estes elementos, normalmente fechados ou abertos, possibilitam alterações na topologia da rede.

Com o crescimento da demanda e/ou variação do fluxo de potência ativa nos pontos de fronteira do sistema, abre-se margem para diferentes condições viáveis de operação ou possibilidades para o atendimento de determinadas regiões do sistema.

As Figuras 3.2 e 3.3 ilustram duas situações de operação de um sistema exemplo, envolvendo simples alteração no estado das chaves. 


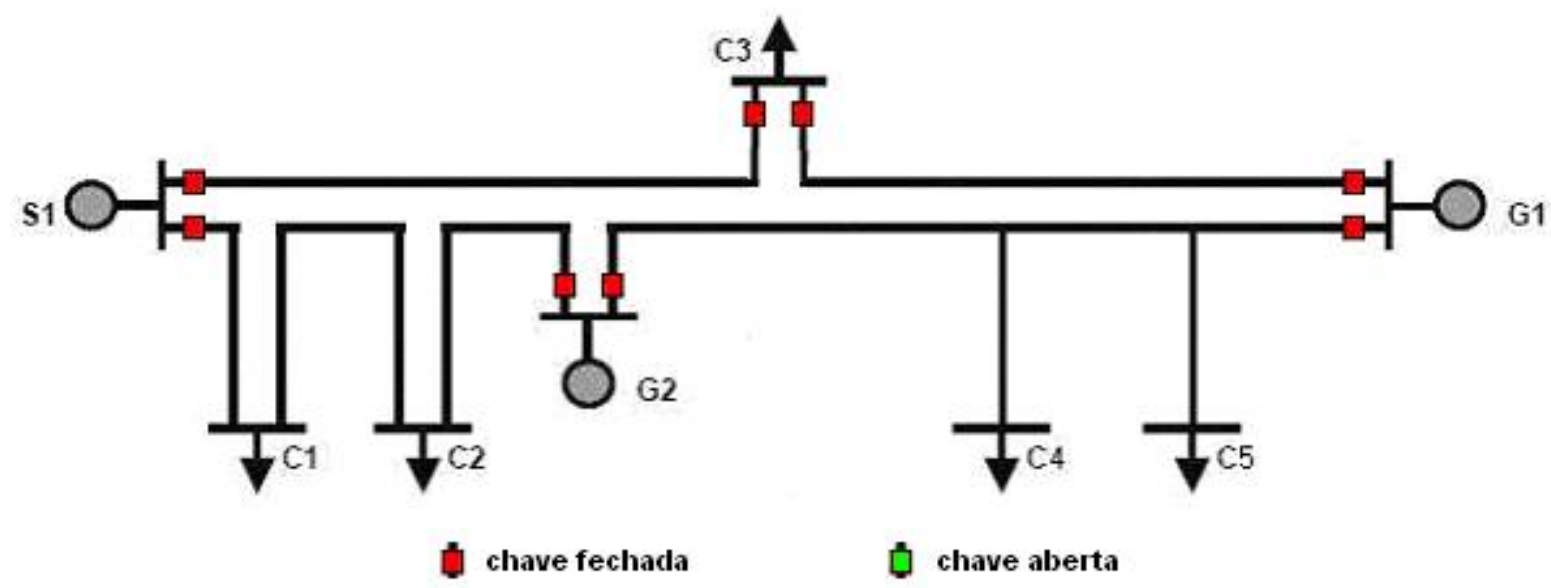

Figura 3.2 - Exemplo de um sistema elétrico de subtransmissão, com três pontos de fronteira com a Rede Básica, cinco subestações com carga e quatro circuitos

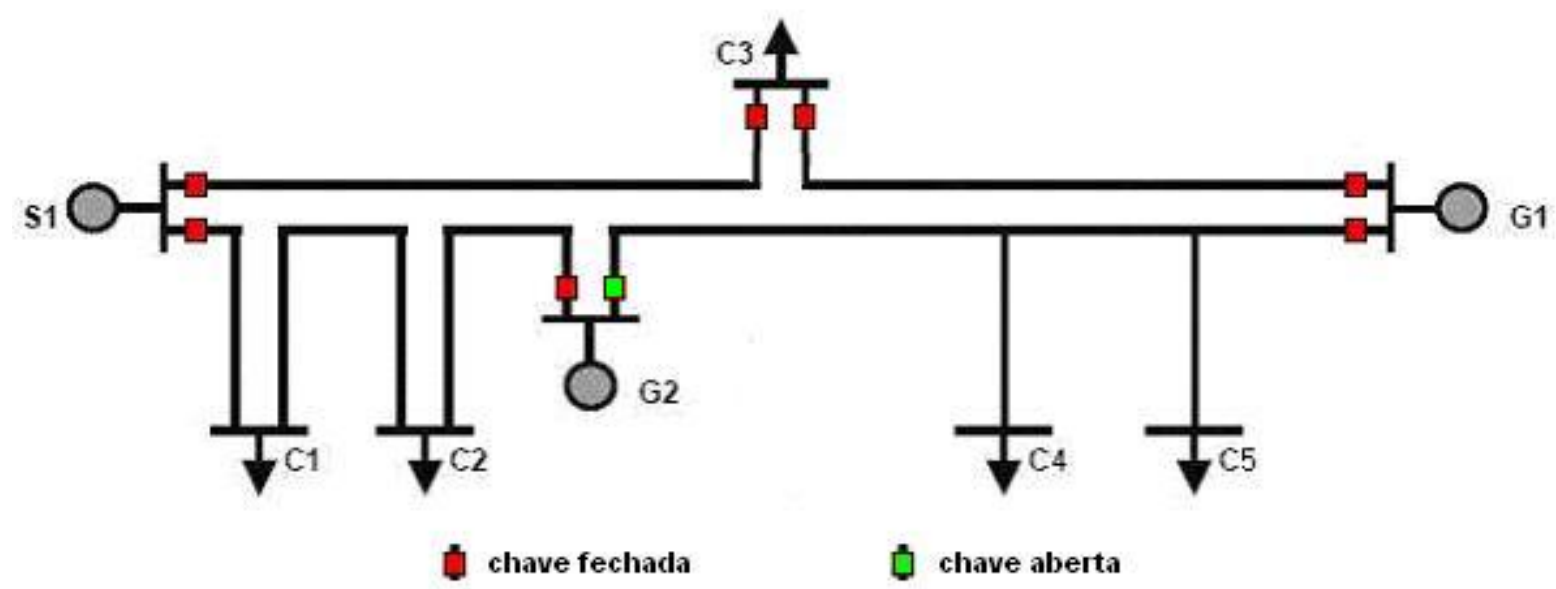

Figura 3.3 - Alternativa de atendimento às subestações $C_{4}$ e $C_{5}$ no sistema ilustrado pela Figura 3.2

Uma representação que permite simplificar a análise surge com a definição de blocos de cargas, subconjuntos de elementos de rede conectados entre duas ou mais chaves (disjuntores ou outros dispositivos de proteção e seccionamento) ou entre uma chave e um final de linha [10]. Esta representação, normalmente utilizada para sistemas de distribuição primária (média tensão), será utilizada para os sistemas elétricos de subtransmissão. 
A Figura 3.4 ilustra como a representação do sistema exemplificado na Figura 3.3 pode ser simplificada, quando considerados seus blocos de carga.

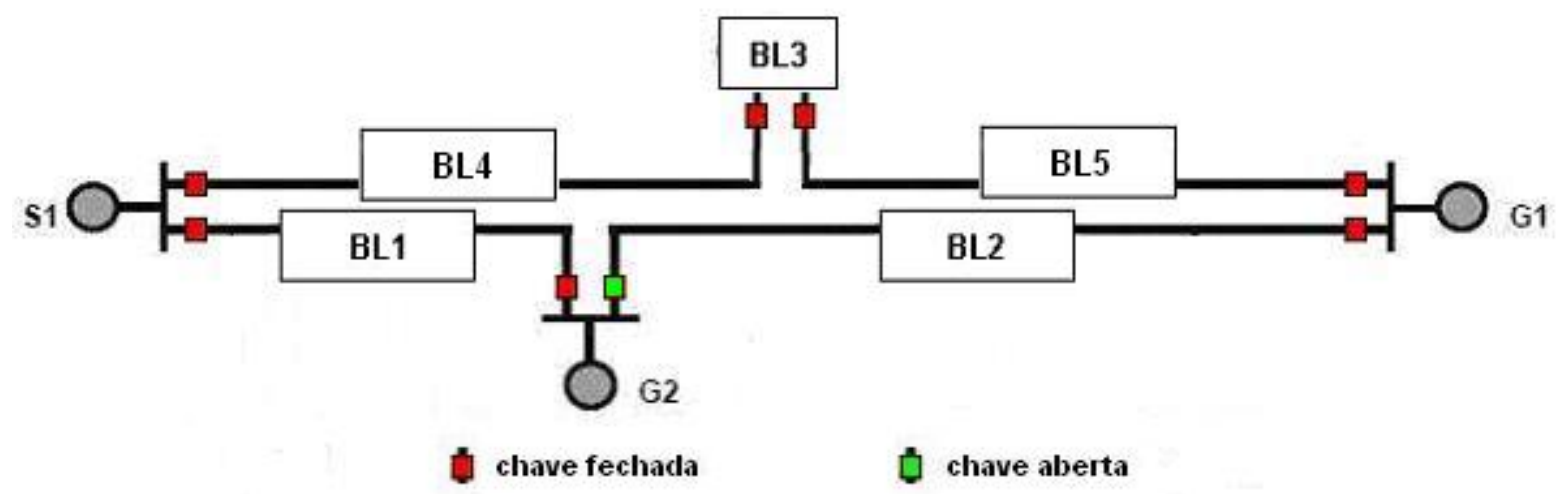

Figura 3.4 - Representação do sistema elétrico de subtransmissão ilustrado na Figura 3.3 através do conceito de blocos de carga

A modelagem proposta para as redes de subtransmissão admite trechos da rede tanto radial quanto em malha, desde que esta seja conexa, ou seja, com blocos de carga não desenergizados. Assim, considera-se a configuração dentro de um bloco de carga inalterada ao longo do estudo, o que permite simplificar a análise da rede sem prejuízo do resultado final.

A partir dos exemplos ilustrados pelas Figuras 3.2, 3.3 e 3.4, pode-se notar que, em redes de subtransmissão, não existe limitação para o número de chaves aberta ou fechada. Basta apenas que todos os blocos de carga sejam plenamente atendidos e que a rede opere dentro das restrições de tensão e carregamento estabelecidos. Desta forma, diferentemente dos sistemas de distribuição primária, em sistemas elétricos de subtransmissão não se limita as soluções de operação do sistema pela sua radialidade, mesmo porque muitas vezes, do ponto de vista operacional, as melhores configurações para o sistema costumam ser com trechos conectados em malha. 
O estudo de configurações de redes é um problema de natureza combinatória. Variáveis associadas com o estado de cada elemento de seccionamento do sistema podem, por exemplo, ser descritos assumindo valores 0 ou 1 , conforme estejam aberto ou fechado, respectivamente. Para um número $n$ de chaves, têm-se $2^{n}$ possíveis estados para o sistema, o que naturalmente exige o uso de técnicas de pesquisa de soluções refinadas, pelo grande número de chaves normalmente encontradas em sistemas elétricos de subtransmissão e por razões de compatibilidade dos tempos de processamento.

Métodos exaustivos de pesquisa de soluções, onde todos os estados das chaves são avaliados, costumam conduzir a tempos de processamentos incompatíveis com as aplicações em planejamento operacional. A técnica de AG tem se mostrado bastante eficiente na busca deste tipo de solução de problemas de otimização com variáveis discretas, neste caso, os dispositivos de seccionamento da rede.

Para a resolução do problema de otimização de fluxo de potência ativa em sistemas de subtransmissão de energia elétrica pode-se empregar diferentes métodos de otimização. Entretanto, este trabalho não pretende explorar as formas de aplicação dos diferentes métodos de otimização existentes ao problema enunciado, mas demonstrar os resultados que podem ser obtidos a partir da aplicação de uma das técnicas da CE.

\subsection{Aplicação de um Algoritmo Genético ao Problema}

Os Algoritmos Genéticos [14], [15], representam uma classe de algoritmos de otimização com mecanismo de pesquisa probabilístico de soluções, baseado no processo de evolução biológico, combinando aspectos da mecânica da genética e da seleção natural de indivíduos. 
Os AG são um algoritmo de busca e otimização baseados na analogia com os processos de seleção natural e genética evolucionária [16]. Eles empregam uma estratégia de busca paralela e estruturada, mas aleatória, que é voltada em direção ao reforço da busca de pontos de "alta aptidão", ou seja, pontos no qual a função a ser minimizada (ou maximizada) tem valores relativamente baixos (ou altos). Apesar de aleatórios, os AG promovem buscas direcionadas, pois exploram informações históricas para encontrar novos pontos de busca onde são esperados melhores desempenhos. Isto é feito através de processos iterativos, onde cada iteração é chamada de geração. Durante cada iteração, os princípios de seleção, reprodução e mutação são aplicados a uma população de candidatos que pode variar, dependendo da complexidade do problema e dos recursos computacionais disponíveis. Através da seleção, determinam-se quais indivíduos conseguirão reproduzir-se, gerando um número determinado de descendentes para a próxima geração, com uma probabilidade determinada pelo seu índice de aptidão. Em outras palavras, os indivíduos com maior adaptação relativa têm maiores chances de se reproduzir.

A essência do método consiste em manter uma população de indivíduos (cromossomos), os quais representam possíveis soluções para um problema específico. A melhor solução é atingida através de um processo de seleção, competitivo, envolvendo cruzamentos e mutações. O que torna um AG atrativo é sua habilidade para acumular informações sobre um espaço de busca inicial desconhecido e explorar este conhecimento para levá-lo a buscas subseqüentes em subespaços úteis. Desde a formulação inicial de Holland [14], em 1975, os AG vêm sendo empregados para solucionar problemas complexos, cujas propriedades das funções objetivo não são boas, tal como continuidade e diferenciabilidade.

Em um AG, os cromossomos são representados por códigos, compondo um alfabeto ou string, geralmente formada por dígitos binários (0 e 1). A codificação binária tem dominado a pesquisa em AG, pois é de fácil implementação e apresenta resultados promissores. 
Entretanto, é possível encontrar outros alfabetos, como os de ponto flutuante (codificação real).

Assim, conforme será detalhado adiante, soluções de um problema de otimização são representadas através de strings, seqüências de comprimento finito escritas sobre um alfabeto conhecido. Através de procedimentos aleatórios de recombinação de strings e seleção dos melhores, o AG pode ser capaz de obter soluções otimizadas. Assim, apesar de envolver procedimentos aleatórios, o AG se distancia dos métodos de pesquisa puramente aleatórios.

Inicialmente serão vistas algumas noções de AG. Apresentam-se as características principais dos AG, analisando o algoritmo canônico, ou básico, e seus operadores genéticos.

Conforme ressaltado por Goldberg [16], os AG são métodos numéricos de otimização que, para maior robustez, se diferenciam das outras técnicas em quatro aspectos fundamentais:

1. Os AG não trabalham com os parâmetros originais do problema, mas com uma codificação destes em seqüências de comprimento conhecido e fixo, empregando alfabeto binário. Estas representações para soluções do problema original são também chamadas strings ou indivíduos. A Figura 3.5 ilustra uma string qualquer, a estrutura básica de informações do AG.

\begin{tabular}{|c|c|c|c|c|c|c|c|}
\hline 1 & 0 & 1 & 1 & 0 & 0 & 0 & 1 \\
\hline$b_{7}$ & $b_{6}$ & $b_{5}$ & $b_{4}$ & $b_{3}$ & $b_{2}$ & $b_{1}$ & $b_{0}$ \\
\hline
\end{tabular}

Figura 3.5 - Representação de uma string do AG

2. Como em todos os outros métodos evolucionários, os AG buscam soluções otimizadas a partir de um conjunto de soluções, não a partir de uma solução única [17]. 
3. O AG canônico emprega uma função de avaliação para as diferentes soluções pesquisadas.

4. Os AG utilizam regras probabilísticas na pesquisa de novas soluções e não determinísticas.

O problema abordado neste trabalho emprega sempre strings codificadas no alfabeto binário $\{0,1\}$ do AG canônico. De maneira geral, um indivíduo qualquer $a_{i} \in B^{l}$ onde $B=\{0,1\}$ e "l" denota o comprimento da string. No exemplo ilustrado pela Figura 3.5, $l=8$.

A representação de soluções para um determinado problema por strings é, de certa forma, semelhante à maneira como os cromossomos organizam os genes e suas informações. Conforme ilustrado na Figura 3.5, cada posição $b_{i}$ da string corresponde a um bit, ou os genes do indivíduo $a_{i}$, e cada valor representado, aos alelos.

Conforme exposto por Goldberg [16], existem inúmeras maneiras de codificação do problema, ou de mapear soluções do problema original em strings de comprimento fixo. Entretanto, as particularidades de cada problema devem ser consideradas na codificação, evitando que os procedimentos aleatórios do algoritmo acabem gerando muitas soluções inviáveis, o que pode tornar a convergência difícil, senão impossível.

Conforme será descrito com maior detalhe, o funcionamento do AG é simples e, de certa forma, se resume a procedimentos aleatórios de seleção e recombinação de strings, direcionados pelos operadores genéticos: seleção, cruzamento (ou crossover) e mutação.

O diagrama de blocos da Figura 3.6 ilustra os procedimentos de uma execução completa de um AG, desde o início à obtenção de uma solução para um problema proposto. 


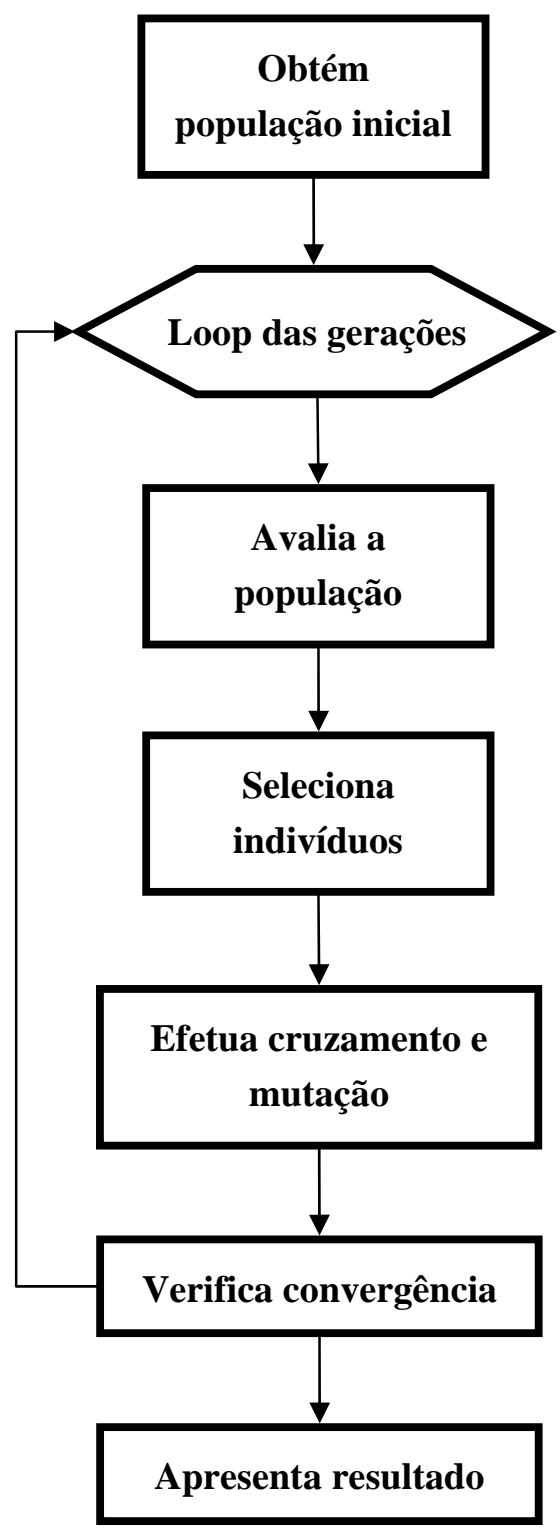

Figura 3.6 - Diagrama de blocos de um Algoritmo Genético canônico

Um AG é projetado, na sua configuração canônica, conforme as seguintes etapas:

1. Criar a população inicial de parâmetros compreendendo um número $n_{\text {ind }}$ de indivíduos que representam as soluções para o problema. Cada uma das soluções consiste de vetores $x_{i} \in\{0,1\}$. Estes parâmetros são inicializados aleatoriamente, de acordo com uma distribuição uniforme; 
2. Classificar cada solução $x_{i}, i=1, \ldots, n_{\text {ind }}$ com relação ao cálculo da função de avaliação, ou seja, avalia-se o grau de adaptação de cada indivíduo da população em relação ao problema;

3. Selecionar os indivíduos mais aptos de acordo com uma estratégia de seleção;

4. Aplicar o operador genético de cruzamento;

5. Aplicar o operador genético de mutação;

6. Gerar uma nova população;

7. Repetir as etapas 2 a 6 até que um critério de convergência seja satisfeito.

O princípio básico do funcionamento dos AG é que um critério de seleção faz com que, depois de muitas gerações, o conjunto inicial de indivíduos gere indivíduos mais aptos. O operador de seleção emprega o princípio de sobrevivência dos indivíduos mais aptos, através de uma metáfora aos procedimentos de reprodução assexuada e seleção natural, de acordo com o grau de adaptação do indivíduo ao ambiente. O objetivo básico do operador de seleção é enfatizar as melhores soluções que constituem uma população. O operador não cria nenhuma nova solução. Este operador seleciona as soluções relativamente aptas de uma população e remove as soluções remanescentes.

O operador de seleção é uma combinação de dois conceitos diferentes: reprodução e seleção. As múltiplas cópias de uma solução (indivíduo) são alocadas em uma população pela remoção de algumas soluções inferiores. Entretanto, alguns estudos de AG utilizam ambos conceitos de reprodução e seleção, simultaneamente, em um operador, e outros os utilizam separadamente [18].

A verificação se uma solução é apta (ou não) em uma população é baseada no valor da função de avaliação da referida solução. Para que uma solução tenha maior avaliação deve ter uma alta probabilidade de seleção. Contudo, os operadores de seleção diferem na maneira que as 
cópias são designadas para serem as melhores soluções. Os operadores de seleção mais utilizados são os métodos de seleção proporcional (roleta ou ranking), de seleção elitista com truncamento e de seleção por torneio.

Um conjunto de operações é necessário para que, dada uma população, se consiga gerar populações sucessivas que (espera-se) melhorem sua aptidão com o tempo. Estes operadores são o cruzamento ou crossover e a mutação. Eles são utilizados para assegurar que a nova geração seja totalmente nova, mas possua, de alguma forma, características de seus pais, ou seja, a população se diversifica e mantém características de adaptação adquiridas pelas gerações anteriores.

O operador genético de cruzamento ou crossover é responsável pela troca de material genético entre os indivíduos, com maior probabilidade de reproduzirem os indivíduos mais aptos ao ambiente. O cruzamento é o responsável pelo intercâmbio de material genético proveniente dos cromossomos geradores. Usando o cruzamento, as chances das características ideais se perpetuarem durante o processamento aumentam devido aos pais com graus de adaptações maiores se reproduzirem com maior freqüência.

Já o operador de mutação modifica o valor dos genes do indivíduo e visa restaurar o material genético perdido ou não explorado em uma população. As mutações provêem certa variação e ocasionalmente introduzem alterações benéficas aos cromossomos. Este operador, quando projetado de forma apropriada, pode prevenir a convergência prematura do AG para soluções sub-ótimas e manter a diversidade da população.

Para a verificação da convergência do processo, o final da execução do algoritmo deve atender um critério de parada. Comumente limita-se o número de gerações ou ainda estabelece-se um número de gerações limite para cancelar a execução caso não se obtenha um indivíduo com avaliação superior. 
É importante também, analisar de que maneira alguns parâmetros influem no comportamento dos AG, para que se possa estabelecê-los conforme as necessidades do problema e dos recursos disponíveis. A definição dos parâmetros intrínsecos aos AG - parâmetros de controle dos AG - geralmente são determinados heuristicamente, tais como: tamanho da população, tamanho da estrutura dos cromossomos, probabilidade ou taxa de cruzamento, probabilidade ou taxa de mutação, intervalo de geração e tipos dos operadores genéticos a serem adotados.

O tamanho da população afeta o desempenho global e a eficiência dos AG. Com uma população pequena o desempenho pode cair, pois deste modo a população fornece uma pequena cobertura do espaço de busca do problema. Uma grande população geralmente fornece uma cobertura representativa do domínio do problema, além de prevenir convergências prematuras para soluções locais ao invés de globais. No entanto, para se trabalhar com grandes populações, são necessários maiores recursos computacionais, ou que o algoritmo trabalhe por um período de tempo muito maior.

Quanto maior for esta taxa de cruzamento, mais rapidamente novas estruturas serão introduzidas na população. Mas se esta for muito alta, estruturas com boas aptidões poderão ser retiradas mais rapidamente, a maior parte da população será substituída e pode ocorrer perda de estruturas de alta aptidão. Com um valor baixo, o algoritmo pode tornar-se muito lento.

Uma baixa taxa de mutação previne que uma dada posição fique estagnada em um valor, além de possibilitar que se chegue a qualquer ponto do espaço de busca. Com uma taxa muito alta a busca se torna essencialmente aleatória.

O intervalo de geração controla a porcentagem da população que será substituída durante a próxima geração. Com um valor alto, a maior parte da população será substituída, mas com valores muito altos pode ocorrer perda de estruturas de alta aptidão. Com um valor baixo, o algoritmo pode tornar-se muito lento. 
Não é o objetivo enfocar os AG e seus operadores, mas verificar sua aplicabilidade como técnica de otimização dos objetivos do planejamento operacional de sistemas de subtransmissão de energia elétrica. O leitor interessado poderá encontrar maiores detalhes nas bibliografias presentes no final do trabalho.

Inseridos no contexto mais abrangente da CE, os trabalhos [19], [20], [21] e [22], destacam o uso do AG em problemas relacionados com Sistemas Elétricos de Potência, tais como o planejamento de redes em múltiplos estágios, reconfiguração de redes, operação de sistemas hídricos, despacho de usinas, despacho de reativos, fluxo de potência, diagnóstico de falhas e outros problemas, trazendo grande conjunto de referências, que permitem aprofundar o estudo dos AG aplicados aos mais diferentes tipos de problemas, relacionados à energia elétrica. A seguir, descreve-se como o AG pode ser aplicado à otimização do fluxo de potência ativa em sistemas de subtransmissão quanto à configuração da rede para atendimento a de um determinado objetivo de um sistema qualquer.

Devido ao uso de alfabeto binário para representação dos alelos, o AG canônico manipula diretamente apenas os problemas pseudobooleanos ${ }^{1}$, na forma $f: B^{l} \rightarrow R$, onde a função objetivo $f$ equivale à própria função de avaliação [17]. Por isso, para emprego do AG em problemas de otimização com restrições, como o de otimização do fluxo de potência ativa em redes de subtransmissão de energia elétrica, deve-se inicialmente definir uma codificação para as strings, que será mantida fixa ao longo do estudo, e um procedimento de decodificação da mesma em uma rede válida, evitando assim que o algoritmo trabalhe com um número elevado de indivíduos inviáveis.

Kagan [10] utiliza o AG canônico no problema de otimização e configuração de redes de distribuição de energia elétrica, com tomada de decisão modelada com números fuzzy. Algumas restrições topológicas e específicas das redes de distribuição, como conectividades

\footnotetext{
${ }^{1}$ Problemas pseudobooleanos são aqueles onde as variáveis são associadas diretamente com uma posição no string e o valor da função objetivo é obtido sem uso de função de decodificação. Por exemplo, um exercício numérico de maximizar a contagem de ' 1 ' em um string.
} 
de barras do sistema, são consideradas na codificação das strings que representam os indivíduos do AG, tornando o modelo extremamente eficiente.

A modelagem proposta a seguir, para a configuração de redes, apresenta aspectos semelhantes ao trabalho de Kagan, porém aplicados para as redes de subtransmissão de energia elétrica.

\subsubsection{Codificação dos Indivíduos}

Conforme exposto, existem inúmeras maneiras de codificação do problema, ou de mapear soluções do problema original em strings de comprimento fixo. Entretanto, as particularidades de cada problema devem ser consideradas na codificação, evitando que os procedimentos aleatórios do algoritmo acabem gerando muitas soluções inviáveis, o que pode tornar a convergência difícil, senão impossível.

Das diversas possibilidades para a codificação dos indivíduos, uma alternativa imediata é definir seu tamanho como equivalente à quantidade de chaves e demais elementos de seccionamento da rede e associar um lócus para cada componente, dado que neste estudo estas serão as únicas variáveis consideradas e que irão claramente assumir valores 'fechada' ou 'aberta', facilmente associados aos valores ' 1 ' e '0', respectivamente. A vantagem de se utilizar o conceito de blocos de carga é que ele limita o número de chaves a serem manobradas, já que os blocos de carga permanecem com suas configurações inalteradas, permitindo que o AG possa encontrar a solução desejada com mais rapidez.

Dado que as strings empregadas pelo AG são escritos com emprego do alfabeto binário $\{0,1\}$, um número $n$ de bits permitirá a representação de até $2^{n}$ estados de chaves. 
Considerando esta codificação, a partir da rede ilustrada na Figura 3.7, a sua correspondente string seria codificada de acordo com o ilustrado na Figura 3.8.

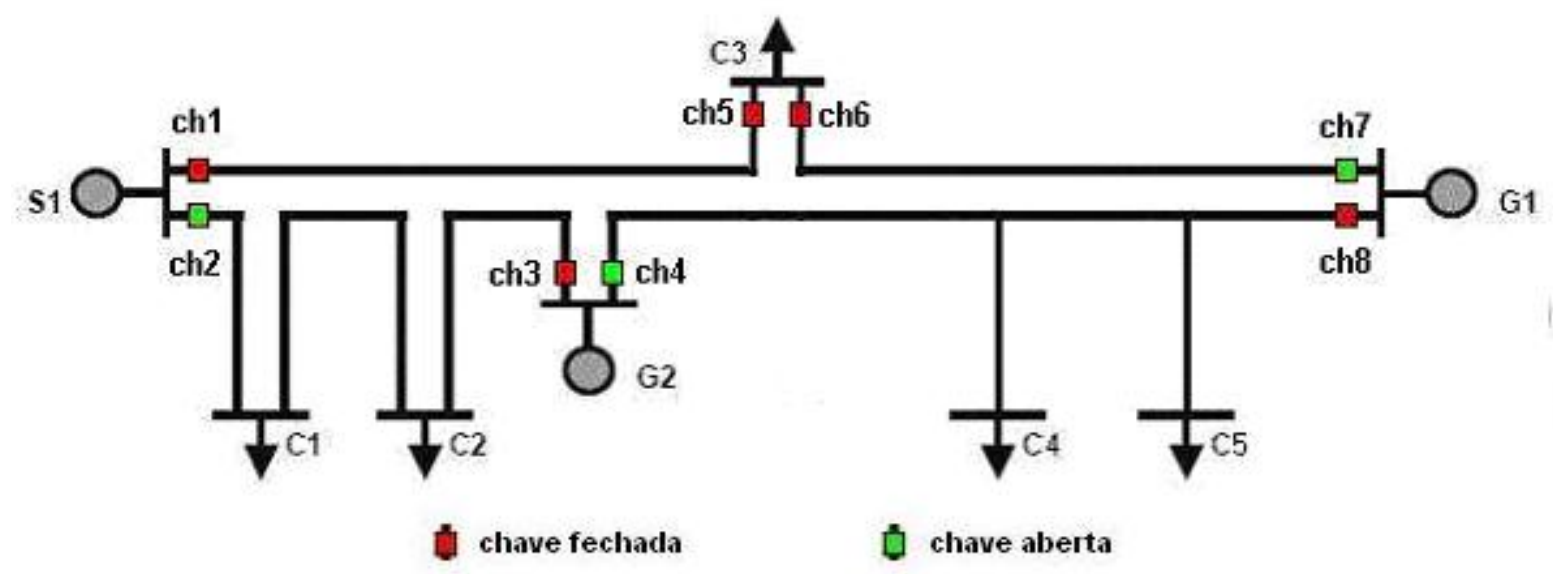

Figura 3.7 - Exemplo de configuração de um sistema elétrico de subtransmissão

\begin{tabular}{|c|c|c|c|c|c|c|c|}
\hline 1 & 0 & 1 & 0 & 1 & 1 & 0 & 1 \\
\hline$b_{7}$ & $b_{6}$ & $b_{5}$ & $b_{4}$ & $b_{3}$ & $b_{2}$ & $b_{1}$ & $b_{0}$ \\
\hline$c h_{1}$ & $c h_{2}$ & $c h_{3}$ & $c h_{4}$ & $c h_{5}$ & $c h_{6}$ & $c h_{7}$ & $c h_{8}$ \\
\hline
\end{tabular}

Figura 3.8 - Representação para a rede da Figura 3.7, seguindo a codificação utilizada

Nota-se que, da forma como está sendo definida a codificação dos indivíduos, onde cada chave é codificada em uma posição da string, haverá grande possibilidade de muitos indivíduos corresponderem a soluções inviáveis, por exemplo, contendo blocos de carga desconexos. Isto ocorre principalmente em redes maiores, onde se espera um número elevado de chaves.

Sob tais condições, o funcionamento do AG torna-se não tão eficiente, pois se assemelha a uma busca aleatória sem direção definida, em um vasto espaço de possibilidades e repleto de indivíduos com avaliação igual a zero, o que certamente não traz resultado algum, mesmo considerando populações maiores ou muitas gerações. 
Assim, surge a necessidade do AG possuir um processo de decodificação dos indivíduos. A decodificação dos indivíduos é de grande importância para o bom funcionamento deste AG, pois trata do problema ao transformar todos os indivíduos gerados que representam configurações de rede inviáveis em redes viáveis.

\subsubsection{Decodificação dos Indivíduos}

Utilizando-se a codificação proposta no item anterior existe uma tendência à formação de indivíduos que correspondam às soluções inviáveis do problema, sob o aspecto topológico. As strings são geradas aleatoriamente e a escolha das chaves a serem fechadas é determinada diretamente pelos bits de cada string. Para este tipo de codificação, não se garante que determinados indivíduos gerados no AG correspondam a configurações de rede que, por exemplo, não apresentem regiões desconectadas no sistema.

Para evitar o surgimento de indivíduos que correspondam a configurações de rede inviáveis, é necessário o desenvolvimento de um procedimento de decodificação dos indivíduos gerados pelo AG.

Primeiramente, a decodificação serve para tornar os indivíduos que representam redes contendo blocos de carga desconexos do sistema em redes onde todos os blocos são atendidos por pelo menos um ponto de suprimento, isto é, um ponto de fronteira com a Rede Básica. Assim, o processo de decodificação percorre seqüencialmente a representação de cada string, analisando o estado operativo resultante do sistema e a cada configuração parcial de rede encontrada efetua, se necessário, o fechamento de determinadas chaves do sistema mediante determinadas regras. Como conseqüência, haverá situações onde strings distintas 
corresponderão a configurações de rede idênticas. Isto não traz inconvenientes à convergência do AG, pois não se inibe o surgimento de qualquer configuração e, desta forma, qualquer solução viável poderá ser gerada ao longo da execução.

A decodificação dos indivíduos emprega, juntamente com o conceito de blocos de carga, o conceito de famílias de blocos [8] [10]. Este último é muito importante, pois permite analisar se os blocos de carga estão ou não isolados do sistema.

A cada família de blocos é associada uma variável de estado. Esta grandeza é acumulada durante o processo de decodificação das strings e permite alguns diagnósticos do sistema, antes mesmo da execução do fluxo de potência correspondente. Entretanto, deve-se ressaltar que não é conveniente inibir, a priori, o surgimento de famílias que violem quaisquer restrições da rede, para que não se perca, por conseqüência, eventuais boas características presentes nesses indivíduos [10]. Conforme dito anteriormente, esta variedade nas informações trazidas pelos indivíduos é essencial ao bom desempenho do AG. Eliminar estes indivíduos arbitrariamente pode prejudicar o resultado final indicado pelo AG.

A variável de estado de cada família tem por finalidade informar se esta já está conectada ou não a um ou mais pontos de suprimentos, através de uma ou mais chaves. Este parâmetro corresponde a um número inteiro positivo, quando não houver conexão com nenhum ponto de suprimento ou negativo, caso contrário. Sempre que uma família $f_{i}$ é criada, quando não estiver conectada a um ponto de suprimento, será atribuído ao seu estado um valor seqüencial, i, positivo. Se no momento de sua criação houver uma conexão com um ou mais pontos de suprimentos, seu estado passará a um valor correspondente ao negativo da numeração de uma das chaves conectadas à família.

Importante destacar que os pontos de suprimento não pertencem às famílias, embora possam ser conectadas a elas via chaves normalmente fechadas (NF). Assim, para a representação 
desses pontos, considera-se um "bloco fonte", $B L_{0}$, constituído por todos os pontos de suprimentos do sistema.

Inicialmente, assume-se que todos os blocos estão isolados e não pertencem a qualquer família.

O processo de decodificação executa uma leitura da string do indivíduo bit a bit e a cada passo analisa a situação dos blocos $B L_{i}$ e $B L_{v i z, i}$ conectados aos terminais da respectiva chave $c h_{j}$ indicada. À medida que o processo percorre a string do indivíduo, famílias de blocos vão sendo criadas e a elas atribuem-se estados positivos ou negativos. As seguintes possibilidades poderão ocorrer com o fechamento da chave $c h_{j}$ :

Condição "A": Tanto o bloco $B L_{i}$ quanto $B L_{v i z, i}$ estão isolados, isto é, ainda não foram atribuídos a nenhuma família. Neste caso, duas situações, A1 e A2, podem ocorrer:

Situação A1: $\quad$ O bloco $B L_{v i z, i}$ não é um ponto de suprimento. Neste caso, uma nova família $f_{i}$ é criada, atribuindo-se ao seu estado est $f$ o valor $i$, positivo.

Situação A2: O bloco $B L_{v i z, i}$ representa uma ponto de suprimento. Nesta situação, uma nova família é criada com estado $e s t_{f i}=-j$, referente à chave $c h_{j}$ fechada.

Condição " $B$ ”: $O$ bloco $B L_{i}$ ainda não foi atribuído a uma família mas $B L_{v i z, i}$ já pertence à família $f_{v i z, i}$, de estado est $f_{v i z, i}$ qualquer. Nestas condições, o bloco $B L_{i}$ passa a pertencer à $f_{v i z, i}$.

Condição “C”: O bloco $B L_{i}$ já foi atribuído à família $f_{i}$, de estado $e s t_{f i}$ qualquer, mas o bloco vizinho $B L_{v i z, i}$ está isolado do sistema. Nesta condição, duas possibilidades, C1 e C2 podem ocorrer: 
Situação C1: $\quad$ O bloco $B L_{v i z, i}$ não é um ponto de suprimento. Neste caso, o bloco $B L_{v i z, i}$ passa a pertencer a família $f_{i}$, do bloco $B L_{i}$.

Situação C2: O bloco $B L_{v i z, i}$ é um ponto de suprimento. Nesta condição, se o estado da família $f_{i}$ for positivo, este será alterado para $e s t_{f i}=-j$, referente à chave $c h_{j}$ fechada, indicando que esta agora está conectada a um ponto de suprimento através de $B L_{v i z, i}$. Outras famílias que estejam conectadas a $f_{i}$ devem também ter seus estados alterados para $e s t_{f i}$ Caso contrário, se o estado da família $f_{i}$ for negativo, este será alterado para $e s t_{f i}=e s t_{f i}-j$, referente à chave $c h_{j}$ fechada, indicando que esta agora está conectada a mais um ponto de suprimento através de $B L_{v i z, i \cdot}$ Também nesse caso, outras famílias que estejam conectadas a $f_{i}$ devem também ter seus estados alterados para $e t_{f i}$.

Condição " $D$ ”: Ambos blocos $B L_{i}$ e $B L_{v i z, i}$ pertencem às famílias $f_{i}$ e $f_{v i z, i}$, respectivamente, cujos estados est $t_{i}$ e est fviz,i podem ou não ser distintos. Desta condição decorrem quatro situações possíveis, D1, D2, D3 e D4, a saber:

Situação D1: Os estados de $f_{i}$ e $f_{v i z, i}$ são positivos, isto é, tanto o bloco $B L_{i}$ como $B L_{v i z, i}$ ainda não estão conectados a um ponto de suprimento. Neste caso, o estado de $f_{v i z, i}$ é feito igual ao estado de $f_{i}$, bem como o estado de outras famílias que estejam conectadas a $f_{v i z, i}$. 
Situação D2: $\mathrm{O}$ estado de $f_{i}$ é negativo e o de $f_{v i z, i}$, positivo, isto é, $f_{i}$ encontra-se conectada a pelo menos um ponto de suprimento, mas não $f_{v i z, i}$. Neste caso, é alterado o estado de $f_{v i z, i}$ e quaisquer outras famílias conectadas a $f_{v i z, i}$, para o estado de $f_{i}$.

Situação D3: $\mathrm{O}$ estado de $f_{i}$ é positivo e o de $f_{\text {viz,i }}$ é negativo, representando que $f_{i}$ não se encontra conectada a um ponto de suprimento, diferentemente de $f_{v i z, i}$. Neste caso, ocorre o inverso da situação D2, o estado de $f_{i}$ e quaisquer outras famílias conectadas a $f_{i}$ é alterado para o estado de $f_{v i z, i}$.

Situação D4: Os estados de $f_{i}$ e $f_{v i z, i}$ são negativos, isto é, tanto o bloco $B L_{i}$ como $B L_{v i z, i}$ já estão conectados a pelo menos um ponto de suprimento. Neste caso, o estado de $f_{v i z, i}$ é feito igual ao estado de $f_{i}$, bem como o estado de outras famílias que estejam conectadas a $f_{\text {viz, } i \text {. }}$

Entretanto, após a decodificação da string, podem ainda existir famílias com estado positivo, representando blocos de carga não atendidos. Se após o processo de decodificação ainda houver famílias com estado positivo, em decorrência do não atendimento das condições de fechamento de chave em uma determinada situação, procura-se na lista de chaves ainda abertas, aquelas que tenham um de seus terminais conectados em famílias de estado positivo e, quando isto ocorre, uma das chaves é fechada. Isto é feito até que todas as famílias tenham seus estados negativos, finalizando o processo. Da mesma forma, poderá haver ainda blocos de carga isolados do sistema e, então, procede-se com o fechamento de uma das chaves conectadas a esses blocos. Apesar desses procedimentos provocarem alterações nos estados operativos de algumas chaves, eles não agem diretamente na string (genótipo do indivíduo), limitando-se a alterar apenas a configuração operativa do sistema (fenótipo do indivíduo). 
O processo de decodificação descrito funciona como uma pré-seleção topológica, podendo gerar configurações de rede tanto radiais quanto em malha, mas que sejam isentas de cargas não atendidas. Este aspecto contribui para tornar o algoritmo mais eficiente, pois se limita o número de configurações de rede possíveis de serem geradas, reduzindo assim os cálculos de fluxo de potência sobre o sistema.

É interessante notar que diversas regras podem ser aplicadas ao processo de decodificação de forma a impor outros modos de operação do sistema. Por exemplo, poderia criar-se uma regra que evitasse a abertura de duas linhas de subtransmissão em paralelo devido a restrições de proteção, ou outra que favorecesse o fechamento do sistema em anel, visando uma maior confiabilidade do sistema. Quanto maior o número de regras consideradas, menor o número de configurações de rede operativamente viáveis.

\subsubsection{Função de Avaliação dos Indivíduos}

O próximo passo depois de definida a maneira de codificar e decodificar as strings é compor uma função de avaliação dos indivíduos a partir dos objetivos e das restrições do problema estudado.

Um dos objetivos do planejamento operacional de sistemas elétricos de subtransmissão é a minimização do custo dos encargos de uso dos sistemas de transmissão.

Os encargos de uso dos sistemas de transmissão estão definidos na Resolução Normativa $n^{\circ}$ 281, de $1^{\circ}$ de Outubro de 1999, da ANEEL [23], a qual estabelece as condições gerais de contratação do acesso, compreendendo o uso e a conexão, aos sistemas de transmissão e distribuição de energia elétrica. Eles são uma condição comercial estabelecida pelo Contrato 
de Uso dos Sistemas de Transmissão (CUST) firmado com o ONS e celebrado entre as empresas concessionárias do serviço de transmissão e de distribuição de energia elétrica. O CUST é o documento no qual estabelece as condições técnicas e obrigações relativas ao acesso e uso das instalações de transmissão componentes da Rede Básica pelos usuários dos sistemas de transmissão.

Os encargos de uso dos sistemas de transmissão são custos devidos por todos os usuários das instalações de transmissão componentes da Rede Básica, calculados com base nos maiores valores dos montantes de uso contratados ou verificados, por ponto de conexão, de conformidade com a seguinte fórmula:

$$
E_{C}=T_{P} \cdot U_{P}+T_{F P} \cdot U_{F P}
$$

Onde,

$E_{C}=$ encargo pelo uso dos sistemas de transmissão do ponto de conexão, em R\$.

$T_{P}=$ tarifa de uso dos sistemas de transmissão do ponto de conexão no horário de ponta, em $\mathrm{R} \$ / \mathrm{kW}$.

$U_{P}=$ montante do uso no horário de ponta, em kW.

$T_{F P}=$ tarifa de uso dos sistemas de transmissão do ponto de conexão fora do horário de ponta, em R\$/kW.

$U_{F P}=$ montante do uso fora do horário de ponta, em kW.

Os pontos de conexão a serem utilizados para a contratação dos montantes de uso de transmissão, pelas concessionárias de distribuição, são as fronteiras com a Rede Básica ou 
com as demais instalações de transmissão compartilhadas entre concessionárias de distribuição, a partir dos quais as mesmas demandem potência elétrica.

Para o correto funcionamento de alguns operadores genéticos do AG, é essencial que a função de avaliação sempre atribua valores não negativos aos indivíduos. Apesar deste aspecto não ser relevante para algumas variantes de operadores genéticos, esta particularidade será considerada para manter-se a mesma modelagem, independente dos operadores selecionados. Para compor a função de avaliação dos indivíduos, considera-se apenas uma das parcelas do encargo pelo uso dos sistemas de transmissão do ponto de conexão (parcela do horário de ponta ou do horário fora de ponta). De fato, o que se procura como solução do problema é uma única configuração otimizada da rede de subtransmissão capaz de atender ao objetivo de minimização do custo dos encargos de uso dos sistemas de transmissão nos dois períodos. O procedimento de otimização do fluxo de potência ativa leva em conta apenas um instante diário de carga do sistema. Assim, é possível realizar este procedimento para dois instantes correspondentes aos períodos de horário de ponta e de horário fora de ponta, respectivamente, e analisar os resultados em função das configurações de rede e dos valores de custo obtidos.

Uma possibilidade para definição da função de avaliação é empregar uma relação entre um valor de referência para o custo dos encargos pelo uso dos sistemas de transmissão e o valor do custo dos encargos pelo uso dos sistemas de transmissão da configuração representada pelo indivíduo sob avaliação, na forma:

$$
\begin{gathered}
f_{\text {aval }, i}=\frac{\text { custo }_{\text {ref }}}{\text { custo }_{i}} \\
\text { Custo }_{i}=\sum_{j=1}^{n_{\text {fromtera }}} T_{\text {fronteira }, j} \cdot U_{\text {fronteira }, j}
\end{gathered}
$$


Onde,

$f_{\text {aval }, i}=$ função de avaliação do indivíduo $i$.

custo $_{\text {ref }}=$ valor de referência para o custo dos encargos pelo uso dos sistemas de transmissão, em R\$.

custo $_{i}=$ custo dos encargos pelo uso dos sistemas de transmissão do indivíduo $i$, em R $\$$.

$T_{\text {fronteira }, j}=$ tarifa de uso dos sistemas de transmissão do ponto de fronteira $j$, em R $\$ / \mathrm{kW}$.

$U_{\text {fronteira, } j}=$ montante do uso do ponto de fronteira $j$, em $\mathrm{kW}$.

$n_{\text {fronteira }}=$ número de pontos de fronteira com a Rede Básica.

A cada indivíduo decodificado em uma rede válida e avaliado, será relacionado um valor de custo dos encargos pelo uso dos sistemas de transmissão, obtido através do respectivo cálculo do fluxo de potência na rede por ele representada.

A função de avaliação é sempre positiva e a alternativa ótima terá a função de avaliação tão mais próxima de 1 quanto mais próximo do ótimo for o valor de custo $_{\text {ref }}$. Nada impede, porém, que a função de avaliação apresente um valor maior que 1, o que representa um custo inferior à referência adotada. A Figura 3.9 ilustra essa opção, quando a função de avaliação correspondente é disposta graficamente em relação ao custo dos encargos pelo uso dos sistemas de transmissão. 


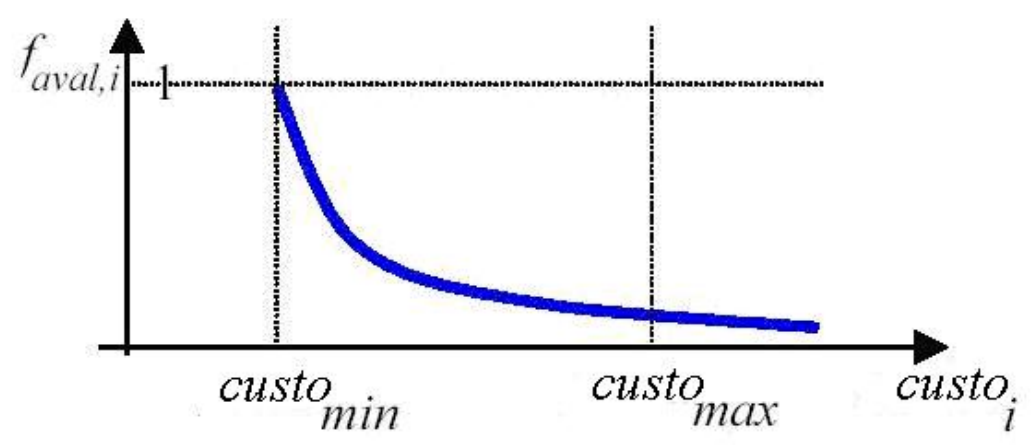

Figura 3.9 - Representação da função de avaliação proposta

A função de avaliação deve sempre procurar avaliar os indivíduos de maneira gradual, mesmo que ocorram violações das restrições, pois as informações trazidas por estes indivíduos devem ser consideradas, para que as possibilidades de evolução possam aumentar. Do contrário, a expectativa maior é que o AG acabe vagando entre inúmeros indivíduos de avaliação baixa, sem possibilidade de apresentar uma resposta satisfatória. A forma mais usual para atingir esse objetivo é degradando a função de avaliação à medida que as soluções encontradas transgridam mais as restrições originais do problema [4], [10].

Conforme visto, as restrições são incorporadas à função objetivo através de fatores de penalização [2], os quais representam as restrições originais do problema. Um número $n_{\text {restr }}$ de restrições poderia ser facilmente incorporado à equação (3.2), resultando numa expressão na forma:

$$
f_{\text {aval }, i}=\frac{\text { custo }_{\text {ref }}}{\text { custo }_{i}+\sum_{k=1}^{n_{\text {restr }}} r_{k} P_{i, k}}
$$

Onde cada fator de penalização, $P_{i, k}$, definidos conforme as restrições do problema, será aplicado ao indivíduo $i$, se houver transgressão daquela restrição. Cada fator de penalização será ponderado por um coeficiente, $r_{k}$, permitindo aplicação de diferentes graus de rigor com 
relação às transgressões. Conforme mencionado anteriormente, este aspecto auxilia o desempenho do AG de maneira geral.

Este trabalho considera as restrições de excesso de carregamento dos transformadores de fronteira, $P_{F R}$, a sobrecarga em trechos das linhas de subtransmissão, $P_{T R}$, e a violação do nível de tensão nos barramentos das subestações do sistema, $P_{V}$. Dado que o processo de decodificação apresentado no item anterior fornece apenas soluções viáveis sob o ponto de vista de topologia de rede, as funções de penalização representam tão somente possíveis violações nos critérios de carregamento e de tensão dos componentes da rede.

Uma proposição interessante para as funções de penalidade, descrita por Kagan [10], parte do conceito de notas (ou índices de mérito) associadas aos perfis de carregamento (de transformadores de fronteira e de trechos de rede) e ao perfil de tensão. Essa alternativa permite considerar uma análise destes perfis e, a partir destes, proceder a uma melhor penalização da função de avaliação.

Os coeficientes de penalização, $r_{F R}, r_{T R}$ e $r_{V}$, associados aos seus respectivos fatores de penalização, são instrumentos de ajuste da sensibilidade da função de avaliação do AG em relação a essas restrições do problema. Para realizar uma avaliação dos indivíduos onde todas as restrições possuam a mesma importância na busca da melhor solução para o problema, os coeficientes devem ser definidos com o mesmo valor, por exemplo, unitário. Para eliminar uma ou mais restrições da avaliação dos indivíduos, basta definir o valor zero para os coeficientes dos fatores de penalização desejados. Ou, caso deseje realizar uma avaliação dos indivíduos em que cada restrição possua diferentes graus de importância, aplica-se valores distintos a esses coeficientes. Desta forma, os coeficientes de penalização permitem obter resultados distintos para o mesmo problema, utilizando a mesma função de avaliação dos indivíduos. Deve-se ter cuidado, porém, ao se aplicar valores elevados a esses coeficientes, 
pois isso tende a tornar as restrições do problema mais importantes que o próprio objetivo a ser alcançado.

\subsubsection{Fator de penalização por transgressão de carregamento dos transformadores de}

\section{fronteira}

Através do cálculo de fluxo de potência do sistema elétrico de subtransmissão, são determinadas as correntes elétricas (ou as potências aparentes) em todas as ligações do sistema para a análise dos níveis de diagnóstico de carregamento dos componentes da rede. A classificação dos transformadores de fronteira ocorre de acordo com seu nível de carregamento em relação à sua corrente admissível, Inom (ou à sua potência admissível, Snom ), em três diagnósticos: bom, regular e ruim. A Tabela 3.1 ilustra como é feita a classificação dos transformadores de fronteira de um sistema após o cálculo de fluxo de potência, onde se assume o carregamento adequado de um transformador de fronteira como sendo inferior a 70\% da sua capacidade nominal. Este valor é um parâmetro que pode ser alterado.

\begin{tabular}{|c|c|}
\hline Carregamento $(I)$ em A & Diagnóstico \\
\hline $0,7 \cdot$ Inom $>I$ & BOM \\
\hline $0,7 \cdot$ Inom $\leq I<$ Inom & REGULAR \\
\hline$I \geq$ Inom & RUIM \\
\hline
\end{tabular}

Tabela 3.1 - Diagnóstico de carregamento de cada transformador de fronteira de um sistema elétrico de subtransmissão, sendo $I$ a corrente elétrica que percorre o transformador 
Definido o diagnóstico dos transformadores de fronteira do sistema elétrico de subtransmissão, a nota de carregamento dos transformadores de fronteira por indivíduo é dada pela equação:

$$
N_{F R}=\frac{10 \cdot N F_{B O M}+5 \cdot N F_{R E G U L A R}+0 \cdot N F_{R U I M}}{N F} \cdot f_{\text {penalização }}\left(N F_{R U I M}\right)
$$

Onde,

$N_{F R}=$ Nota de carregamento dos transformadores de fronteira do sistema.

$N F_{\text {вом }}=$ Número de transformadores de fronteira com diagnóstico bom.

$N F_{\text {REGULAR }}=$ Número de transformadores de fronteira com diagnóstico regular .

$N F_{\text {RUIM }}=$ Número de transformadores de fronteira com diagnóstico ruim.

$N F=$ Número total de transformadores de fronteira do sistema.

$f_{\text {penalizą̧ão }}\left(N F_{\text {RUIM }}\right)=$ Função de penalização por sobrecarregamento de transformador de fronteira.

Note que na equação (3.5), $N_{F R}$, tem valor mínimo igual a zero e valor máximo igual a dez, o que foi definido por conveniência, sendo possível configurar as notas de carregamentos dos transformadores de inúmeras maneiras diferentes.

A função de penalização por sobrecarregamento de transformador de fronteira, $f_{\text {penalização }}\left(N F_{\text {RUIM }}\right)$, se faz necessária devido à necessidade de restringir ao máximo as soluções que causam fluxo de potência aparente nos componentes maiores que suas capacidades. A sobrecarga em transformadores de fronteira do sistema, além de causar danos irreversíveis aos equipamentos, pode sensibilizar seus dispositivos de proteção, causando a 
interrupção de fornecimento de energia elétrica a consumidores, uma situação inadmissível, principalmente em sistemas elétricos de subtransmissão. Essa função, contudo, não deve introduzir muitas variações abruptas na nota de carregamento dos transformadores de fronteira, devendo incrementar continuamente penalizações quanto maior o número de transformadores sobrecarregados. Isso é necessário no processo de evolução do algoritmo, para que seja possível diferenciar duas soluções ruins, ou seja, para que o algoritmo consiga “caminhar” sobre o espaço de soluções no sentido dos melhores vetores.

Uma das possíveis formas que a função de penalização por sobrecarregamento de transformadores pode ser definida é:

$$
f_{\text {penalização }}\left(N F_{\text {RUIM }}\right)=\left\{\begin{array}{cll}
1 & \text { se } & N F_{\text {RUIM }}=0 \\
\frac{1}{N F_{\text {RUIM }}} \cdot k_{\text {pen }} & \text { se } & N F_{\text {RUIM }}>0
\end{array}\right.
$$

Onde $k_{\text {pen }}$ é a constante de penalização, sendo necessariamente $k_{\text {pen }}<1$, por exemplo, $k_{\text {pen }}=0,5$.

Note que, para a presença de apenas um transformador sobrecarregado no sistema em análise, a função de sobrecarregamento é penalizada, por exemplo, em $50 \%$, tornando assim, as redes sem nenhum sobrecarregamento bem mais valiosas para a perpetuação durante o processo evolutivo.

A função proposta de penalização por sobrecarregamento de transformadores é ilustrada graficamente, para os valores de $N F_{\text {RUIM }}$ maiores que zero, através da Figura 3.10. 


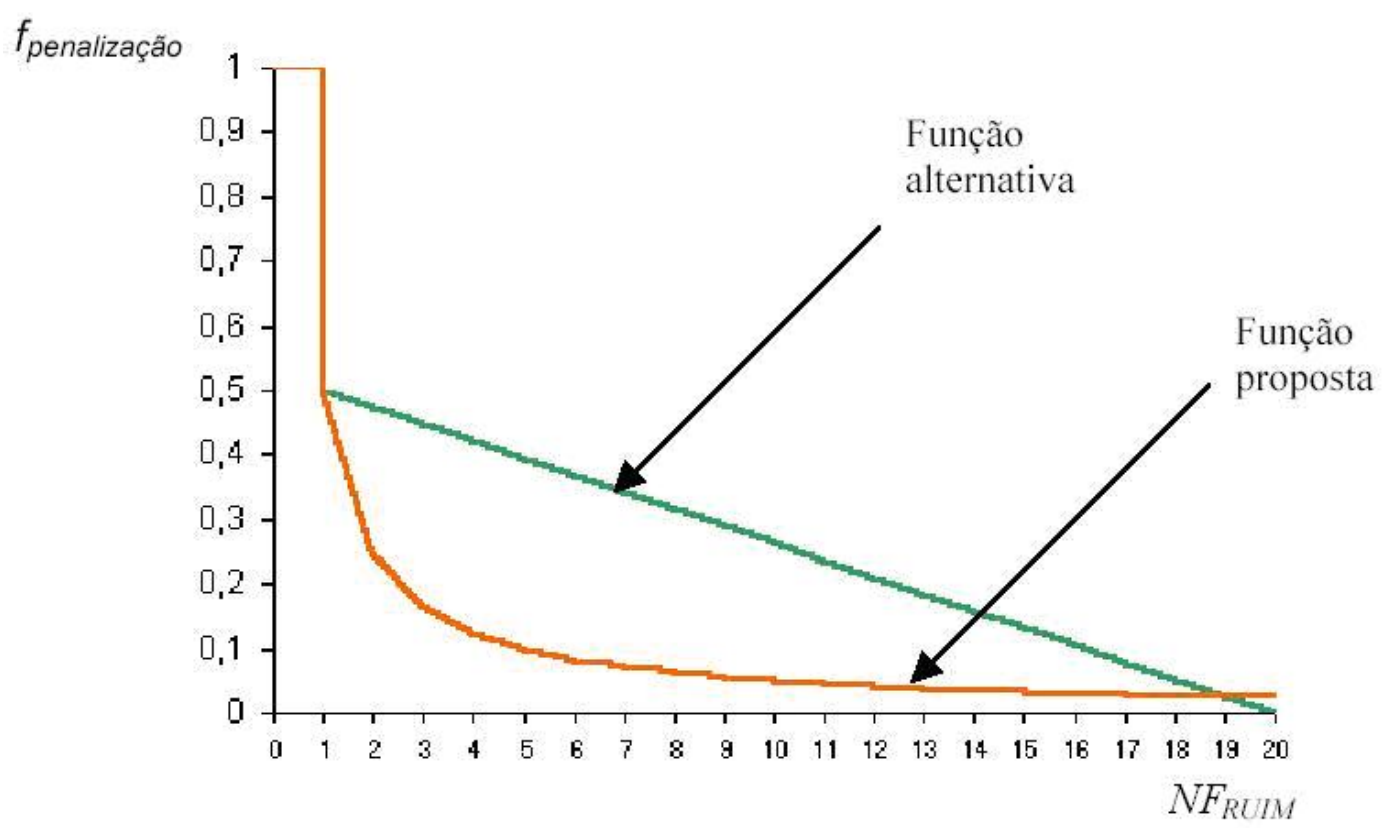

Figura 3.10 - Representação da função proposta (3.6) para $k_{p e n}=0,5$ e de uma possível função alternativa linear

Com as definições (3.5) e (3.6), pode-se dizer que o perfil de carregamento dos transformadores de fronteira do sistema elétrico de subtransmissão estará melhor (ou mais ajustado) quanto mais próximo estiver da nota 10 e tanto pior quanto mais próximo estiver da nota 0 . Obviamente, o número de diagnósticos poderia ser variado conforme o problema em estudo.

O fator de penalização de transgressão de carregamento de transformadores de fronteira, $P_{F R}$, que penaliza a função de avaliação pode ser estabelecido como função de tais notas, dado por:

$$
P_{F R}=\left\{\begin{array}{ccc}
k_{F R} & \text { para } & N_{F R}=0 \\
\left(\frac{-k_{F R}}{10}\right) *\left(N_{F R}-10\right) & \text { para } & 0<N_{F R}<10 \\
0 & \text { para } & N_{F R}=10
\end{array}\right.
$$

Onde $k_{F R}$ é uma constante. O fator de penalização $P_{F R}$ é sempre punitivo para $N_{F R}<10$, porém, se aplicado um valor elevado de $P_{F R}$ ao custo dos encargos pelo uso do sistema de 
transmissão, custo $_{i}$, poderá distorcer a avaliação dos indivíduos. Por isso, $k_{F R}$ deve apresentar valores de $10 \%$ a $20 \%$ da ordem de grandeza do custo $_{i}$, suficientes para distinguir dois indivíduos distintos em suas avaliações. A Figura 3.11 ilustra o fator de penalização por transgressão de carregamento dos transformadores de fronteira em função da nota de carregamento dos transformadores de fronteira.

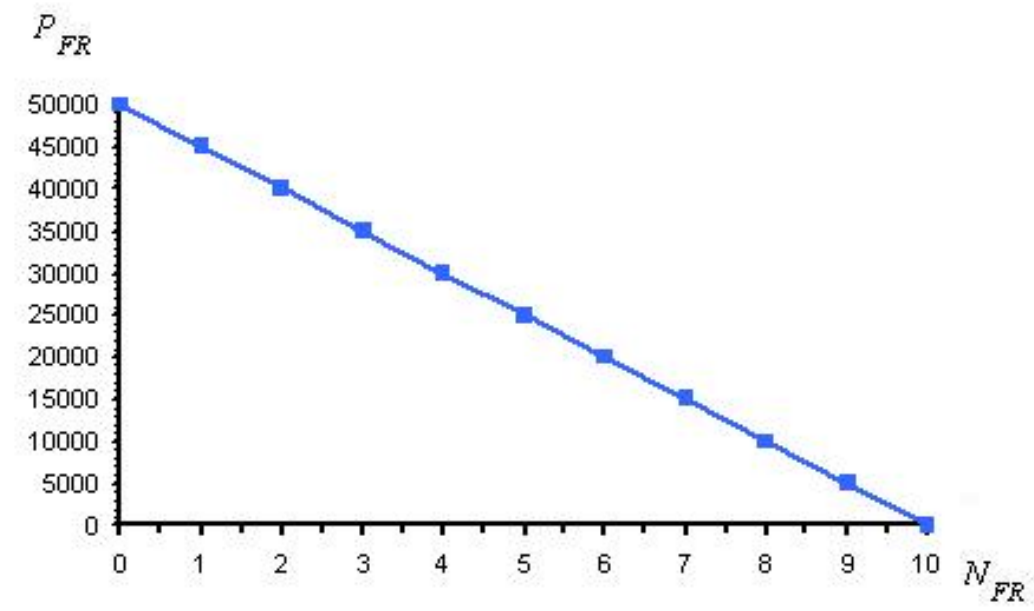

Figura 3.11 - Representação gráfica do fator de penalização por transgressão de carregamento de transformadores de fronteira em função da nota de carregamento

\subsubsection{Fator de penalização por transgressão de carregamento dos trechos das linhas de subtransmissão}

O estabelecimento do diagnóstico do carregamento dos trechos das linhas de subtransmissão é análogo ao dos transformadores de fronteira. A classificação dos trechos ocorre de acordo com seu nível de carregamento em relação à sua corrente admissível, Inom (ou à sua potência 
admissível, Snom), em três diagnósticos: bom, regular e ruim. A Tabela 3.2 ilustra como é feita a classificação dos trechos de linhas de um sistema após o cálculo de fluxo de potência.

\begin{tabular}{|c|c|}
\hline Carregamento (I) em A & Diagnóstico \\
\hline $0,7 \cdot$ Inom $>I$ & BOM \\
\hline $0,7 \cdot$ Inom $\leq I<$ Inom & REGULAR \\
\hline$I \geq$ Inom & RUIM \\
\hline
\end{tabular}

Tabela 3.2 - Diagnóstico de carregamento de cada trecho das linhas de um sistema elétrico de subtransmissão, sendo $I$ a corrente elétrica que percorre o trecho

Definido o diagnóstico dos trechos das linhas do sistema elétrico de subtransmissão, a nota de carregamento dos trechos das linhas de subtransmissão por indivíduo é dada pela equação:

$$
N_{T R}=\frac{10 \cdot N T_{B O M}+5 \cdot N T_{R E G U L A R}+0 \cdot N T_{R U I M}}{N T} \cdot f_{\text {penalização }}\left(N T_{\text {RUIM }}\right)
$$

Onde,

$N_{T R}=$ Nota de carregamento dos trechos das linhas de subtransmissão do sistema.

$N T_{\text {Вом }}=$ Número de trechos com diagnóstico bom.

$N T_{\text {REGULAR }}=$ Número de trechos com diagnóstico regular.

$N T_{\text {RUIM }}=$ Número de trechos com diagnóstico ruim.

$N T$ = Número total de trechos das linhas de subtransmissão do sistema.

$f_{\text {penalização }}\left(N T_{\text {RUIM }}\right)$ - Função de penalização por sobrecarregamento de trechos das linhas de subtransmissão. 
Na função (3.8), $N_{T R}$, tem valor mínimo igual a zero e valor máximo igual a dez, o que foi definido por conveniência, sendo possível configurar as notas de carregamentos dos trechos de rede de inúmeras maneiras diferentes.

A função de penalização por sobrecarregamento de trechos das linhas de subtransmissão, $f_{\text {penalização }}\left(N T_{\text {RUIM }}\right)$, pode ser definida por:

$$
f_{\text {penalizaşã }}\left(N T_{R U I M}\right)=\left\{\begin{array}{cll}
1 & \text { se } & N T_{\text {RUIM }}=0 \\
\frac{1}{N T_{\text {RUIM }}} \cdot k_{\text {pen }} & \text { se } & N T_{\text {RUIM }}>0
\end{array}\right.
$$

Sendo necessariamente, $k_{\text {pen }}<1$, por exemplo, $k_{\text {pen }}=0,5$.

O fator de penalização de transgressão de carregamento de trechos das linhas de subtransmissão, $P_{T R}$, que penaliza a função de avaliação pode ser estabelecido como função de tais notas, dado por:

$$
P_{T R}=\left\{\begin{array}{ccc}
k_{T R} & \text { para } & N_{T R}=0 \\
\left(\frac{-k_{T R}}{10}\right) *\left(N_{T R}-10\right) & \text { para } & 0<N_{T R}<10 \\
0 & \text { para } & N_{T R}=10
\end{array}\right.
$$

Onde $k_{T R}$ é uma constante. Para que o fator de penalização $P_{T R}$ seja punitivo, porém não distorça a avaliação dos indivíduos, $k_{T R}$ deve apresentar um valor de $10 \%$ a $20 \%$ da ordem de grandeza do $\mathrm{Custo}_{i}$. 


\subsubsection{Fator de penalização por transgressão do nível de tensão nos barramentos das subestações}

O cálculo de fluxo de potência determina também os níveis de tensão nos barramentos das subestações do sistema. Analogamente ao diagnóstico dos transformadores de fronteira e dos trechos das linhas de subtransmissão, os barramentos são classificados, de acordo com seu nível de tensão em relação à tensão nominal do sistema, em diagnósticos bom, regular e ruim. Distintamente ao diagnóstico dos transformadores e dos trechos, o diagnóstico das barras considera tensões inadequadas àquelas muito baixas ou muito altas. A Tabela 3.3 ilustra através de um exemplo de parâmetros limites como é feita a classificação das barras de um sistema após o cálculo de fluxo de potência.

\begin{tabular}{|c|c|}
\hline Tensão $(\boldsymbol{V})$ em pu & Diagnóstico \\
\hline$V<0,90 p u$ & RUIM \\
\hline $0,90 p u \leq V<0,95 p u$ & REGULAR \\
\hline $0,95 p u \leq V<1,03 p u$ & BOM \\
\hline $1,03 p u \leq V<1,05 p u$ & REGULAR \\
\hline$V \geq 1,05 p u$ & RUIM \\
\hline
\end{tabular}

Tabela 3.3 - Diagnóstico de tensão nos barramentos de cada subestação de um sistema elétrico de subtransmissão, sendo $V$ a sua tensão em $p u$ (por unidade)

Os valores utilizados para a definição dos níveis de diagnóstico de tensão nos barramentos são baseados na Resolução Normativa $n^{0}$ 505, de 26 de Novembro de 2001, da ANEEL [24], a qual estabelece de forma atualizada e consolidada, as disposições relativas à conformidade dos níveis de tensão de energia elétrica em regime permanente. A resolução define as faixas 
de tensão como Adequada, Precária e Crítica, referentes às faixas recém definidas Bom, Regular e Ruim, respectivamente.

Definido o diagnóstico dos barramentos das subestações do sistema elétrico de subtransmissão, a nota do nível de tensão nos barramentos das subestações por indivíduo é dada pela equação:

$$
N_{V}=\frac{10 \cdot N V_{B O M}+5 \cdot N V_{\text {REGULAR }}+0 \cdot N V_{\text {RUIM }}}{N V} \cdot f_{\text {penalização }}\left(N V_{\text {RUIM }}\right)
$$

Onde,

$N_{V}=$ Nota de nível de tensão nos barramentos das subestações do sistema.

$N V_{\text {BOM }}=$ Número de barramentos com diagnóstico bom.

$N V_{\text {REGULAR }}=$ Número de barramentos com diagnóstico regular .

$N V_{\text {RUIM }}=$ Número de barramentos com diagnóstico ruim.

$N V=$ Número total de barramentos das subestações do sistema.

$f_{\text {penalização }}\left(N V_{\text {RUIM }}\right)$ - Função de penalização por nível de tensão nos barramentos das subestações.

Uma penalização é proposta na função de nota para o nível de tensão nos barramentos das subestações. Apesar da transgressão do nível de tensão não acarretar o mesmo efeito sistêmico que o sobrecarregamento de equipamentos, algumas subestações não possuem reguladores de tensão ou transformadores com barras secundárias de tensão controlada, equipamentos que amenizam o efeito de tensão abaixo do nível adequado de fornecimento. É 
o caso, principalmente, das subestações particulares de clientes industriais, grandes consumidores de energia que, portanto, devem ser levados em consideração.

A função de penalização por violação do nível de tensão nos barramentos das subestações, $f_{\text {penalizą̧ão }}\left(N V_{\text {RUIM }}\right)$, pode ser definida por:

$$
f_{\text {penalização }}\left(N V_{\text {RUIM }}\right)=\left\{\begin{array}{cll}
1 & \text { se } & N V_{\text {RUIM }}=0 \\
\frac{1}{N V_{\text {RUIM }}} \cdot k_{\text {pen }} & \text { se } & N V_{\text {RUIM }}>0
\end{array}\right.
$$

Sendo necessariamente, $k_{\text {pen }}<1$, por exemplo, $k_{p e n}=0,5$.

O fator de penalização de transgressão de nível de tensão nos barramentos das subestações, $P_{V}$, que penaliza a função de avaliação pode ser estabelecido como função de tais notas, dado por:

$$
P_{V}=\left\{\begin{array}{ccc}
k_{V} & \text { para } & N_{V}=0 \\
\left(\frac{-k_{V}}{10}\right) *\left(N_{V}-10\right) & \text { para } & 0<N_{V}<10 \\
0 & \text { para } & N_{V}=10
\end{array}\right.
$$

Onde $k_{V}$ é uma constante. Para que o fator de penalização $P_{V}$ seja punitivo, porém não distorça a avaliação dos indivíduos, $k_{V}$ deve apresentar um valor de $10 \%$ a $20 \%$ da ordem de grandeza do Custo $_{i}$. 


\section{MODELO DE OTIMIZAÇÃO DO FLUXO DE POTÊNCIA REATIVA UTILIZANDO UMA ESTRATÉGIA EVOLUTIVA}

\subsection{Descrição e Formulação do Problema}

A potência reativa que ingressa em um sistema de subtransmissão de energia elétrica contendo múltiplos pontos de fronteira com a Rede Básica está relacionada basicamente à configuração de rede interna do sistema e aos níveis de tensão relativos aos ajustes dos taps dos transformadores de fronteira. Variando-se o módulo da tensão nos barramentos de fronteira do sistema, pode-se alterar o estado operativo da rede elétrica, sendo que quanto maior o número de pontos de fronteira o sistema apresentar, maior a dimensão do problema a ser solucionado.

A partir de uma configuração de rede pré-estabelecida, o problema de otimização do fluxo de potência reativa consiste em determinar uma configuração dos taps dos transformadores de fronteira do sistema analisado, visando atender a um ou mais objetivos e sujeito às restrições impostas e que não devem ser violadas.

As principais variáveis de controle do problema são os valores de tensão verificados nos barramentos do lado secundário dos transformadores de fronteira do sistema. Esses valores de tensão estão contidos dentro de faixas operativas estabelecidas entre as concessionárias transmissoras e distribuidoras de energia elétrica, respeitando os limites definidos pelos Procedimentos de Rede em vigor. Assim, o modelo a ser elaborado considera esses valores para buscar uma alternativa de solução do problema em que as necessidades do planejador sejam plenamente satisfeitas. 
As mesmas premissas adotadas no modelo de otimização do fluxo de potência ativa também devem estar incorporadas nesse novo modelo, sendo elas:

- Todos os transformadores de fronteira devem operar dentro dos limites técnicos de capacidade de transformação;

- Todos os trechos das linhas de subtransmissão devem operar dentro dos limites técnicos de carregamento admissíveis; e

- Todos os barramentos das subestações do sistema devem apresentar níveis de tensão apropriados.

Para a determinação dos níveis de tensão, carregamento e perdas de uma rede elétrica, é necessário o cálculo do fluxo de potência do sistema, determinando assim, a tensão em todas as barras e a corrente elétrica em todos os trechos da rede em questão.

Como o algoritmo propõe-se a determinar qual a melhor configuração dos níveis de tensão dos barramentos de fronteira em um sistema elétrico de subtransmissão, é necessário que se utilize um método numérico capaz de calcular o fluxo de potência de um sistema em malha, contendo, pelo menos, barras de interligação do tipo $P V$, barras de referência do tipo $V \theta$ e barras de carga do tipo $P Q$.

No problema de otimização do fluxo de potência reativa em sistemas de subtransmissão de energia elétrica, faz-se necessário o uso de um método apropriado para a manipulação de variáveis contínuas. Existem diversos métodos que podem ser aplicados para a resolução desse tipo de problema. Diferentemente dos AG, a técnica de EE possui certas características que a favorece no tratamento de problemas de otimização contendo variáveis contínuas. Este capítulo propõe a utilização de uma EE que, em primeira análise, contenha todos os prérequisitos básicos para o cumprimento eficaz da proposta. Entretanto, e devido a razões a 
serem esclarecidas, será proposta uma nova estrutura de processos evolutivos para a sua solução, conforme será visto a seguir.

\subsection{Aplicação de uma Estratégia Evolutiva ao Problema}

Neste item, são analisados os processos e a estrutura básica de uma Estratégia Evolutiva canônica [18] com algumas observações, comentários e comparações entre a EE a ser descrita e o AG canônico [14], [16].

As Estratégias Evolutivas [25], [26] foram inicialmente propostas com o intuito de solucionar problemas de otimização de parâmetros, tanto discretos quanto contínuos. Em virtude de originalmente somente utilizarem operadores de mutação, grandes contribuições em relação à análise e síntese destes operadores foram elaboradas, principalmente a análise de convergência e o desenvolvimento de mecanismos de auto-adaptação de parâmetros [27].

As EE, inicialmente, foram desenvolvidas para a resolução de problemas de otimização em engenharia. A primeira EE desenvolvida foi a $(1+1) E E$, proposta por I. Rechenberg e H. P. Schwefel, nos anos 60. A $(1+1) E E$ original utiliza somente o operador de mutação, onde apenas uma solução ancestral produz um único descendente [18]. A (1+1)EE foi progressivamente generalizada em variantes do número de ancestrais (pais), $\mu>1$, e número de descendentes (filhos), $\lambda>1$, por geração. As EE são divididas de acordo com o mecanismo de seleção em:

- Estratégia soma (plus strategy) ou $(\mu+\lambda) E E$, onde os $\mu$ ancestrais geram $\lambda$ descendentes e competem entre si pela sobrevivência. 
- Estratégia vírgula (comma strategy) ou $(\mu, \lambda) E E$, onde os $\lambda$ descendentes competem para sobreviver e os $\mu$ ancestrais são completamente substituídos a cada geração.

A $(\mu, \lambda) E E$ tem a tendência de manter uma maior diversidade de indivíduos na população, o que pode ser uma vantagem de forma a evitar-se mínimos locais. A desvantagem da $(\mu, \lambda) E E$ é a possibilidade de uma solução “ótima” obtida, em uma dada geração, não “sobreviver” até o final do procedimento evolutivo.

A $(\mu+\lambda) E E$, ao contrário, dependendo de sua configuração, pode ser mais susceptível a mínimos locais, ou seja, o domínio de uma elite de ancestrais (soluções similares) antes da obtenção de um valor adequado. Entretanto, uma solução ótima obtida, durante o procedimento evolutivo, não é perdida e “sobrevive” até o final do procedimento evolutivo.

É interessante notar que a presença e a perpetuação de um indivíduo muito melhor que os demais em uma população por muitas gerações pode levar o processo de busca à estagnação em torno de ótimos locais. Para evitar que isso ocorra, pode-se determinar o número máximo de gerações para sobrevivência dos indivíduos, fazendo com que a eliminação de indivíduos muito bons e "velhos" possa permitir ao algoritmo encontrar outras tendências, ou outros indivíduos próximos a melhores soluções. Esta forma de seleção, mais genérica, é denominada $(\mu, k, \lambda) E E$, para qual $k$ representa o número máximo de gerações permitidas aos indivíduos. Nota-se que, para $k=1$, a forma de seleção é $(\mu, \lambda) E E$, e para $k=\infty$, a forma de seleção é $(\mu+\lambda) E E$, com a característica adicional da restrição de perpetuação. A estrutura de uma EE canônica pode ser descrita simplificadamente através da Figura 4.1, na qual são considerados $\mu$ indivíduos pais e $\lambda$ indivíduos descendentes a cada geração. Todos os $\lambda$ indivíduos descendentes são obtidos através dos processos de recombinação e mutação. 


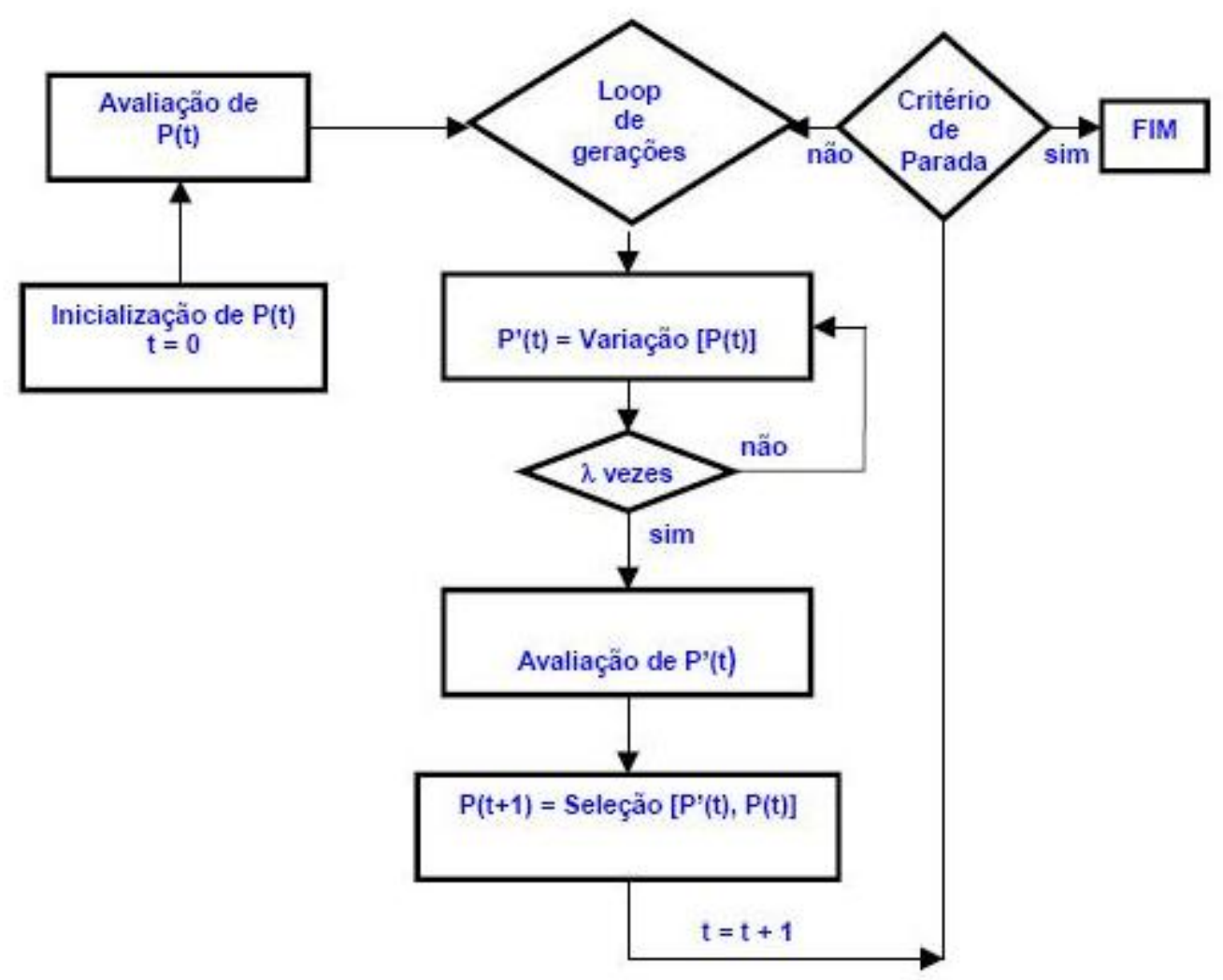

Figura 4.1 - Estratégia Evolutiva canônica

O algoritmo da Estratégia Evolutiva canônica funciona basicamente da seguinte maneira:

1. Sorteiam-se aleatoriamente todos os primeiros $\mu$ indivíduos do tipo $(\vec{x}, \vec{\sigma})$, sendo $\vec{x}$ o vetor de variáveis objetivas e $\vec{\sigma}$ o vetor de estratégias de evolução, pertencentes à população inicial $P(t)$, para a geração $t=0$;

2. Avaliam-se todos os $\mu$ indivíduos da população inicial através da função objetivo $f(\vec{x})$;

3. São escolhidos aleatoriamente 2 ou mais indivíduos pertencentes a população de genitores para a recombinação, da qual resulta um indivíduo descendente. A este indivíduo é aplicado o processo de mutação, geralmente uma alteração de pequena proporção às variáveis objetivas do indivíduo. Este procedimento, também conhecido por variação, é repetido $\lambda$ vezes para a geração $t$; 
4. Avaliam-se todos os $\lambda$ indivíduos resultantes do processo de variação, pertencentes a uma nova população $P^{\prime}(t)$;

5. Selecionam-se os $\mu$ indivíduos melhores avaliados dentre a população de descendentes $P^{\prime}(t)-(\mu, \lambda) E E$, ou da união desta com a população de genitores $P(t)-(\mu+\lambda) E E$

6. Incrementa-se a geração $t$ e repete-se o processo a partir do item 3, caso nenhum critério de parada tenha sido satisfeito.

Uma característica particular em EE é que para representar um problema real, não são somente consideradas as variáveis objetivas da função objetivo, mas também os parâmetros estratégicos, ou ainda denominados passos de mutação.

Os indivíduos (soluções), $(\vec{x}, \vec{\sigma})$, são diretamente representados por dois vetores de mesmo tamanho. O primeiro, $\vec{x} \in \mathfrak{R}^{n}$, denominado vetor de variáveis objetivas, representa todas as variáveis a serem otimizadas, e o outro, $\vec{\sigma} \in \mathfrak{R}^{n}$, denominado vetor de parâmetros estratégicos, representa o potencial de alteração das variáveis durante o processo de mutação. Na criação da população inicial os vetores $\vec{x}$ e $\vec{\sigma}$ são gerados aleatoriamente dentro de intervalos definidos pelo usuário.

A Figura 4.2 ilustra um indivíduo $\alpha$ qualquer composto por uma cadeia de 4 loci com suas variáveis objetivas e parâmetros estratégicos: 


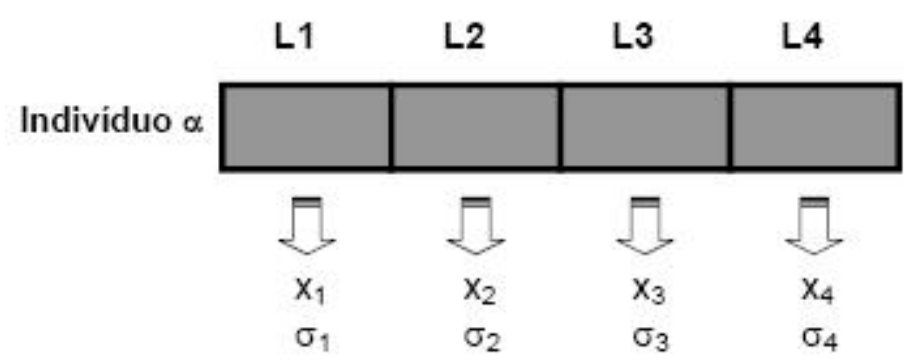

Figura 4.2 - Representação de um indivíduo em EE

A implementação das EE apresenta diversas variantes, destacando-se as EE contemporâneas e as EE com mecanismos de auto-adaptação, com a realização de mutações correlacionadas. O desempenho das EE, comparadas com outras técnicas de otimização, depende da configuração adequada dos seus parâmetros internos de controle. As EE apresentam facilidades no ajuste de tais parâmetros através da utilização de auto-adaptação. Nos AG, os parâmetros de controle são ajustados, usualmente, através de métodos heurísticos de tentativa e erro.

O princípio da auto-adaptação é facilitar o controle implícito dos parâmetros da EE, pela sua incorporação na representação do indivíduo com a evolução usual das variáveis objetivas. O termo parâmetros estratégicos (ou parâmetros de controle) refere-se aos parâmetros que controlam o procedimento de busca evolutiva, tais como: taxa de mutação, variância da mutação e taxa de cruzamento [18].

Os mecanismos de auto-adaptação, no nível de componente dos parâmetros estratégicos, providenciam uma das características principais do sucesso das EE. As EE utilizam princípios de busca no espaço de variáveis objetivas e estratégia interna de controle dos parâmetros, simultaneamente. Assim, a potencialidade de uma EE é baseada principalmente na habilidade de executar uma otimização de parâmetros de segundo nível. Este procedimento adapta o poder de mutação de tal forma que a EE apresente um excelente desempenho. 
O algoritmo a ser proposto é semelhante ao definido por Hage [9]. Em sua maior parte, possui características análogas ou idênticas às descritas pela EE canônica, com exceção de alguns mecanismos impostos ao corpo principal do algoritmo.

Na escolha da forma básica de funcionamento do algoritmo proposto, são importantes as seguintes considerações:

- O algoritmo proposto deve ter representação real, já que esta característica elimina a necessidade de codificação e decodificação de variáveis;

- O algoritmo deve utilizar os processos de mutação com auto-adaptação para tornar a busca por soluções mais eficiente e, ainda, indicar convergência para que possíveis critérios de parada possam ser empregados;

- Da mesma forma que no AG canônico, é interessante à EE proposta que os processos de mutação e recombinação sejam independentes, não impondo, por exemplo, que a mutação ocorra somente aos indivíduos recombinados, como na EE canônica. A recombinação produz indivíduos novos, que concorrerão com indivíduos mutados;

- O processo de mutação pode ocorrer $n$ vezes para cada indivíduo genitor, tornando a variação em torno de um único indivíduo mais ampla, resultando assim, mais opções de busca pela direção de melhor aproximação da solução;

- O processo de seleção pode ser idêntico ao esquema $(\mu, k, \lambda) E E$, já que este possui, ao mesmo tempo, características elitistas e um mecanismo que inibe a estagnação precoce em máximos ou mínimos locais, como já mencionado.

Estas considerações delimitam o desenvolvimento do algoritmo proposto a uma EE com processos de representação, mutação, recombinação e seleção derivados basicamente da 
Estratégia Evolutiva canônica, diferenciando-se na forma como o processo evolutivo será conduzido. A Figura 4.3 ilustra como será o algoritmo proposto.

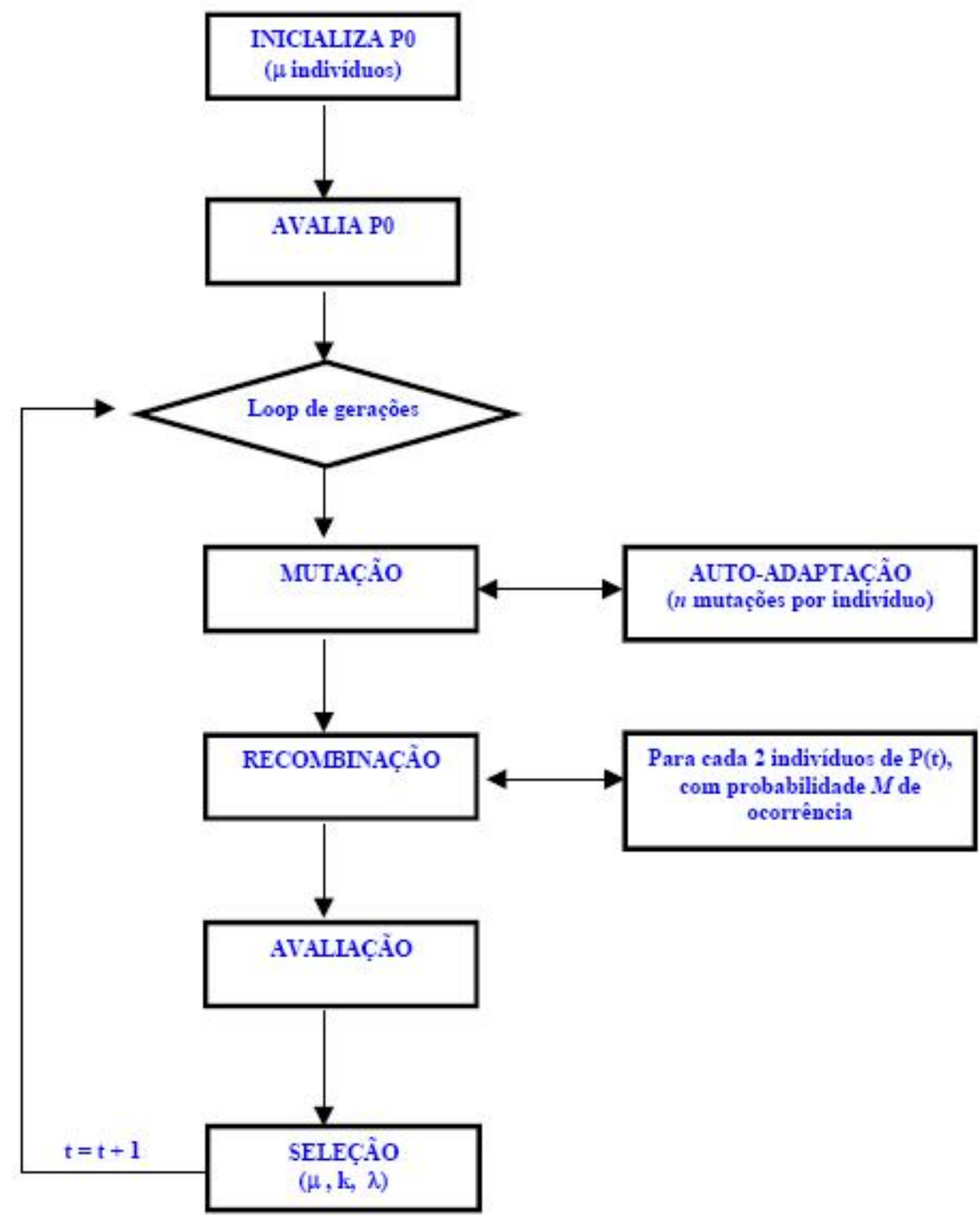

Figura 4.3 - Estratégia Evolutiva proposta

A Estratégia Evolutiva proposta funcionará da seguinte maneira: 
1. Sorteiam-se aleatoriamente todos os primeiros $\mu$ indivíduos do tipo $(\vec{x}, \vec{\sigma})$, sendo $\vec{x}$ o vetor de variáveis objetivas e $\vec{\sigma}$ o vetor de estratégias de evolução, pertencentes à população inicial $P(t)$, para a geração $t=0$;

2. Avaliam-se todos os $\mu$ indivíduos da população inicial através da função objetivo $f(\vec{x})$;

3. Todos os $\mu$ indivíduos da população $P(t)$ sofrem $n$ mutações, sendo que cada mutação produz um indivíduo descendente. Nesta etapa, $P^{\prime}(t)$ conta $\operatorname{com} n \cdot \mu$ indivíduos;

4. Com uma certa probabilidade $M$, são escolhidos aleatoriamente 2 indivíduos pertencentes a população de genitores $P(t)$ para a Recombinação, da qual resulta um indivíduo descendente acrescentado à população $P^{\prime}(t)$. Este procedimento é repetido $\mu$ vezes, uma por par de cada indivíduo de $P(t)$;

5. Avaliam-se todos os $\lambda$ indivíduos resultantes do processo de variação, pertencentes a uma nova população $P^{\prime}(t)$. É importante ressaltar que $\lambda$ pode variar de acordo com as ocorrências de recombinação, sendo $n \cdot \mu \leq \lambda \leq(n \cdot \mu)+\mu$;

6. Selecionam-se os $\mu$ indivíduos melhores avaliados da união da população $P^{\prime}(t)$ com a população de genitores $P(t)$, através do esquema similar ao $(\mu, k, \lambda) E E$, descartando-se os indivíduos cuja idade ultrapassou $k$ gerações;

7. Incrementa-se a geração $t$ e repete-se o processo a partir do item 3 , caso $t$ não tenha excedido o número máximo de gerações.

O primeiro passo para a implementação de uma EE é a determinação do processo de codificação dos indivíduos, o qual promove a conexão entre o problema de fato e sua representação. Não menos importante é a escolha da função objetivo a ser otimizada, pois 
através dela os indivíduos serão avaliados e posteriormente selecionados de forma a proporcionar, geração a geração, a adequação das variáveis objetivas à solução ótima local ou global.

\subsubsection{Codificação dos Indivíduos}

O indivíduo utilizado neste algoritmo representa uma possível configuração dos níveis de tensão nos barramentos de fronteira de um sistema elétrico de subtransmissão, não se tratando de uma representação direta, mas de uma codificação capaz de armazenar as informações relativas às fronteiras componentes do sistema.

Para cada ponto de fronteira presente, codifica-se um loci no indivíduo representante para designar o parâmetro módulo da tensão elétrica em pu (por unidade) no seu barramento.

Seja então $n$ o número de pontos de fronteira ou barras do tipo $P V$ e $V \theta$ presentes em um sistema elétrico, faz-se necessária a utilização de $n$ loci do indivíduo representante para codificar os parâmetros dos $n$ pontos de fronteira.

Cada lócus, por sua vez, armazena informações relativas à variável objetiva e ao seu passo de mutação $\sigma$ correspondente. Assim, para cada variável tensão do ponto de fronteira, tem-se o respectivo passo de mutação de tensão.

As variáveis objetivas e seus passos de mutação podem, devido ao prévio conhecimento do problema, ser restringidos quanto aos sorteios iniciais de seus valores reais.

Durante a execução do algoritmo, é perfeitamente aceitável que os passos de mutação “caminhem” para valores elevados, principalmente em gerações precoces, já que os mesmos 
são resultados de uma busca aleatória por bons parâmetros e que a probabilidade de encontrar bons indivíduos rapidamente é pequena.

A Figura 4.4 ilustra um sistema elétrico de subtransmissão genérico, contendo três conexões com a Rede Básica S1 (representada como uma barra swing), G1 e G2 (representadas como barras de geração) e três subestações $C 1, C 2$ e $C 3$ (representadas como barras de carga), além da sua correspondente representação através da codificação do indivíduo.

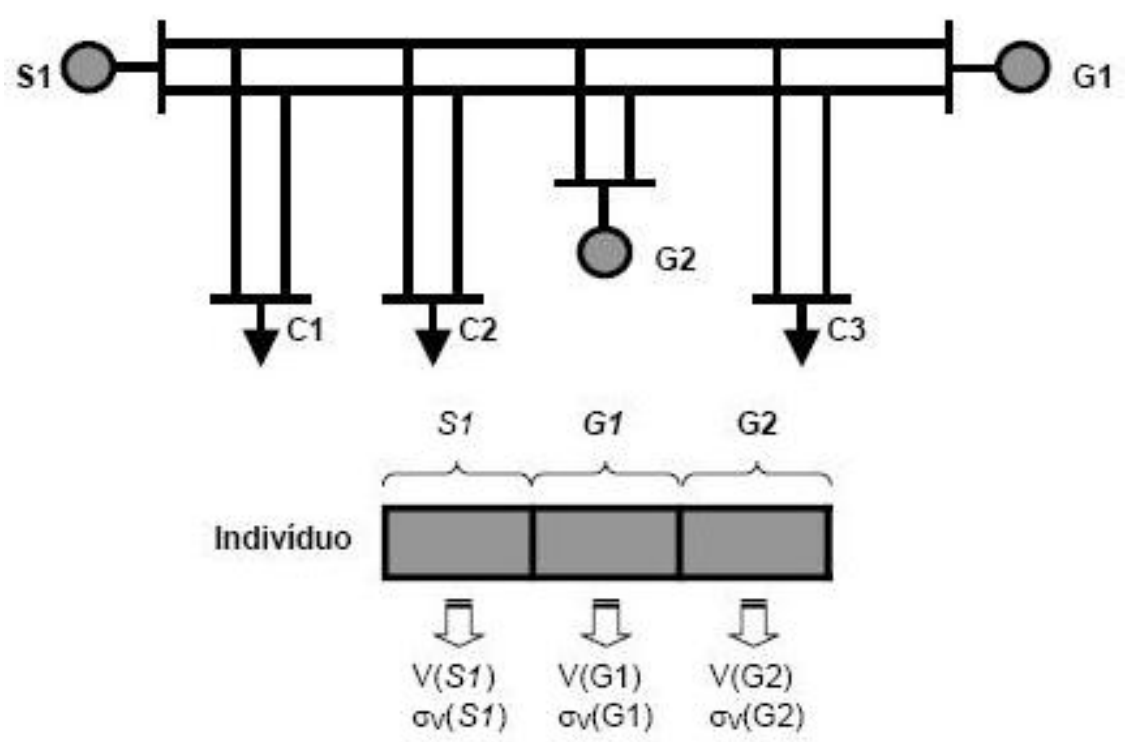

Figura 4.4 - Representação de um sistema elétrico de subtransmissão contendo três pontos de fronteira e três subestações e sua representação em um indivíduo codificado

\subsubsection{Função de Avaliação dos Indivíduos}

Conforme descrito, cada indivíduo representará um conjunto de dados operacionais referentes aos pontos de fronteira do sistema elétrico de subtransmissão com a Rede Básica, mais especificamente as configurações de cada fronteira do tipo $P V$ e $V \theta$ presentes no sistema. 
Para o modelo de otimização de potência reativa, utiliza-se a mesma formulação da função de avaliação dos indivíduos definida em (3.3) e (3.4) e, considerando os mesmos fatores de penalização de (3.5), (3.8) e (3.11), define-se a função de avaliação dos indivíduos para a minimização do custo dos encargos de uso do sistema de transmissão.

Conforme já dito, uma configuração interessante para as funções objetivo, conforme já mencionado, parte do conceito de notas (ou índices de mérito) associadas aos perfis de carregamento (de transformadores de fronteira e de trechos de rede) e ao perfil de tensão. Essa alternativa permite considerar uma análise destes perfis e, a partir destes, proceder a uma melhor avaliação da função.

Assim, as funções objetivo e de restrições para a avaliação de um sistema de subtransmissão de energia elétrica genérico e otimização do fluxo de potência reativa do sistema são as mesmas já definidas anteriormente. 


\section{APLICAÇÃo DOS MODELOS DE OTIMIZAÇÃO DO FLUXO DE POTÊNCIA ATIVA E REATIVA DE SISTEMAS ELÉTRICOS DE SUBTRANSMISSÃO}

\subsection{Considerações Gerais}

Apresenta-se a seguir a metodologia de aplicação dos modelos desenvolvidos para a otimização do fluxo de potência em sistemas elétricos de subtransmissão.

Os modelos de otimização do fluxo de potência ativa e reativa foram desenvolvidos para operarem de modo independente um do outro. Assim, a metodologia faz uso desses modelos separadamente, porém, seguindo uma seqüência lógica de otimização.

A lógica da seqüência de otimização é muito simples. Dado que a otimização do fluxo de potência ativa tem por finalidade uma solução que representa uma configuração de rede e que para realizar a otimização do fluxo de potência reativa é necessário que haja uma configuração de rede pré-estabelecida, é necessário que o procedimento se inicie com a otimização da potência ativa para em seguida realizar a otimização da potência reativa.

Em sistemas elétricos de subtransmissão mais simples, contendo um único ponto de fronteira (radial) ou sem possibilidades de fechamento em anel, dependendo do objetivo a ser alcançado, pode ser possível efetuar inicialmente a otimização da potência reativa. Tudo depende da estrutura física do sistema e dos dispositivos de seccionamento a serem selecionados. A lógica definida neste trabalho refere-se a sistemas complexos, contendo mais de um ponto de fronteira e diversas possibilidades de configurações de rede, inclusive em anel. 
Em estudos de planejamento da operação de sistemas de energia elétrica, partes da rede podem ser representadas pelos equivalentes externos [28]. Além de visar à redução das dimensões dos problemas de análise e, conseqüentemente, do esforço computacional, os equivalentes externos são necessários devido à falta de informações completas e atualizadas sobre o estado atual de toda a rede de transmissão, pois, geralmente, dispõe-se apenas de informações atualizadas sobre o estado da rede pertencente ao sistema da própria concessionária de distribuição de energia elétrica. Assim sendo, é essencial a representação das regiões não monitoradas através de redes equivalentes.

A Figura 5.1 representa uma rede subdividida em três partes: rede interna, fronteira e rede externa. A rede interna, juntamente com a fronteira, constitui a área de interesse do estudo.

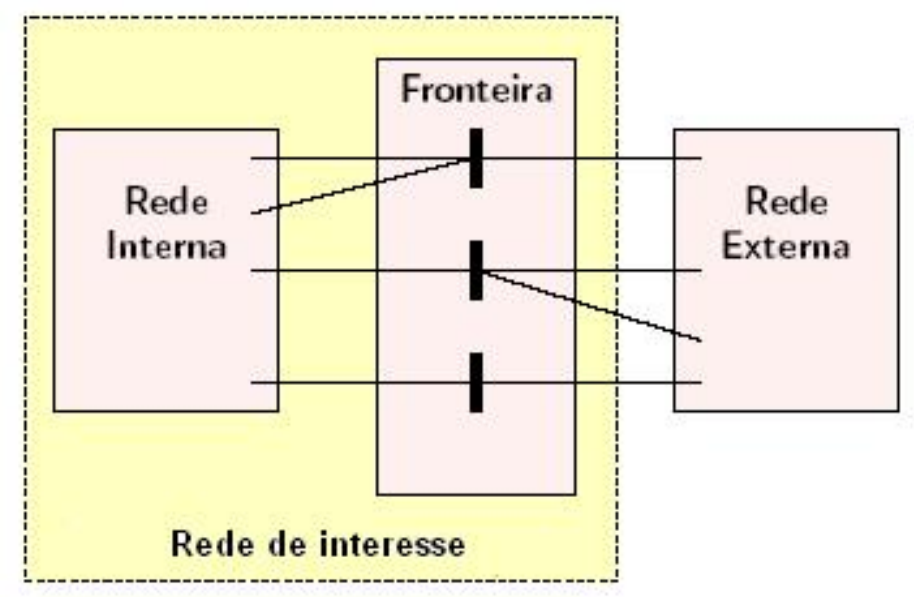

Figura 5.1 - Decomposição de uma rede em rede interna, fronteira e rede externa

A rede equivalente é obtida utilizando-se as informações sobre o estado e a configuração da rede de interesse e sobre a configuração da rede externa. O objetivo básico do equivalente externo é o de simular as reações da rede externa quando ocorrem alterações na rede de interesse. É claro que o ideal seria a representação completa da rede externa, mas, conforme dito, isto nem sempre é possível ou desejável. 
É importante salientar que a análise leva em conta apenas um instante diário de carga do sistema e, caso seja de interesse, deve ser repetida em outros instantes para eventuais análises de comportamento temporal do sistema.

Para a análise e validação dos modelos propostos, foi selecionada uma parte de um sistema real, contendo dois pontos de fronteira com a Rede Básica e diversas possibilidades de configuração operativa da rede via abertura e fechamento dos dispositivos de seccionamento do sistema.

\subsection{Otimização do Fluxo de Potência Ativa de um Sistema Elétrico de}

\section{Subtransmissão}

Uma pequena parte do sistema selecionado é utilizada para realizar uma análise mais detalhada do modelo de otimização do fluxo de potência ativa. A rede de interesse estudada contém dois pontos de fronteira com a Rede Básica e dela foram selecionados estrategicamente cinco dispositivos de seccionamento para comporem as variáveis de controle do modelo. A validação do modelo é baseada na análise da função de avaliação, a partir da simulação de todos os indivíduos possíveis de serem gerados, e na comparação dos resultados observados com o resultado alcançado com a aplicação do algoritmo genético desenvolvido de acordo com a metodologia proposta.

Dispõe-se para aplicação dos resultados, uma ferramenta computacional concebida pelo Centro de Estudos em Regulação e Qualidade de Energia da Escola Politécnica da Universidade de São Paulo (ENERQ-USP), a qual permite a edição de redes elétricas e seu 
conseqüente cadastro em um banco de dados estruturado [29], de forma a proporcionar todas as informações necessárias ao cálculo de fluxo de potência de um sistema elétrico.

Foi desenvolvido o módulo de otimização do fluxo de potência ativa por AG, de acordo com a metodologia proposta, de forma integrada a esta ferramenta computacional de análise de sistemas elétricos de subtransmissão. Esta opção, como já mencionado, deve-se à conveniência de utilização da ferramenta para cadastro e cálculo de fluxo, além de proporcionar ao módulo de otimização uma interface para visualização rápida de resultados, dado que o sistema possui relatórios gráficos para diagnósticos da rede.

A Figura 5.2 mostra o diagrama unifilar da rede de interesse do sistema elétrico de subtransmissão selecionado e o equivalente externo a ela acoplado.

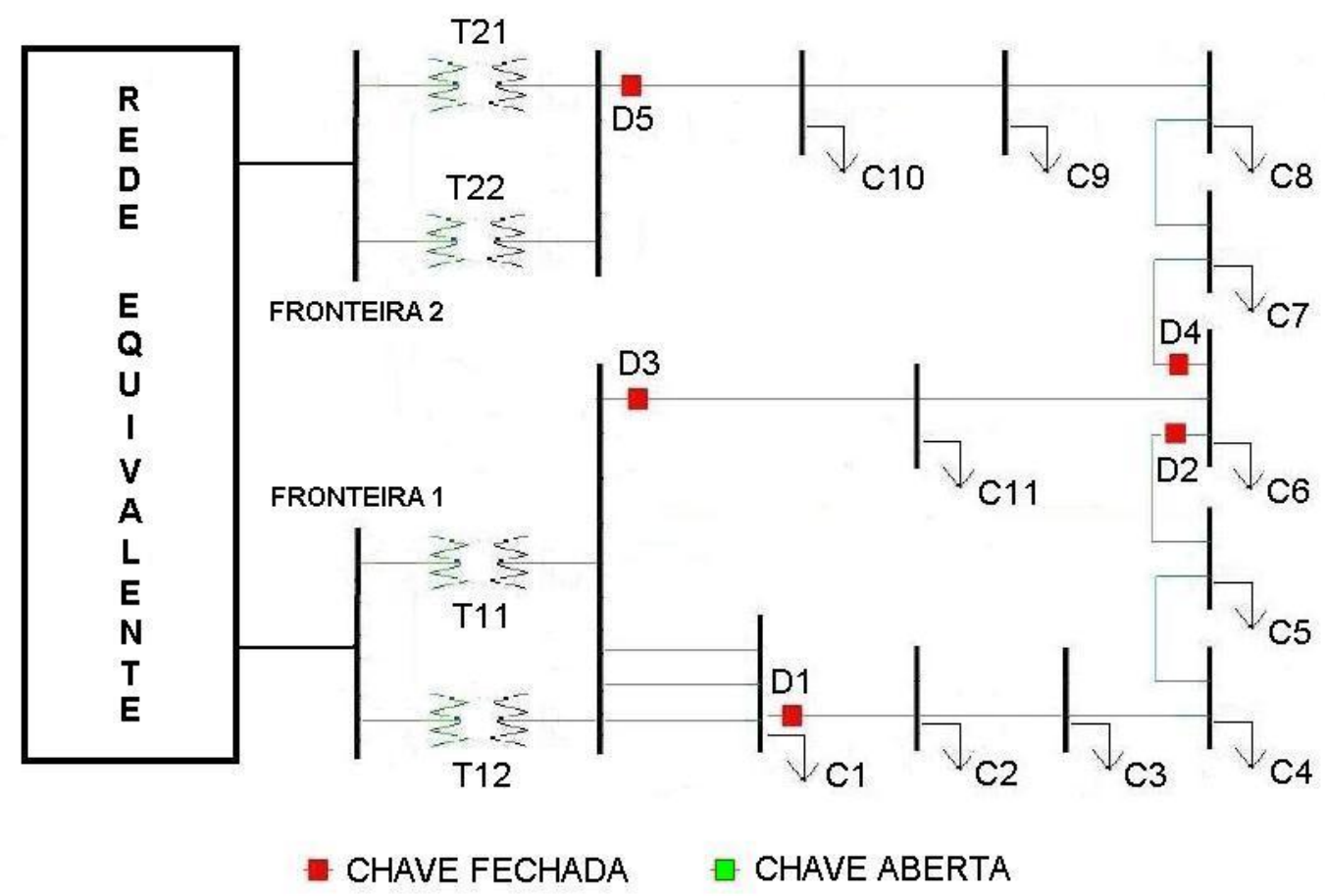

Figura 5.2 - Rede de interesse do sistema elétrico de subtransmissão selecionado e equivalente externo a ela acoplado para a minimização do custo dos encargos de uso dos sistemas de transmissão

As principais características da rede ilustrada pela Figura 5.2 estão resumidas na Tabela 5.1: 


\begin{tabular}{|c|c|}
\hline Característica & Valor \\
\hline Número de pontos de fronteira & 2 \\
\hline Número de transformadores de fronteira & 4 \\
\hline Número de trechos de linhas de subtransmissão & 12 \\
\hline Número de subestações com carga & 11 \\
\hline
\end{tabular}

Tabela 5.1 - Resumo das principais características da rede de interesse ilustrada na Figura 5.2

A rede de interesse contém dois pontos de fronteira em que as tarifas de uso do sistema de transmissão de energia elétrica foram estabelecidas em $C_{\text {fronteira }, 1}=0,087 R \$ / k W \quad$ e $C_{\text {fronteira, } 2}=1,523 R \$ / k W$, de acordo com a Resolução Normativa $\mathrm{n}^{0} 118$, de 3 de Dezembro de 2004, da ANEEL [30], a qual estabelece o valor das tarifas de uso do sistema de transmissão de energia elétrica, componentes do Sistema Interligado Nacional, e fixa a tarifa de transporte da energia elétrica proveniente de Itaipu Binacional.

Os cinco dispositivos de seccionamento selecionados são manobráveis e podem produzir até 32 combinações de indivíduos distintos. Consideram-se, como configuração operativa padrão para o cálculo dos fluxos de potência dos indivíduos, os níveis de tensão dos barramentos dos pontos de fronteira ajustados em 1,000 pu (por unidade). Através da simulação de todas as combinações desses dispositivos, procura-se decodificar os indivíduos que podem ser gerados em suas respectivas redes válidas e avaliá-los segundo a função de avaliação para o custo dos encargos de uso dos sistemas de transmissão.

Não foi considerada uma condição operacional prévia para o estabelecimento de um valor de referência para o custo dos encargos pelo uso dos sistemas de transmissão. Neste caso, emprega-se um valor arbitrário, por exemplo, custo $_{\text {ref }}=R \$ 500.000,00$ apenas para permitir a localização do indivíduo que represente o menor valor de custo para a rede de interesse estudada.

Os coeficientes de penalização, $r_{F R}, r_{T R}$ e $r_{V}$, aplicados a cada fator de penalização para as transgressões de carregamento dos transformadores de fronteira, de carregamento dos trechos 
das linhas de subtransmissão e de nível de tensão nos barramentos das subestações respectivamente, foram definidos como unitários. Assim, todas as restrições possuem o mesmo grau de importância na avaliação dos indivíduos.

A Tabela 5.2 mostra todas as possíveis combinações de estados dos dispositivos de seccionamento selecionados, destacando-se o indivíduo que representa a melhor configuração operativa da rede de interesse para a minimização do custo dos encargos de uso dos sistemas de transmissão.

\begin{tabular}{|c|c|c|c|c|c|c|}
\hline $\begin{array}{c}\text { Indivíduo } \\
c h_{1} \text { a } c h_{5} \\
\end{array}$ & $\begin{array}{c}\text { Decodificação } \\
c h_{1} \text { a } c h_{5} \\
\end{array}$ & custo $_{i}(R \$)$ & $\boldsymbol{P}_{F R}$ & $P_{T R}$ & $\boldsymbol{P}_{V}$ & $f_{\text {aval, } i}$ \\
\hline 00000 & 11010 & 502402,00 & 43750,00 & 46093,75 & 49573,86 & 0,779035 \\
\hline 00001 & 11001 & 519373,00 & 43750,00 & 29166,67 & 13636,36 & 0,825183 \\
\hline 00010 & 11010 & 502402,00 & 43750,00 & 46093,75 & 49573,86 & 0,779035 \\
\hline 00011 & 10011 & 531035,00 & 34375,00 & 2083,33 & 15909,09 & 0,857041 \\
\hline 00100 & 10110 & 499356,00 & 43750,00 & 4166,67 & 18181,82 & 0,884244 \\
\hline 00101 & 10101 & 519373,00 & 34375,00 & 2083,33 & 9090,91 & 0,885078 \\
\hline 00110 & 10110 & 499356,00 & 43750,00 & 4166,67 & 18181,82 & 0,884244 \\
\hline 00111 & 10111 & 522332,00 & 43750,00 & 2083,33 & 9090,91 & 0,866166 \\
\hline 01000 & 11010 & 502402,00 & 43750,00 & 46093,75 & 49573,86 & 0,779035 \\
\hline 01001 & 11001 & 519373,00 & 43750,00 & 29166,67 & 13636,36 & 0,825183 \\
\hline 01010 & 11010 & 502402,00 & 43750,00 & 46093,75 & 49573,86 & 0,779035 \\
\hline 01011 & 01011 & 566369,00 & 25000,00 & 47500,00 & 49494,95 & 0,726360 \\
\hline 01100 & 01110 & 502663,00 & 43750,00 & 40104,17 & 49621,21 & 0,785993 \\
\hline 01101 & 01101 & 522680,00 & 43750,00 & 29166,67 & 11363,64 & 0,823777 \\
\hline 01110 & 01110 & 502663,00 & 43750,00 & 40104,17 & 49621,21 & 0,785993 \\
\hline 01111 & 01111 & 534255,00 & 34375,00 & 4166,67 & 9090,91 & 0,859273 \\
\hline 10000 & 11010 & 502402,00 & 43750,00 & 46093,75 & 49573,86 & 0,779035 \\
\hline 10001 & 11001 & 519373,00 & 43750,00 & 29166,67 & 13636,36 & 0,825183 \\
\hline 10010 & 11010 & 502402,00 & 43750,00 & 46093,75 & 49573,86 & 0,779035 \\
\hline 10011 & 10011 & 531035,00 & 34375,00 & 2083,33 & 15909,09 & 0,857041 \\
\hline 10100 & 10110 & 499356,00 & 43750,00 & 4166,67 & 18181,82 & 0,884244 \\
\hline 10101 & 10101 & 519373,00 & 34375,00 & 2083,33 & 9090,91 & 0,885078 \\
\hline 10110 & 10110 & 499356,00 & 43750,00 & 4166,67 & 18181,82 & 0,884244 \\
\hline 10111 & 10111 & 522332,00 & 43750,00 & 2083,33 & 9090,91 & 0,866166 \\
\hline 11000 & 11010 & 502402,00 & 43750,00 & 46093,75 & 49573,86 & 0,779035 \\
\hline 11001 & 11001 & 519373,00 & 43750,00 & 29166,67 & 13636,36 & 0,825183 \\
\hline 11010 & 11010 & 502402,00 & 43750,00 & 46093,75 & 49573,86 & 0,779035 \\
\hline 11011 & 11011 & 533907,00 & 43750,00 & 2083,33 & 15909,09 & 0,839420 \\
\hline 11100 & 11110 & 499356,00 & 43750,00 & 4166,67 & 18181,82 & 0,884244 \\
\hline 11101 & 11101 & 519460,00 & 34375,00 & 0,00 & 0,00 & 0,902796 \\
\hline 11110 & 11110 & 499356,00 & 43750,00 & 4166,67 & 18181,82 & 0,884244 \\
\hline 11111 & 11111 & 528250,00 & 34375,00 & 0,00 & 0,00 & 0,888691 \\
\hline
\end{tabular}

Tabela 5.2 - Análise dos indivíduos gerados e avaliação de suas configurações 
A seguir, prossegue-se com a aplicação do algoritmo genético proposto e verifica-se o desempenho do mesmo com relação à busca da solução do problema.

A simulação pelo algoritmo genético proposto foi realizada com os seguintes parâmetros apresentados na Tabela 5.3:

\begin{tabular}{|c|c|}
\hline Parâmetro & Valor \\
\hline Número de gerações & 10 \\
\hline Número de indivíduos por geração & 50 \\
\hline Probabilidade de cruzamento & $85 \%$ \\
\hline Probabilidade de mutação & $1 \%$ \\
\hline$r_{F R}, r_{T R}$ e $r_{V}$ & 1 \\
\hline$k_{F R}, k_{T R}$ e $k_{V}$ & 50000 \\
\hline
\end{tabular}

Tabela 5.3 - Parâmetros para simulação utilizando o algoritmo genético proposto aplicado à rede de interesse ilustrada na Figura 5.2

Apesar de intensas pesquisas na área, não existe uma regra única para estipular o tamanho da população, nem mesmo para a probabilidade de aplicação dos operadores genéticos. A escolha da probabilidade de cruzamento e probabilidade de mutação é um problema complexo de otimização não-linear. Entretanto, as suas configurações são criticamente dependentes da natureza da função objetivo. A literatura menciona que as configurações adotadas em AG com representação binária utilizam usualmente a seguinte sintonia de parâmetros do AG: tamanho da população entre 30 e 200 indivíduos, probabilidade de cruzamento entre $50 \%$ e 100\% e probabilidade de mutação entre 1\% e 5\%.

O processo evolutivo convergiu para a mesma configuração simulada através do mapeamento de soluções. A Figura 5.3 ilustra a configuração operativa encontrada. De acordo com o diagnóstico gráfico do fluxo de potência observado para a rede de interesse, nota-se a inexistência de inconformidades de tensão nos barramentos das subestações ou de sobrecarregamento nos trechos das linhas de subtransmissão. Entretanto, existe uma sobrecarga em um dos transformadores de fronteira da rede estudada. Analisando os melhores 
indivíduos gerados, porém, verifica-se que todos eles apresentam essa sobrecarga, evidenciando que para esse caso não há uma solução para o problema do sobrecarregamento deste transformador.

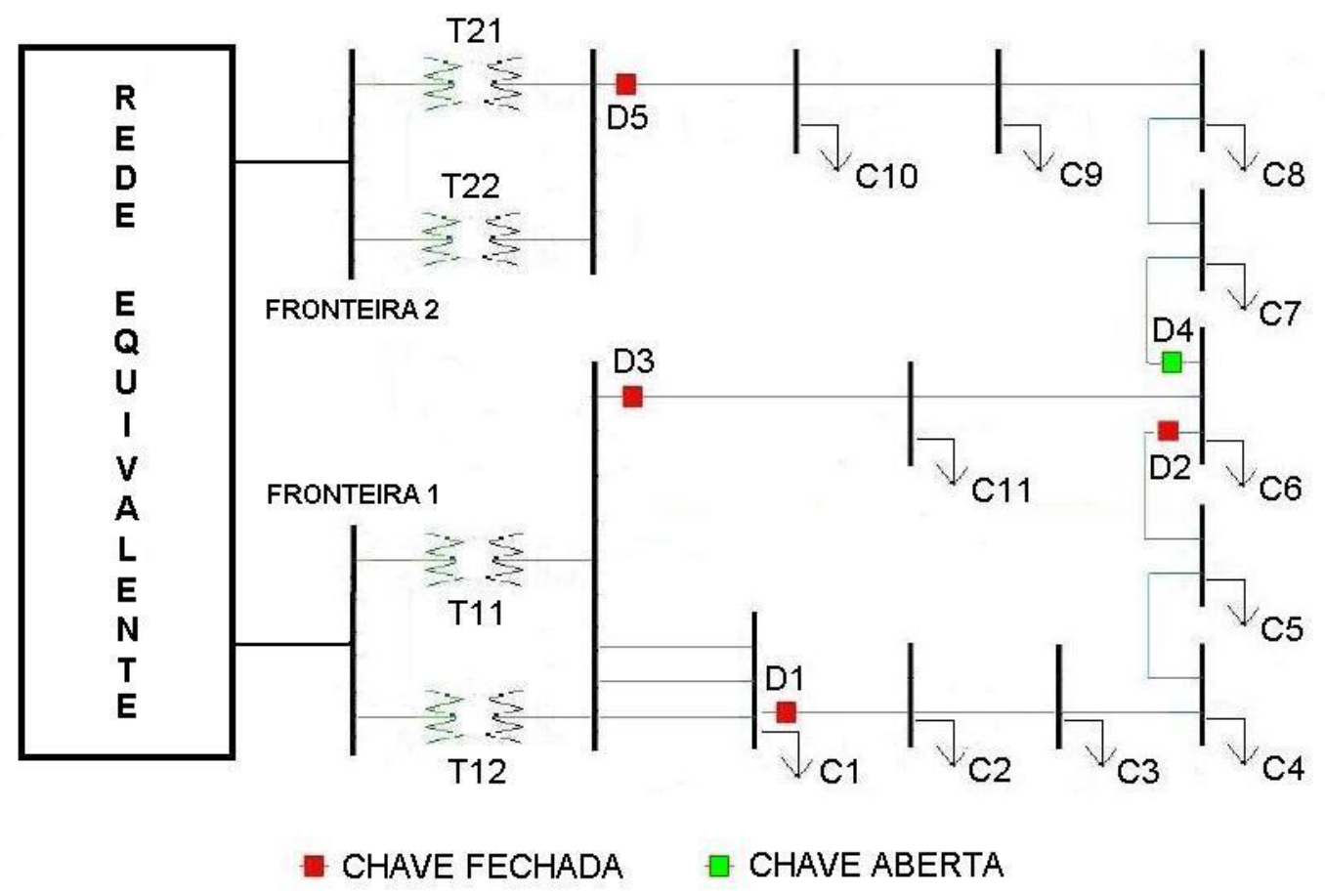

Figura 5.3 - Configuração operativa encontrada para a rede de interesse estudada

Aplica-se agora o modelo de otimização do fluxo de potência ativa de sistemas elétricos de subtransmissão em uma rede de interesse maior, contendo os mesmos dois pontos de fronteira com a Rede Básica, porém com um número maior de trechos de linhas de subtransmissão e subestações. Nela, foram selecionados estrategicamente vinte e três dispositivos de seccionamento para comporem as variáveis de controle do modelo. Para se ter uma idéia do espaço de soluções representado por este problema, o número de combinações de dispositivos de seccionamento equivale a $2^{23}=8.388 .608$ alternativas de configuração operativa de rede, considerando as redes inviáveis (rede desconexa). A Figura 5.4 ilustra o diagrama unifilar da rede de interesse e o equivalente externo a ela acoplado. 


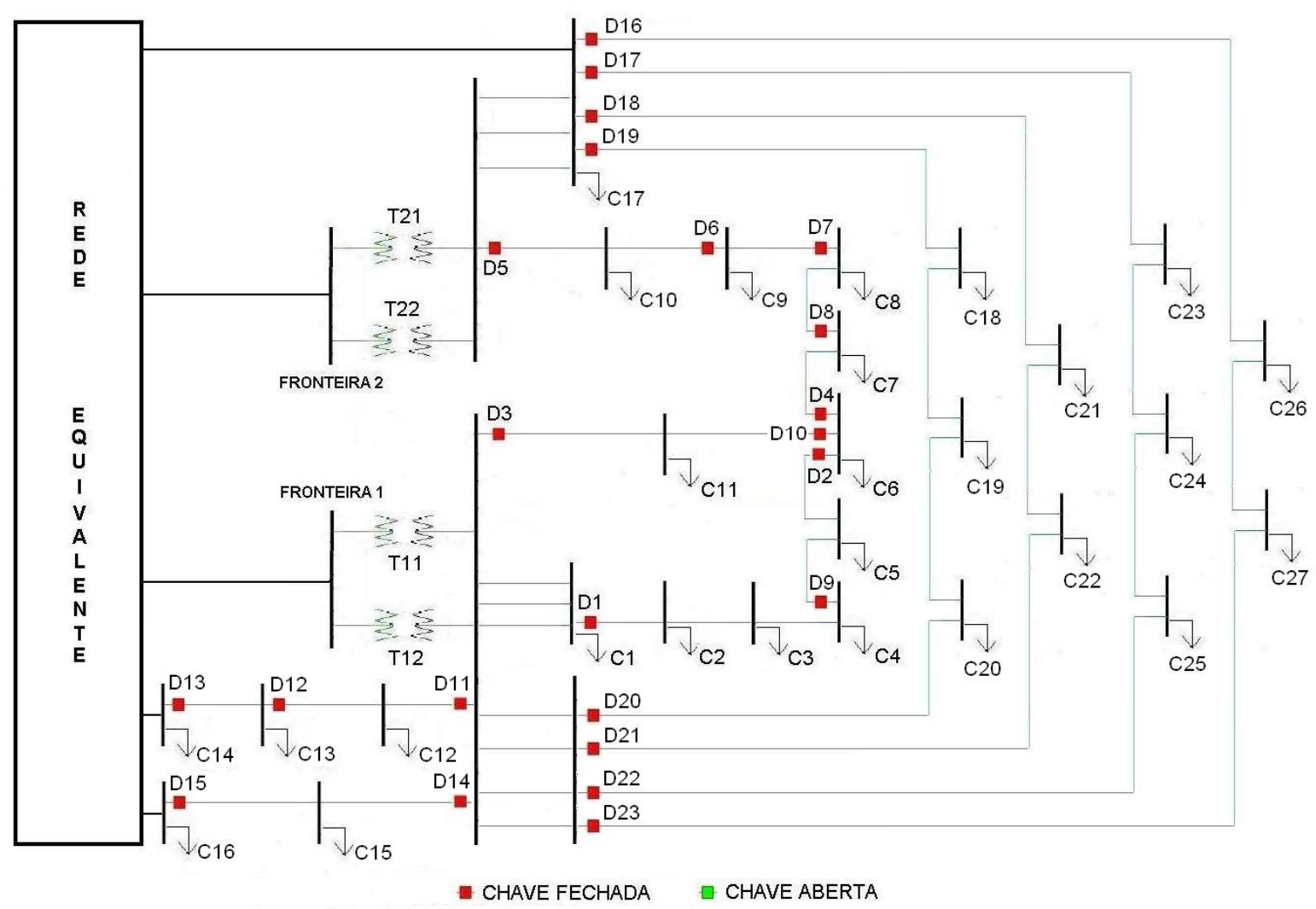

Figura 5.4 - Rede de interesse contendo dois pontos de fronteira, vinte e três dispositivos de seccionamento e equivalente externo a ela acoplado

As principais características da rede ilustrada pela Figura 5.4 estão resumidas na Tabela 5.4:

\begin{tabular}{|c|c|}
\hline Característica & Valor \\
\hline Número de pontos de fronteira & 2 \\
\hline Número de transformadores de fronteira & 4 \\
\hline Número de trechos de linhas de subtransmissão & 41 \\
\hline Número de subestações com carregamento & 27 \\
\hline
\end{tabular}

Tabela 5.4 - Resumo das principais características da rede de interesse ilustrada na Figura 5.4

De acordo com a Resolução Normativa $n^{0}$ 118, de 3 de Dezembro de 2004, da ANEEL, as tarifas de uso do sistema de transmissão de energia elétrica dos pontos de fronteira da rede de interesse foram estabelecidas em $C_{\text {fronteira }, 1}=0,087 R \$ / k W, C_{\text {fronteira }, 2}=1,523 R \$ / k W$. 
A simulação pelo algoritmo genético proposto foi realizada utilizando-se os seguintes parâmetros apresentados na Tabela 5.5:

\begin{tabular}{|c|c|}
\hline Parâmetro & Valor \\
\hline Número de gerações & 10 \\
\hline Número de indivíduos por geração & 100 \\
\hline Probabilidade de cruzamento & $85 \%$ \\
\hline Probabilidade de mutação & $1 \%$ \\
\hline$r_{F R}, r_{T R}$ e $r_{V}$ & 1 \\
\hline$k_{F R}, k_{T R}$ e $k_{V}$ & 50000 \\
\hline
\end{tabular}

Tabela 5.5 - Parâmetros para simulação utilizando o algoritmo genético proposto aplicado à rede de interesse ilustrada na Figura 5.4

O tempo de processamento do algoritmo desenvolvido para o caso analisado foi de aproximadamente 10 segundos utilizando um computador com processador Pentium IV $2.80 \mathrm{GHz}$.

A Figura 5.5 ilustra a configuração operativa obtida para a nova rede de interesse estudada. 


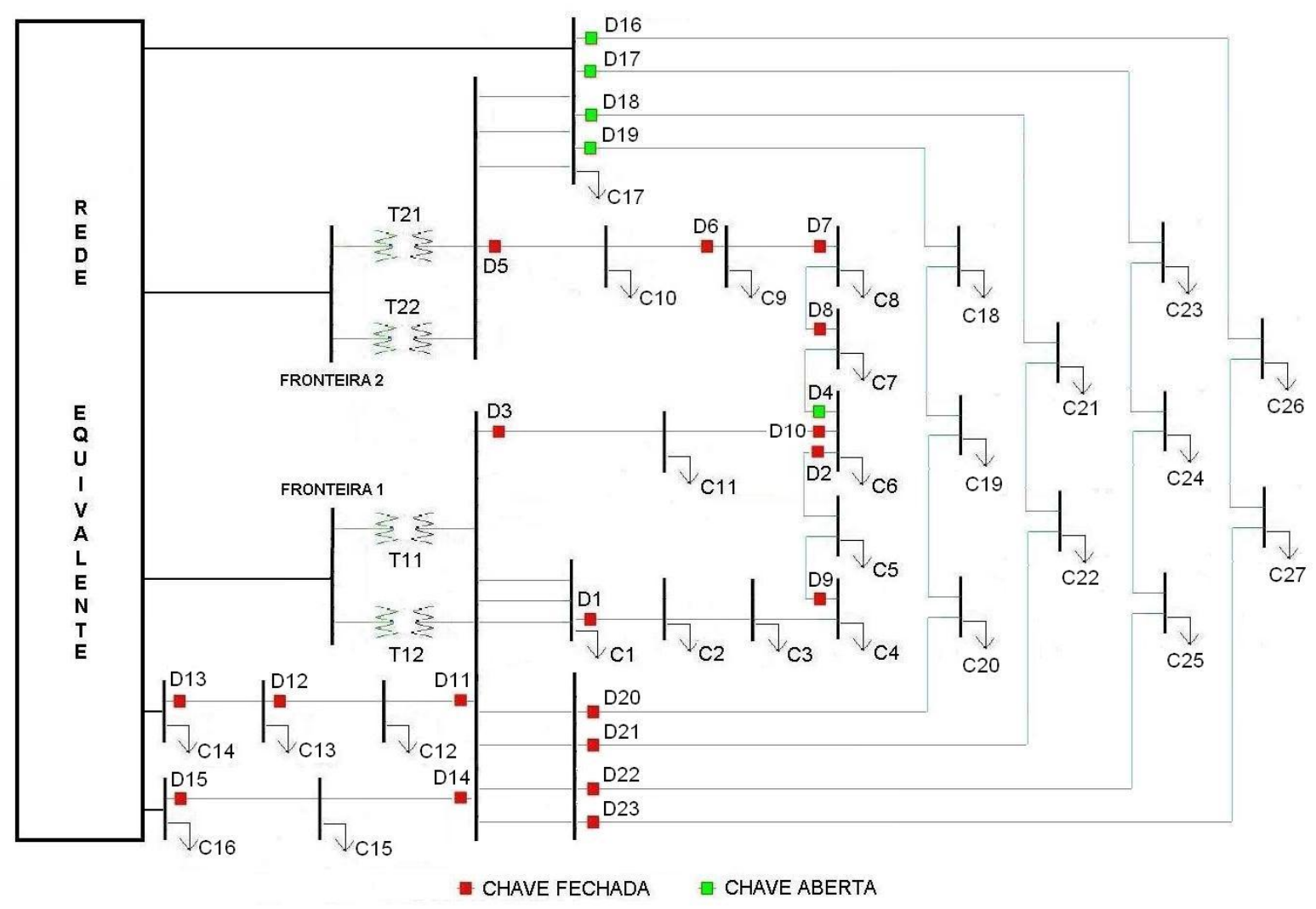

Figura 5.5 - Configuração operativa encontrada para a nova rede de interesse estudada

A Figura 5.6 exibe o gráfico da evolução do valor da função de avaliação do melhor indivíduo a cada geração, até a sua convergência na $4^{\mathrm{a}}$ geração.

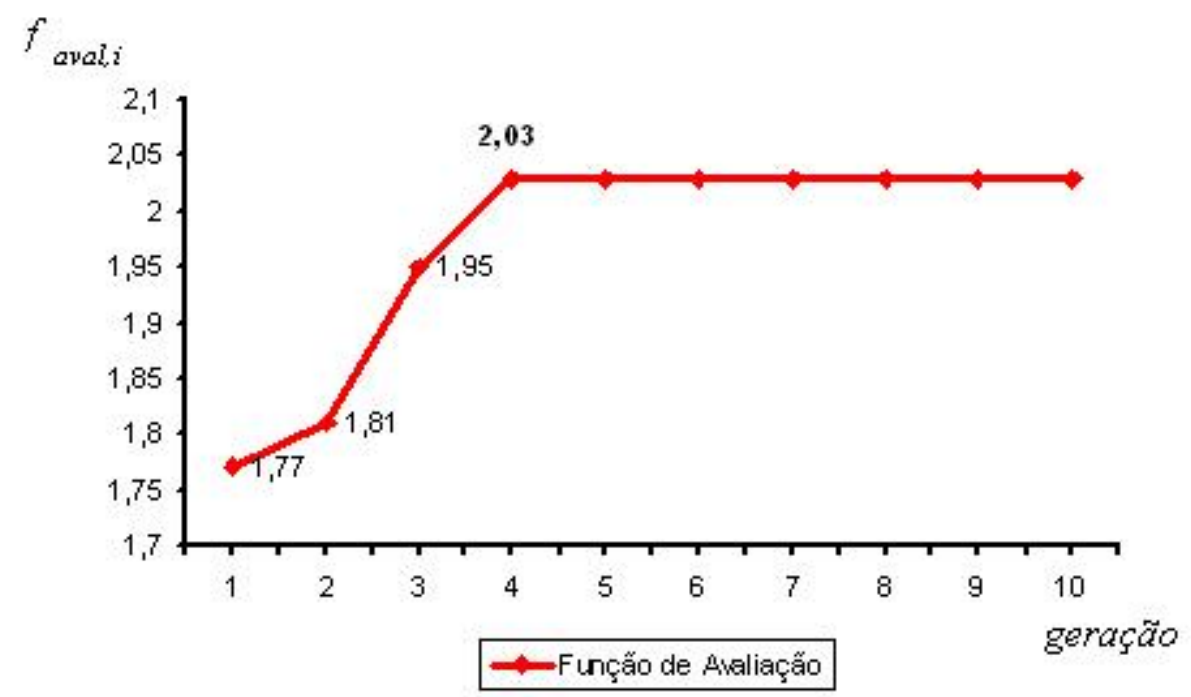


Figura 5.6 - Evolução da função de avaliação e do custo dos encargos de uso dos sistemas de transmissão dos melhores indivíduos de cada geração

A Figura 5.7 exibe o custo dos encargos de uso dos sistemas de transmissão para as redes representadas pelos melhores indivíduos de cada geração.

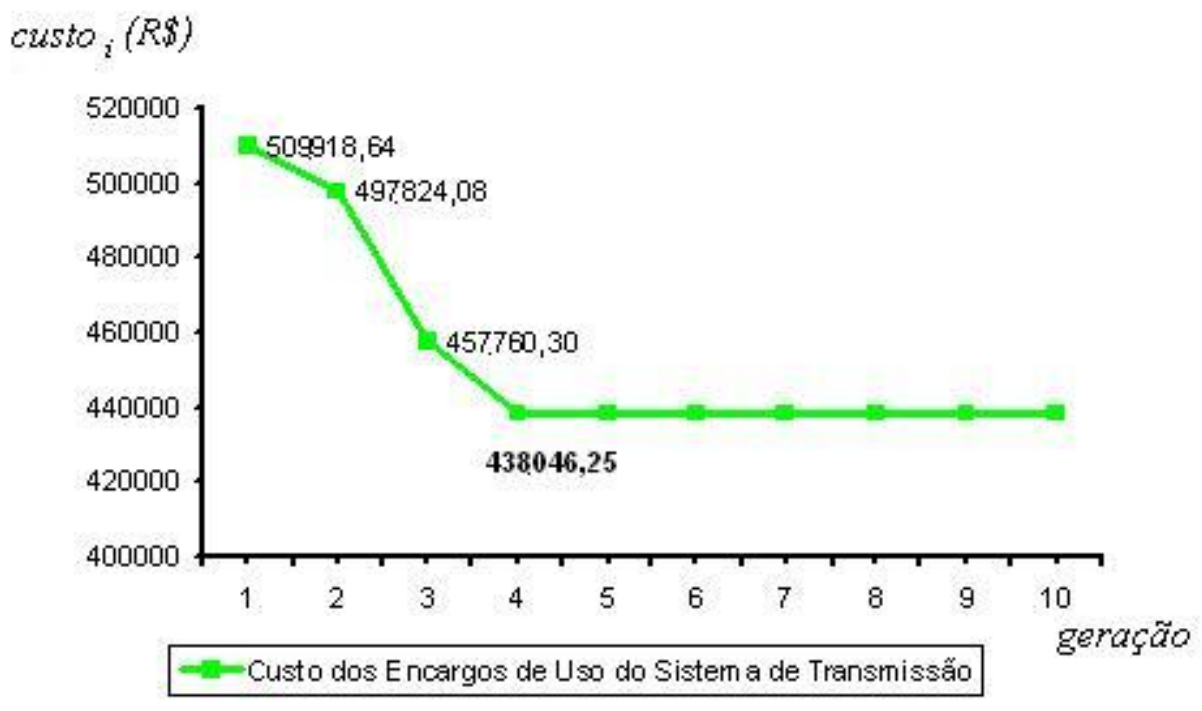

Figura 5.7 - Evolução do custo dos encargos de uso dos sistemas de transmissão dos melhores indivíduos de cada geração

A melhor solução encontrada pelo algoritmo corresponde a um custo dos encargos de uso dos sistemas de transmissão de $\mathrm{R} \$ 438.046,25$. Esse valor representa um custo $20 \%$ menor em relação à configuração que considera todos dispositivos fechados. A partir dessa solução, percebe-se uma tendência a alimentar as subestações pelo ponto de fronteira de menor custo, uma alternativa óbvia quando se deseja minimizar esse custo, porém, mantendo os níveis de tensão e carregamento dentro das mesmas faixas operativas obtidas pela configuração que considera todos os dispositivos fechados. Portanto, o algoritmo genético desenvolvido buscou uma solução viável tecnicamente e de custo otimizado. 


\subsection{Otimização do Fluxo de Potência Reativa de um Sistema Elétrico de}

\section{Subtransmissão}

Dando continuidade ao procedimento de otimização do fluxo de potência em sistemas elétricos de subtransmissão, o próximo passo é a otimização do fluxo de potência reativa da rede de interesse que está sendo utilizada para essa aplicação.

Considerando a configuração de rede obtida com a otimização do fluxo de potência ativa da rede de interesse, avaliam-se os indivíduos a partir da variação do módulo da tensão dos barramentos de fronteira do sistema, os quais compõem as variáveis de controle do modelo. O módulo da tensão dos barramentos de fronteira pode variar dentro de uma faixa operativa estabelecida. A validação do modelo procede de forma semelhante a da otimização da potência ativa, baseada na análise da função de avaliação a partir da simulação discreta dos indivíduos possíveis de serem gerados e na comparação dos resultados observados com o resultado alcançado com a aplicação da estratégia evolutiva desenvolvida de acordo com o modelo proposto.

De acordo com a configuração ilustrada na Figura 5.3, a rede de interesse não está com seus pontos de fronteira conectados em anel e, portanto, a variação dos módulos da tensão nos barramentos de fronteira do sistema não exercerão influência um sobre o outro. Isto quer dizer que a otimização do fluxo de potência reativa tratará do problema como se fossem dois sistemas radiais em que a solução tende a ser estabelecida em um ponto de operação com os valores de tensão mais elevados possíveis. Esses valores serão, geralmente, os limites superiores das faixas operativas de tensão estabelecidas para cada ponto de fronteira, a menos que a restrição de carregamento dos transformadores seja violada. Desta forma, a situação encontrada, por se tratar de um problema simples, possui uma resposta óbvia, do ponto de 
vista de melhor condição operativa do sistema, e não é preciso de um mecanismo de busca para encontrar a melhor solução.

Para análise e validação do modelo proposto de otimização do fluxo de potência reativa, apresenta-se um outro caso contendo a mesma rede de interesse em estudo, porém, define-se uma configuração operativa da rede em que os dois pontos de fronteira estão conectados em anel, tornando o problema um pouco mais complexo. A Figura 5.8 mostra o diagrama unifilar da rede de interesse e o equivalente externo a ela acoplado, onde se define uma nova configuração operativa para realizar o estudo.

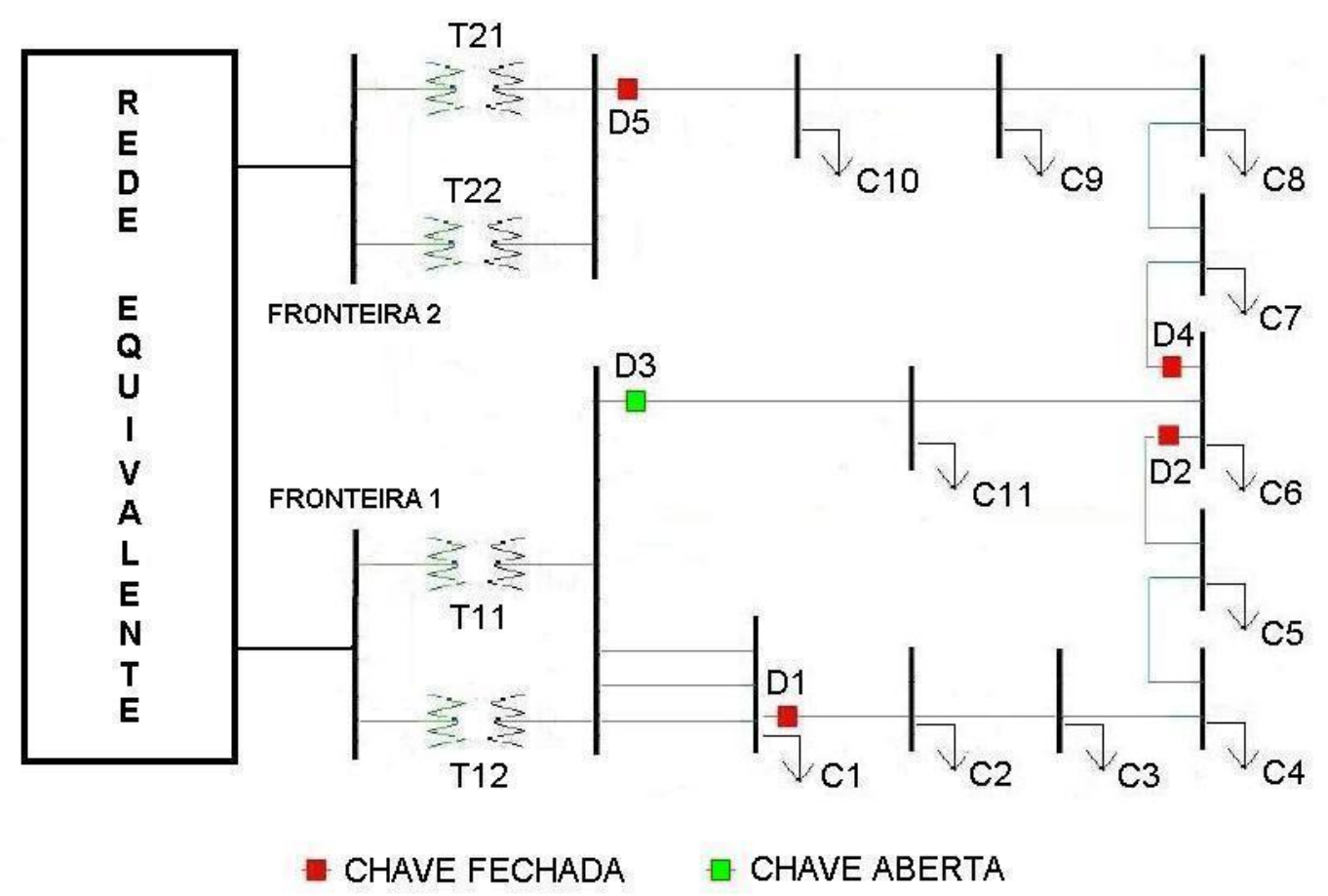

Figura 5.8 - Rede de interesse configurada para o estudo e equivalente externo a ela acoplada para a minimização do custo dos encargos de uso dos sistemas de transmissão

As tarifas de uso do sistema de transmissão de energia elétrica dos pontos de fronteira foram estabelecidas em $C_{\text {fronteira }, 1}=0,087 R \$ / k W$ e $C_{\text {fronteira }, 2}=1,523 R \$ / k W$, conforme visto anteriormente. 
Emprega-se um valor arbitrário, por exemplo, custo $_{\text {ref }}=R \$ 500.000,00$ apenas para permitir a localização do indivíduo que represente o menor valor de custo para a rede de interesse estudada.

Os coeficientes de penalização, $r_{F R}, r_{T R}$ e $r_{V}$, aplicados a cada fator de penalização para as transgressões de carregamento dos transformadores de fronteira, de carregamento dos trechos das linhas de subtransmissão e de nível de tensão nos barramentos das subestações respectivamente, foram definidos como unitários. Assim, todas as restrições possuem o mesmo grau de importância na avaliação dos indivíduos.

Estabelece-se que os valores de tensão dos dois barramentos de fronteira podem variar dentro de uma faixa operativa entre 1,000 pu e 1,030 pu. Computacionalmente, o espaço de soluções a ser mapeado não pode ser obtido de forma contínua, sendo necessária a discretização dos valores de tensão dos barramentos de fronteira em intervalos conhecidos, em pu (por unidade). Variando-se em passos discretos de 0,030 pu dentro das faixas operativas, simulamse o fluxo de potência de todas as combinações desses dispositivos e avaliam-se segundo a função de avaliação para o custo dos encargos de uso dos sistemas de transmissão.

A Figura 5.9 ilustra a representação gráfica da função de avaliação obtida no espaço de soluções limitado pelas faixas operativas de tensão dos barramentos de fronteira. 


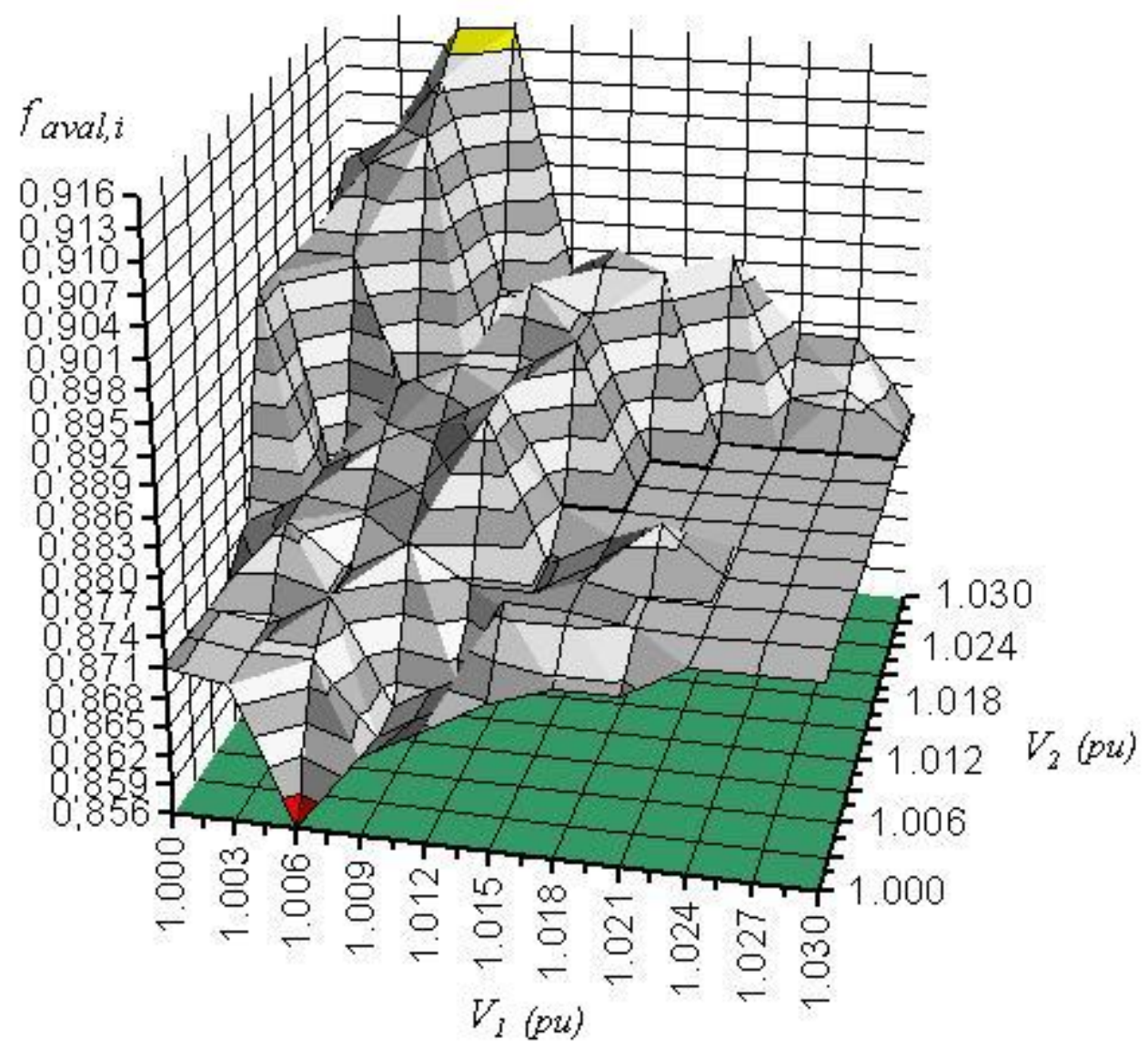

Figura 5.9 - Representação gráfica da função de avaliação para minimização do custo dos encargos de uso dos sistemas de transmissão

Por busca simples em uma matriz de pontos, pode-se determinar quais os valores de tensão dos barramentos das fronteiras 1 e 2, que minimizam o custo dos encargos de uso dos sistemas de transmissão. A Tabela 5.6 apresenta os valores que definem a configuração operativa otimizada do fluxo de potência reativa na rede de interesse:

\begin{tabular}{|c|c|}
\hline Fronteira & Tensão de operação (pu) \\
\hline Fronteira 1 & 1,009 \\
\hline Fronteira 2 & 1,030 \\
\hline
\end{tabular}

Tabela 5.6 - Solução do problema de otimização do fluxo de potência reativa para minimização do custo dos encargos de uso dos sistemas de transmissão 
A seguir da análise inicial dos resultados obtidos a partir do mapeamento das soluções e da avaliação dos indivíduos, prossegue-se com a aplicação da estratégia evolutiva proposta e verifica-se o desempenho do mesmo com relação à busca da solução do problema.

A simulação pela estratégia evolutiva proposta foi realizada com os seguintes parâmetros apresentados na Tabela 5.7:

\begin{tabular}{|c|c|}
\hline Parâmetro & Valor \\
\hline Número de gerações & 100 \\
\hline Número de indivíduos por geração & 10 \\
\hline Mutações por indivíduo & 10 \\
\hline Probabilidade de cruzamento & $50 \%$ \\
\hline Probabilidade de mutações & $100 \%$ \\
\hline Idade máxima dos indivíduos & 5 gerações \\
\hline$r_{F R}, r_{T R}$ e $r_{V}$ & 1 \\
\hline$k_{F R}, k_{T R}$ e $k_{V}$ & 50000 \\
\hline
\end{tabular}

Tabela 5.7 - Parâmetros para simulação utilizando a estratégia evolutiva proposta aplicada à rede de interesse ilustrada na Figura 5.6

Da mesma forma que no AG, a sintonia dos parâmetros do EE segue uma configuração dentro de faixas usualmente adotadas pela literatura relacionada a esse tema.

Foi desenvolvido pelo ENERQ-USP um módulo computacional de otimização por Estratégia Evolutiva, de acordo com o modelo proposto. Este módulo foi adaptado para o caso da otimização do fluxo de potência reativa e utilizado para verificação e visualização dos resultados obtidos.

Diferente do caso da otimização do fluxo de potência ativa, em que o módulo computacional desenvolvido integra-se à ferramenta de cálculo do fluxo de potência para proceder com a avaliação dos indivíduos, este módulo é alimentado diretamente com os resultados da função de avaliação referentes aos valores discretizados dos níveis de tensão dos barramentos de fronteira. A partir de valores quaisquer de níveis de tensão dos barramentos de fronteira, o módulo realiza um conjunto de duas interpolações e uma média aritmética utilizando-se os 
dados discretizados ao redor ponto de operação solicitado e retorna um valor interpolado para a função de avaliação naquele ponto.

A Figura 5.10 ilustra o módulo computacional adaptado para a otimização do fluxo de potência reativa por EE.

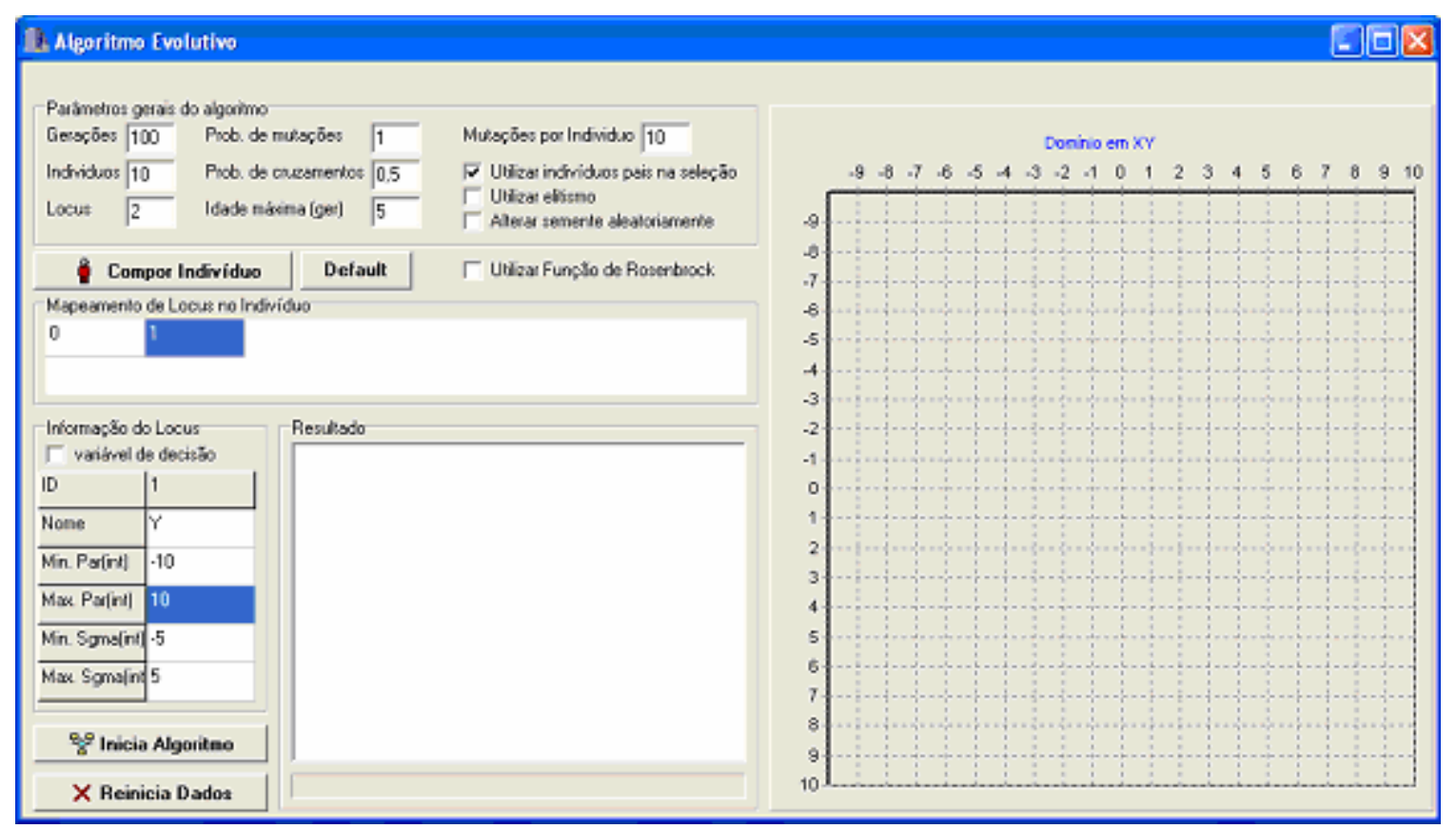

Figura 5.10 - Módulo computacional de EE adaptado para aplicação ao problema de otimização do fluxo de potência reativa de sistemas elétricos de subtransmissão

Através das Figuras 5.11 a 5.14, observa-se a cada geração ilustrada a evolução do algoritmo pela representação das populações originais e suas variações ocasionadas por recombinações e mutações. Lembrando que para este caso específico de representação, cada indivíduo tem correspondência direta com um ponto do espaço de possíveis soluções, nas figuras representadas em vermelho. 


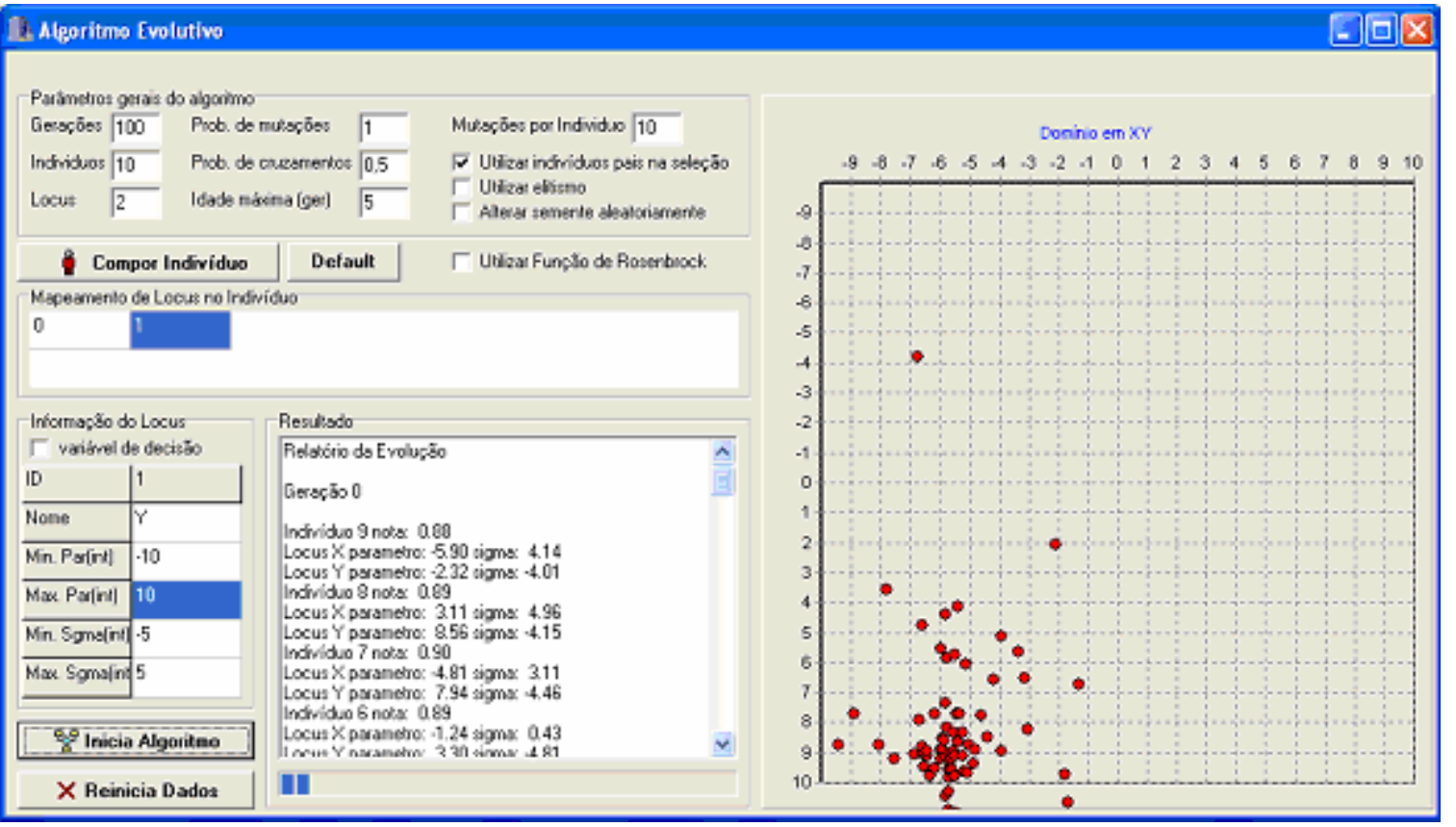

Figura 5.11 - Visualização gráfica da evolução dos indivíduos no início do processo

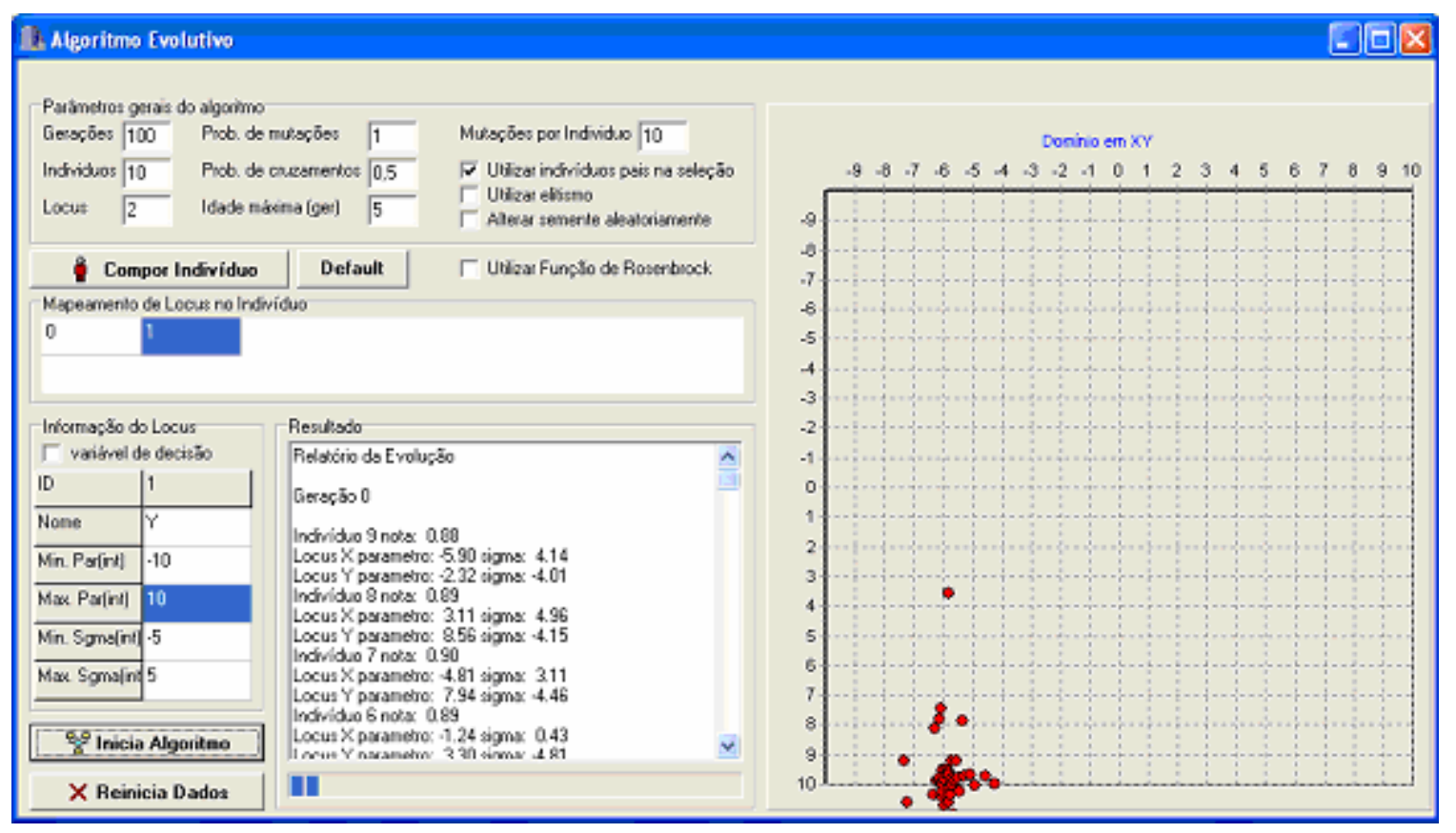

Figura 5.12 - Visualização gráfica da evolução dos indivíduos durante o processo 


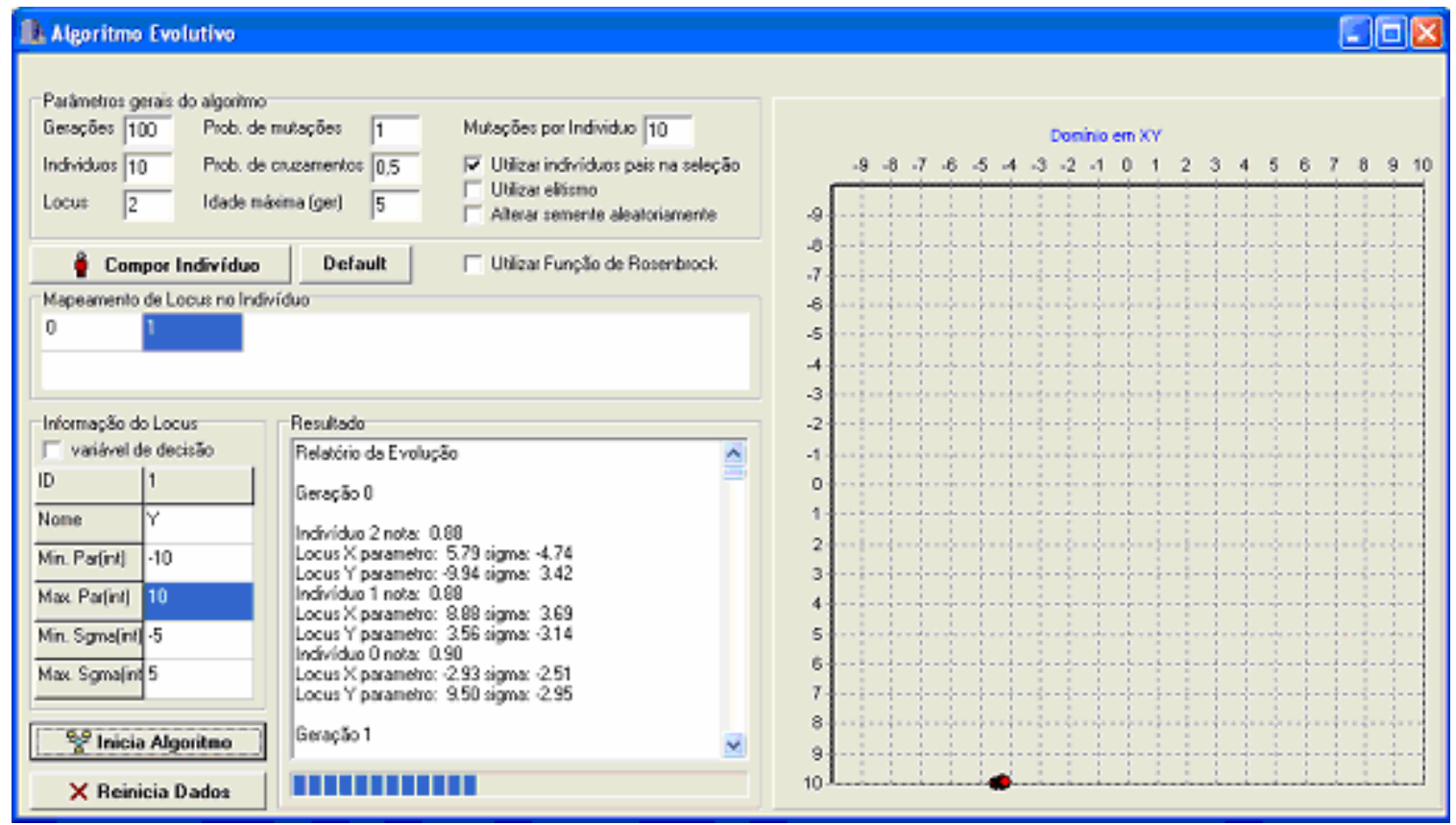

Figura 5.13 - Visualização gráfica da evolução dos indivíduos próximo à convergência do processo

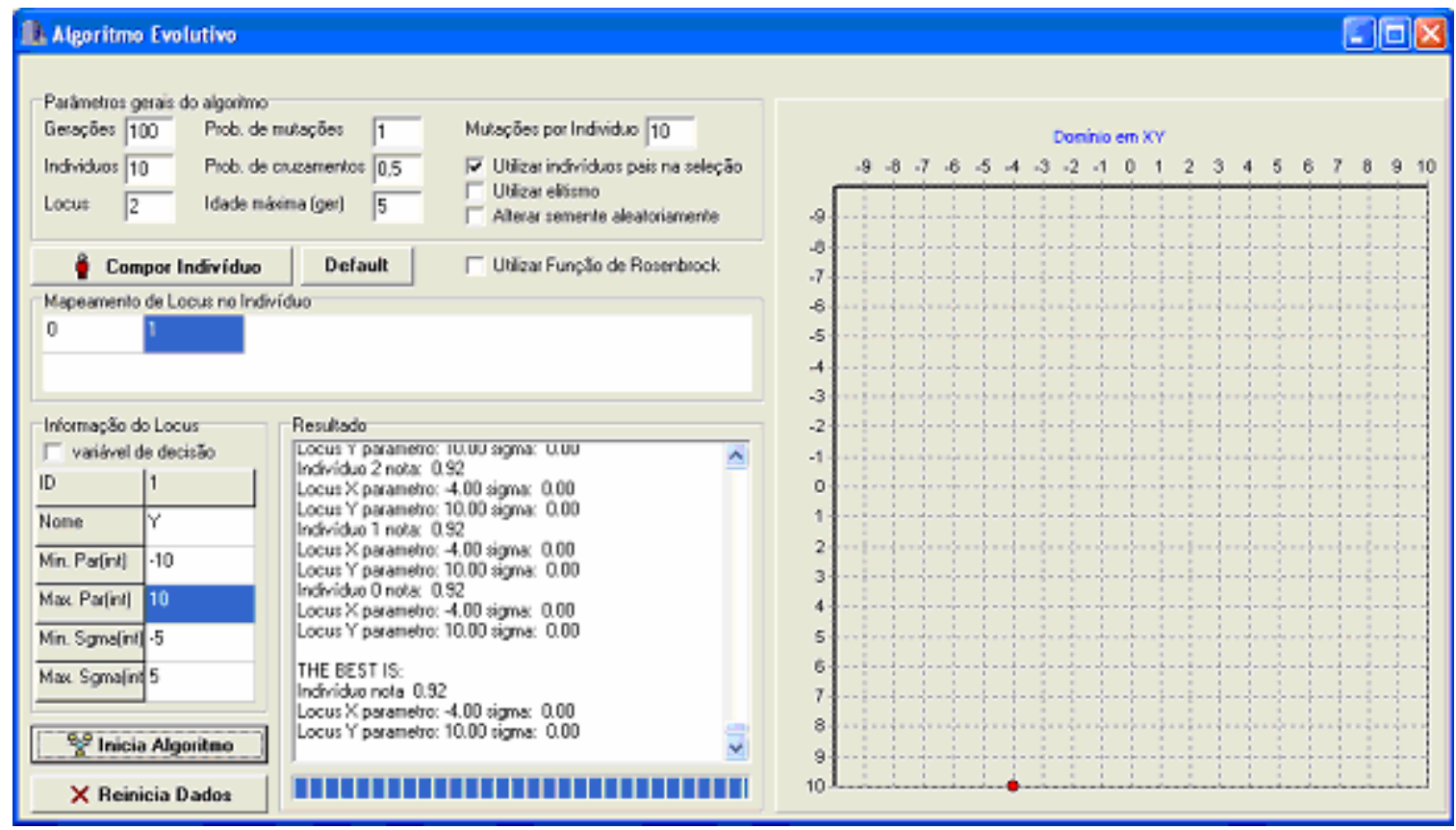

Figura 5.14 - Visualização gráfica da evolução dos indivíduos no final do processo

Nota-se na primeira geração o posicionamento dos indivíduos de forma aleatória, proporcionado pelo sorteio inicial da população. Após algumas gerações, pode-se perceber que os indivíduos selecionados estão cada vez mais próximos da solução, e que os passos de mutação vão gradualmente convergindo para valores nulos. 
O processo evolutivo convergiu para a solução observada através do mapeamento de soluções. Como o módulo computacional foi adaptado para otimizar o fluxo de potência reativa, o quadro de visualização dos resultados na Figura 5.14 mostra como solução do problema a coordenada $(-4,10)$, porém, esta representa corretamente a mesma solução da definida na Tabela 5.6.

A interpolação matemática a partir de uma matriz de dados discretizada da função de avaliação dos indivíduos mostrou-se eficaz no processo de otimização de problemas com duas variáveis contínuas. Os cálculos recriaram um espaço de soluções contínuo e próximo ao real, de forma que o processo convergiu para o resultado esperado. A vantagem desse tipo de aplicação está na rapidez com que a resposta da função de avaliação é obtida em relação ao procedimento de cálculo do fluxo de potência para cada solução, utilizado na otimização do fluxo de potência ativa.

A partir de três ou mais pontos de fronteira, pode ser apresentada dificuldades na utilização da interpolação matemática como meio de obtenção da função de avaliação dos indivíduos, pois o espaço de soluções torna-se mais complexo sendo necessário preenchê-lo com uma matriz de dados bem maior. Para esses casos, uma alternativa viável e mais robusta é a aplicação de uma rede neural. 


\section{CONCLUSÕES}

Os objetivos desta dissertação foram plenamente alcançados e os resultados obtidos com o uso das técnicas de algoritmos genéticos e estratégias evolutivas foram bem sucedidos. Esses resultados mostram o grande potencial de aplicação dessas técnicas na busca de soluções otimizadas de configuração operativa em redes de subtransmissão de energia elétrica.

Os algoritmos desenvolvidos e a metodologia proposta foram modelados de acordo com os problemas envolvidos com a otimização do fluxo de potência em sistemas elétricos de subtransmissão. A metodologia descrita é uma forma eficaz e lógica de se realizar a otimização do fluxo de potência em sistemas elétricos de subtransmissão utilizando os dois algoritmos da forma como foram concebidos. A vantagem de se ter um algoritmo para cada problema descrito está na flexibilidade de se poder realizar apenas uma otimização, ou a do fluxo de potência ativa ou a do fluxo de potência reativa, quando desejado. A metodologia proposta trata desses dois problemas seqüencialmente, mas nada impede que essa ordem seja invertida, ou seja, dado um certo nível de tensão pré-estabelecido nos barramentos de fronteira, proceder com a busca de uma configuração de rede que satisfaça aos objetivos requeridos.

Com relação ao objetivo estudado, a minimização do custo dos encargos de uso dos sistemas de transmissão, apenas uma das parcelas definida para esse encargo foi utilizada na função de avaliação dos algoritmos, já que a otimização foi concebida para um único instante de carga. É possível desenvolver uma metodologia que utilize os mesmos algoritmos, porém que realize a otimização de forma a abranger mais de um instante de carga, por exemplo, a carga nos períodos de ponta e fora de ponta. Desta forma, as duas parcelas do encargo seriam consideradas na otimização do objetivo estudado. 
Através das aplicações dos modelos de otimização do fluxo de potência ativa e reativa em um sistema elétrico de subtransmissão real, pôde-se analisar e comprovar a eficácia dos algoritmos na busca das soluções otimizadas do problema. Os resultados obtidos mostram que os problemas foram adequadamente modelados. Sendo assim, os modelos desenvolvidos estão aptos a serem utilizados para outros objetivos de interesse ou em outras aplicações que requerem a otimização do fluxo de potência de sistemas elétricos de subtransmissão, do ponto de vista do planejamento da operação elétrica de curto e médio prazo. As aplicações e análises foram baseadas na otimização de um único objetivo, mas a metodologia está preparada para contemplar os múltiplos objetivos do planejamento operacional, bastando para isso alterar a função de avaliação dos indivíduos para os objetivos pretendidos.

A metodologia de otimização do fluxo de potência em sistemas elétricos de subtransmissão utilizando algoritmos evolutivos complementa os estudos e análises do planejamento da operação elétrica de curto e médio prazo. Nesses estudos, são realizadas simulações e análises de fluxo de potência com o objetivo de avaliar o desempenho do sistema nos patamares de carga pesada, média, leve e mínima, em condição normal de operação e sob contingências, verificando o nível de tensão e carregamento em linhas de transmissão e equipamentos. Os estudos de fluxo de potência são efetuados para verificar o comportamento do sistema em regime permanente e tem como objetivo avaliar se os níveis de tensão nos barramentos e os carregamentos nas linhas, transformadores e demais componentes da rede de transmissão, para cada uma das configurações do sistema previstas no horizonte em análise e para diversas condições geração-carga atendem aos critérios estabelecidos nos Procedimentos de Rede. Para avaliar o desempenho do sistema sob contingências, os estudos de fluxo de potência contemplam a análise de perdas e de indisponibilidades de linhas, transformadores e outros equipamentos do sistema elétrico. $\mathrm{Na}$ análise de perdas é simulado o desempenho elétrico imediatamente após o desligamento forçado de elementos do sistema, antes da tomada de 
medidas corretivas. Na análise de indisponibilidades, é simulado o desempenho elétrico num momento posterior, depois de um intervalo de tempo no qual sejam viáveis ações corretivas, para restabelecer o atendimento aos critérios de desempenho na nova condição do sistema. Entre estas se refere o remanejamento de carga, desligamentos de circuitos, abertura de barramentos e chaveamentos de capacitores e/ou reatores. Em todos esses casos, os modelos desenvolvidos podem auxiliar o planejamento operacional de curto e médio prazo na definição da melhor configuração operativa de sistemas elétricos de subtransmissão. Outra aplicação, mais aprimorada, é a utilização dos modelos para a busca de uma seqüência otimizada de manobras em caso de situações de emergência, de forma que o novo estado operativo do sistema seja o mais favorável possível, mantendo os padrões de qualidade de fornecimento de energia elétrica dos consumidores a ele conectado.

\section{Tópicos para Ulterior Desenvolvimento}

Dando continuidade ao desenvolvimento de estudos na área da otimização de sistemas elétricos de subtransmissão, o próximo passo é a aplicação da metodologia elaborada visando alcançar mais de um objetivo do planejamento operacional. Deste modo, pode-se analisar o desempenho dos algoritmos com o aumento da complexidade do problema, além de possibilitar a verificação dos resultados obtidos com a variação das ponderações de suas funções objetivo.

Para o aprimoramento da metodologia elaborada para a otimização do fluxo de potência em sistemas elétricos de subtransmissão, sugere-se o desenvolvimento de um modelo de otimização que opere com um único algoritmo de busca da solução para o mesmo problema, capaz de tratar tanto variáveis discretas (binárias) quanto contínuas. Este modelo realiza a otimização do fluxo de potência ativa e reativa simultaneamente, podendo obter resultados 
mais precisos para a configuração operativa de um sistema elétrico de subtransmissão analisado.

Uma análise interessante utilizando o modelo de otimização do fluxo de potência ativa desenvolvido é a aplicação de algumas variantes dos operadores genéticos de seleção, cruzamento e mutação ao algoritmo desse modelo e avaliar o desempenho de cada alternativa na busca da solução do problema. Ao empregar diferentes parametrizações ao algoritmo, é possível melhorar a robustez dos resultados, isto é, a eficiência do algoritmo em localizar respostas otimizadas, além de diminuir o tempo de processamento do mesmo.

Por fim, outro aprimoramento viável, neste caso para o modelo de otimização do fluxo de potência reativa desenvolvido, é a substituição do módulo computacional de interpolação da função de avaliação dos indivíduos por uma rede neural. A rede neural é um instrumento sofisticado, capaz de fornecer respostas mais precisas que o interpolador desenvolvido. Ela é muito interessante para aplicações do modelo em sistemas que contenham mais que dois pontos de fronteira, pois não há necessidade de alimentar o módulo computacional com todas as soluções discretizadas pertencentes ao espaço de soluções analisado. Por serem rápidas em suas respostas, as redes neurais são muito utilizadas, principalmente, em aplicações online, onde se requer tempos de respostas bastante rápidos para as soluções de problemas. Assim, o estudo das redes neurais aplicadas à otimização do fluxo de potência em sistemas elétricos de subtransmissão é de grande importância para o enriquecimento da metodologia desenvolvida. 


\section{REFERÊNCIAS}

[1] FERreirA, A. B. H. Dicionário Aurélio Básico da Língua Portuguesa. $1^{\text {a }}$ Edição. Rio de Janeiro: Nova Fronteira, 2003. 704p.

[2] NOVAES, A. G. Métodos de Otimização - Aplicação aos Transportes. São Paulo: Edgard Blücher Ltda., 1978.

[3] WOLPERT, D. H.; MACREADY, W. G. No Free Lunch Theorems for Optimization. IEEE Transactions on Evolutionary Computation, 1997.

[4] OLIVEIRA, C. C. B. Configuração de Redes de Distribuição de Energia Elétrica com Múltiplos Objetivos e Incertezas Através de Procedimentos Heurísticos. 1997. Tese (Doutorado em Engenharia Elétrica) - Escola Politécnica, Universidade de São Paulo, 1997.

[5] DARWIN, C. R. The Origin of Species. Nova Edição. Nova Iorque: Gramercy Books, 1995. 544p.

[6] PALAZZO, L.A.M.; CASTILHO, J.M.V. Algoritmos para Computação Evolutiva. Pelotas: Universidade Católica de Pelotas, 1997. 12 p. (Relatório Técnico do Grupo de Pesquisa em Inteligência Artificial).

[7] OPERADOR NACIONAL DO SISTEMA. Procedimentos de rede. Rio de Janeiro, 2001. Disponível em: <http://www.ons.org.br>. Acesso em ago. 2006.

[8] BENTO, E. P. Algoritmos Genéticos e suas Variantes na Solução de Problemas de Minimização de Perdas em Redes de Distribuição. 2004. 106f. Dissertação (Mestrado em Engenharia Elétrica) - Escola Politécnica, Universidade de São Paulo, São Paulo, 2004.

[9] HAGE, F. S. E. Desenvolvimento e Aplicação de um Algoritmo Evolutivo para a Otimização de Unidades de Geração Distribuída em Redes de Distribuição de Energia Elétrica. 2004. 114f. Dissertação (Mestrado em Engenharia Elétrica) - Escola Politécnica, Universidade de São Paulo, São Paulo, 2004.

[10] KAGAN, N. Configuração de Redes de Distribuição Através de Algoritmos Genéticos e Tomada de Decisão Fuzzy. 1999. Tese (Livre Docência) - Escola Politécnica, Universidade de São Paulo, São Paulo, 1999. 
[11] AGÊNCIA NACIONAL DE ENERGIA ELÉTRICA. Estabelece os critérios para a composição da Rede Básica do Sistema Interligado Nacional e dá outras providências. Resolução $\mathbf{n}^{\mathbf{0}}$ 67, de 8 de Junho de 2004. Brasília, 2004. Disponível em: $<$ http://www.aneel.gov.br>. Acesso em: ago. 2006.

[12] OLIVEIRA, C. C. B.; SCHMIDT, H. P.; KAGAN, N.; ROBBA, E. J. Introdução a Sistemas de Potência. São Paulo: Edgard Blücher Ltda., 1996.

[13] STAGG, G. W.; EL-ABIAD, A. H. Computer Methods in Power System Analysis. Nova Iorque: McGraw-Hill, 1968.

[14] HOLLAND, J. H. Adaptation in natural and artifcial systems. The University of Michigan Press, Ann Arbor, 1975.

[15] JONG, K. An analysis of the behavior of a class of genetic adaptive systems. Tese de PhD: University of Michigan, 1975.

[16] GOLDBERG, D. E. Genetic Algorithms in Search, Optimization, and Machine Learning. Reading, Massachusetts: Addison-Wesley Publishing Company, Inc. USA, 1989. $412 \mathrm{p}$.

[17] BÄCK, T. Optimal mutation rates in Genetic search. Proceedings of the $5^{\text {th }}$ International Conference on Genetic Algorithms, Págs 2 a 8, San Mateo, USA, 1993.

[18] BÄCK, T.; FOGEL, D. B.; MICHALEWICZ, Z. Handbook of Evolutionary Computation. Bristol, Philadelphia: Oxford University Press and Institute of Physics Publishing. USA, 1997. 988 p.

[19] MIRANDA, V.; SRINIVASAN, D.; PROENÇA, L. M. Evolutionary Computation in Power Systems. Proceedings of PSCC96, Agosto de 1996, Dresden, Alemanha e “Electrical Power \& Energy Systems”, Vol. 20, no. 2, Elsevier Science Ltd., Inglaterra.

[20] SRINIVASAN, D.; WEN, F.; CHANG, C. S.; LIEW, A. C. A survey on Evolutionary Computation to Power Systems. Dept. of Electrical Engeneering, National University of Singapore (0-7803-3115-X/96, IEEE). 
[21] KAGAN, N.; OLIVEIRA, C. C. B.; GUARALDO, J.C.; HAGE, F. S. E.; KAGAN, H.; MIGUEL FILHO, M. Aplicação de Algoritmos Genéticos na Reconfiguração Automática de Redes de Distribuição Primária em Estado de Contingência. São Paulo: Escola Politécnica da Universidade de São Paulo, 2004. 6p. (Artigo Técnico do Centro de Pesquisa em Regulação e Qualidade de Energia).

[22] GALLEGO, R. A.; MONTICELLI, A.; ROMERO, R. Transmission System Expansion Planning by an Extended Genetic Algorithm. IEEE Proc. Gener. Transm. Distrib., Vol.145, no. 3, May 1998.

[23] AGÊNCIA NACIONAL DE ENERGIA ELÉTRICA. Estabelece as condições gerais de contratação do acesso, compreendendo o uso e a conexão, aos sistemas de transmissão e distribuição de energia elétrica. Resolução no 281, de $1^{\circ}$ de Outubro de 1999. Brasília, 1999. Disponível em: <http://www.aneel.gov.br>. Acesso em: ago. 2006.

[24] AGÊNCIA NACIONAL DE ENERGIA ELÉTRICA. Estabelece de forma atualizada e consolidada, as disposições relativas à conformidade dos níveis de tensão de energia elétrica em regime permanente. Resolução no $\mathbf{n}^{\mathbf{5} 05}$, de 26 de Novembro de 2001. Brasília, 2001. Disponível em: <http://www.aneel.gov.br>. Acesso em: ago. 2006.

[25] RECHENBERG, I. Evolutionsstrategie: optimierung technicher systeme nach prinzipien der biologischen evolution. Stuttgart, Frommann-Holzboog, 1973.

[26] SCHWEFEL, H. P. Numerical optimization of computer models. Nova Iorque: John Wiley \& Sons, 1981.

[27] SARAVANAN, N.; FOGEL, D. B. An empirical comparison of methods for correlated mutations under self-adaptation. In "Proceedings of $5^{\text {th }}$ Annual Conference on Evolutionary Programming”, MIT Press, Cambridge, Massachusetts, London, England, pp. 479-485, 1996.

[28] MONTICELLI, A. Fluxo de Carga em Redes de Energia Elétrica. São Paulo: Edgard Blücher Ltda., 1983. 164 p.

[29] KAGAN, N.; OLIVEIRA, C. C. B.; GUARALDO, J.C.; HAGE, F. S. E.; MEFFE, A.; MIGUEL FILHO, M. INTERPLAN - Uma Ferramenta para o Planejamento Integrado de Sistemas de Distribuição de Alta, Média e Baixa Tensão. São Paulo: Escola Politécnica da Universidade de São Paulo, 2004. 6p. (Artigo Técnico do Centro de Pesquisa em Regulação e Qualidade de Energia). 
[30] AGÊNCIA NACIONAL DE ENERGIA ELÉTRICA. Estabelece o valor das tarifas de uso do sistema de transmissão de energia elétrica, componentes do Sistema Interligado Nacional, e fixa a tarifa de transporte da energia elétrica proveniente de Itaipu Binacional. Resolução $n^{0}$ 118, de 3 de Dezembro de 2004. Brasília, 2004. Disponível em: $<$ http://www.aneel.gov.br>. Acesso em: ago. 2006.

[31] DIAZ-DORADO, E.; CIDRAS, J.; MIGUEZ, E. Application of Evolutionary Algorithms for the Planning of Urban Distribution Networks of Medium Voltage. IEEE Transactions on Power Systems, Vol. 17, no. 3, August 2002.

[32] LEE, K. Y.; YANG, F. F. Optimal Reactive Power Planning Using Evolutionary Algorithms: a Comparative Study for Evolutionary Programming, Evolutionary Strategy, genetic Algorithm and Linear Programming. IEEE Transactions on Power Systems, Vol. 13, no.1, February 1998.

[33] DIAZ-DORADO, E.; CIDRAS, J.; MIGUEZ, E. An Application of an Evolution Strategy in Power Distribution System Planning. The 1998 IEEE International Conference on Evolutionary Computation Proceedings, 1998.

[34] WERNER, T. G.; VERSTEGE, J. F. An evolution Strategy for Short-Term Operation Planning of hydrothermal Power Systems. IEEE Transactions on Power Systems, Vol. 14, no. 4, November 1999. 